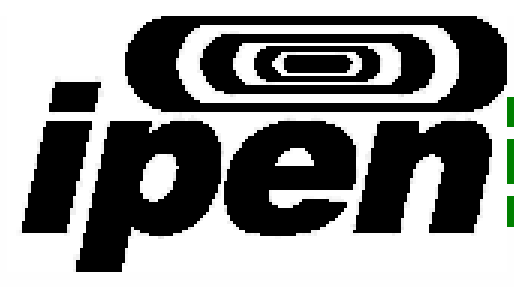

AUTARQUIA ASSO CIAD A A UIIVERSIDADE DE SÄO PAULO

\title{
REGULAMENTAÇÃO DO SISTEMA ELÉTRICO DO REATOR IEA-R1
}

\author{
José Roberto de Mello
}

Dissertação apresentada como parte dos requisitos para obtenção do Grau de Mestre em Ciências na Área de Tecnologia Nuclear - Aplicações.

Orientador:

Prof. Dr. Tufic Madi Filho

SÃO PAULO 


\section{INSTITUTO DE PESQUISAS ENERGÉTICAS E NUCLEARES}

Autarquia associada à Universidade de São Paulo

\section{REGULAMENTAÇÃO DO SISTEMA ELÉTRICO DO REATOR IEA-R1}

José Roberto de Mello

Dissertação apresentada como parte dos requisitos para obtenção do Grau de Mestre em Ciências na Área de Tecnologia Nuclear - Aplicações.

Orientador:

Prof. Dr. Tufic Madi Filho

SÃO PAULO

2016 
Aos meus pais: Paulo e Júlia À minha esposa: Marina Ao meu filho: Roberto Ao meu enteado: Rafael Aos meus irmãos: Paulo, Jairo (in memoriam) e Luis 


\section{AGRADECIMENTOS}

A Deus por proporcionar força durante toda a realização deste trabalho.

Ao Dr. Tufic Madi Filho pela dedicação, paciência, conselhos e orientação da pesquisa.

A minha esposa Marina pela grande ajuda prestada.

Aos amigos Iglésias, Toyoda, Mauro e Vaz pelo companheirismo, união e solidariedade durante o Curso de Pós-graduação.

Ao amigo Davilson pela contribuição nas ilustrações

As chefias pela compreensão e apoio

A todos os amigos do reator IEA-R1 pela amizade e ajuda no desenvolvimento da pesquisa.

A todas as pessoas que de alguma forma contribuíram para a realização deste trabalho. 


\title{
REGULAMENTAÇÃO DO SISTEMA ELÉTRICO DO REATOR IEA-R1
}

\author{
José Roberto de Mello
}

RESUMO

O reator IEA-R1 do Instituto de Pesquisas Energéticas e Nucleares (IPENCNEN/SP) é um reator de pesquisa tipo piscina aberta, projetado e construído pela empresa norte-americana "Babcock \& Wilcox", tendo, como refrigerante e moderador, água leve deionizada e berílio e grafite como refletores. Até cerca de 1988, os sistemas de segurança do reator recebiam alimentação de uma única fonte de energia. Nos anos de 1989 e 1990, uma reforma de modernização do sistema elétrico para aumentar a potência do reator e, também, para atender às normas técnicas da Comissão Nacional de Energia Nuclear (CNEN) e da Associação Brasileira de Normas Técnicas (ABNT) foi realizada. Este trabalho tem o objetivo de mostrar a relação entre o sistema de energia elétrica e a segurança do reator IEA-R1. Além disso, ele demonstra que, caso ocorra alguma interrupção de energia elétrica durante a operação do reator, esta ocorrência não irá começar um evento de acidente. 


\section{ELETRICAL SYSTEM REGULATIONS OF THE IEA-R1 REACTOR}

\section{ABSTRACT}

José Roberto de Mello

The IEA-R1 reactor of the Nuclear and Energy Research Institute (IPEN-CNEN/SP) is a research reactor open pool type, designed and built by the U.S. firm "Babcock \& Wilcox", having, as coolant and moderator, deionized light water and beryllium and graphite, as reflectors. Until about 1988, the reactor safety systems received power from only one source of energy. In the years 1989 and 1990, a reform of the electrical system upgrading to increase the reactor power and, also, to meet the technical standards of the National Commission of Nuclear Energy (CNEN) and of Brazilian Association of Technical Standards (ABNT) was carried out. This work has the objective of showing the relationship between the electric power system and the IEA-R1 reactor security. Also, it demonstrates that, should some electrical power interruption occur during the reactor operation, this occurrence would not start an accident event. 


\section{SUMÁRIO}

Página

LISTA DE FIGURAS 10

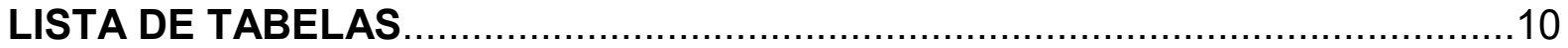

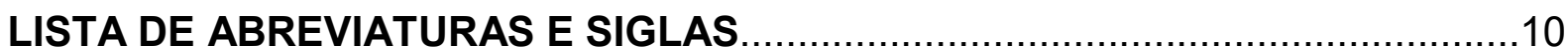

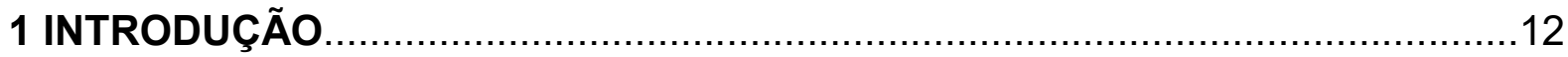

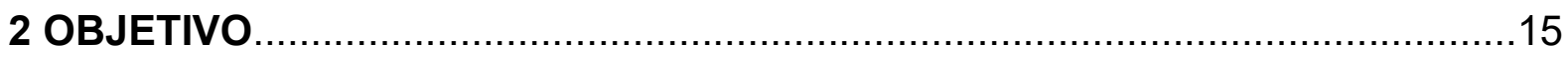

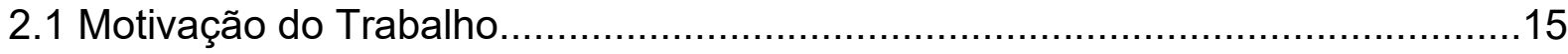

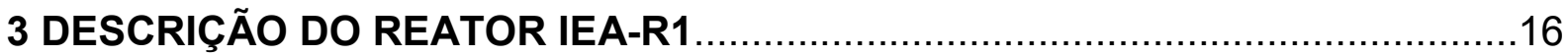

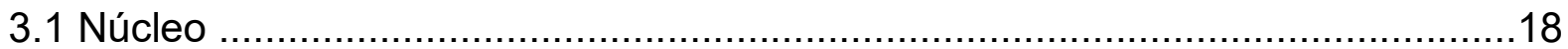

3.2 Sistemas de Proteção e Emergência ...............................................................20

4 SISTEMA DE ENERGIA ELÉTRICA DO REATOR IEA-R1 ...........................22

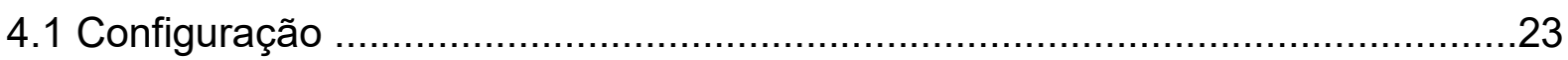

4.1.1 Sistema de Distribuição Elétrica Normal (SDEN) ...................................23

4.1.2 Sistema de Distribuição Elétrica Essencial (SDEE) ...................................24

4.1.3 Sistema de Distribuição Elétrica Vital (SDEV) ...........................................24

4.2 Classificação das Cargas Elétricas ............................................................24

4.3 Descrição do Sistema de Distribuição Elétrica Normal (SDEN) ......................25

4.3.1 Arranjo e Características dos Equipamentos .........................................26

4.3.2 Equipamentos de Média Tensão ......................................................26

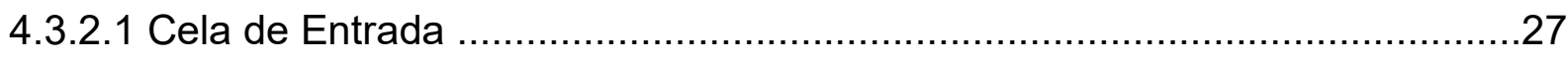

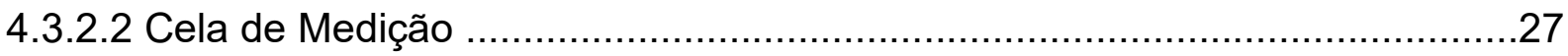

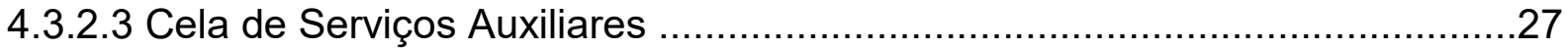

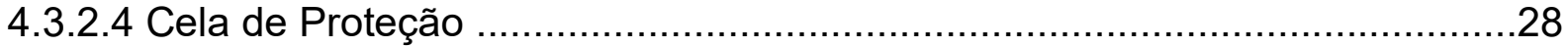

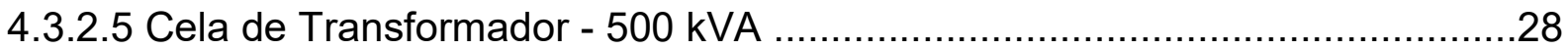

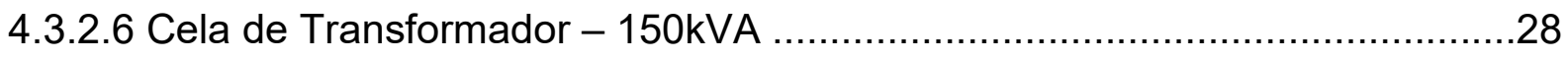

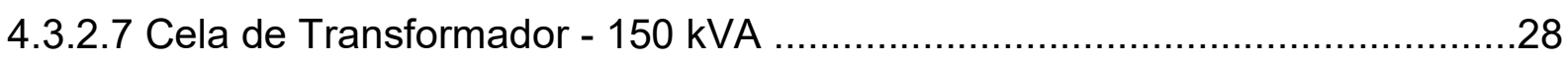

4.3.3 Conjunto de Manobra e Controle de Baixa Tensão (CBT-N-01) ...................29

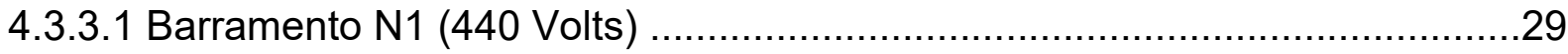

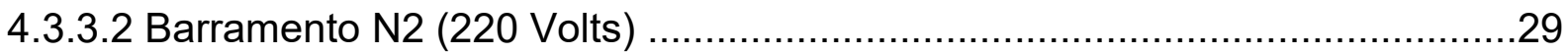

4.3.4 Capacitores de Potência Trifásicos ...........................................................30 
4.4 Descrição do Sistema de Distribuição Elétrica Essencial (SDEE) ......................31

4.4.1 Arranjo e Características dos Equipamentos ...............................................

4.4.2 Grupo Diesel Gerador de 440 Volts (GDG-E-01) ..........................................33

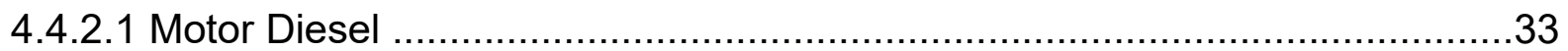

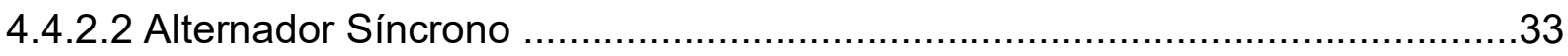

4.4.2.3 Painel de Comando e Controle (PCC-E-01) …...........................................

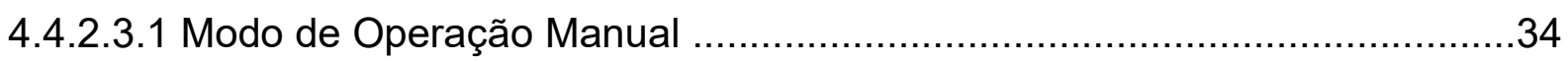

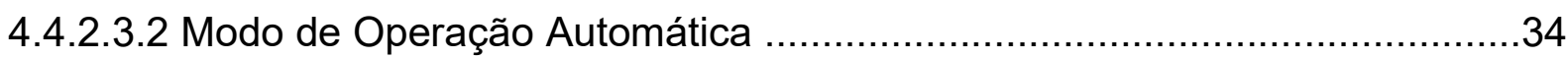

4.4.3 Grupo Diesel Gerador de 220 Volts (GDG-E-02) ........................................

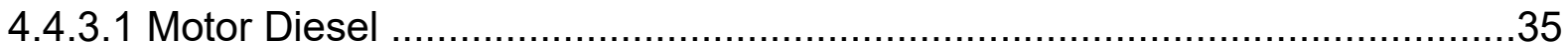

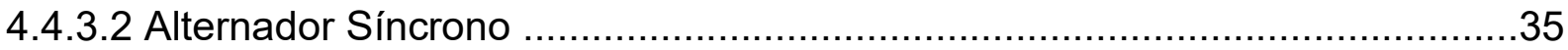

4.4.3.3 Painel de Comando e Controle (PCC-E-02) …….....................................

4.5 Descrição do Sistema de Distribuição Elétrica Vital (SDEV) ................................36

4.5.1 Arranjo e Características dos Equipamentos ................................................37

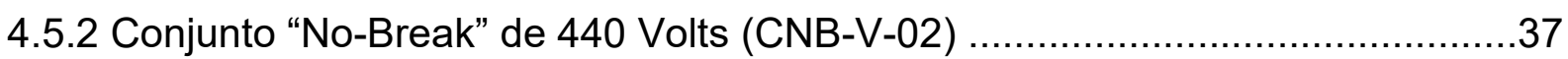

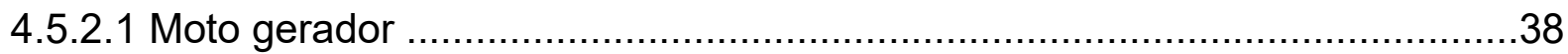

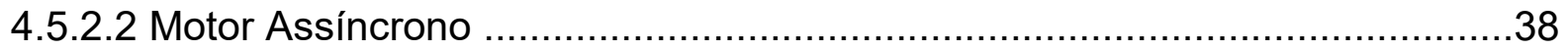

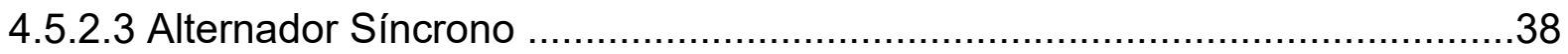

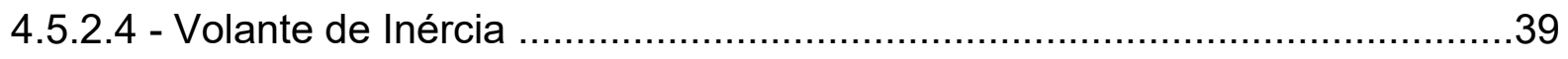

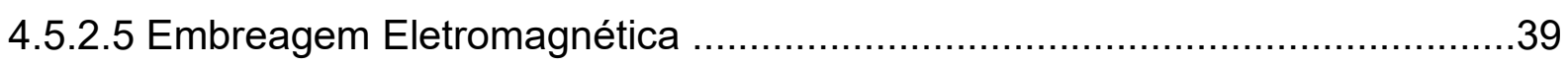

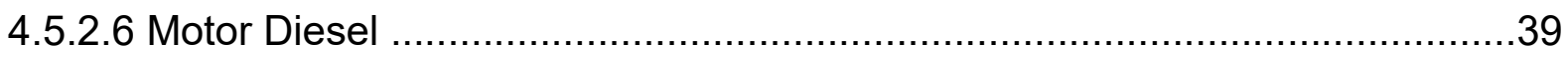

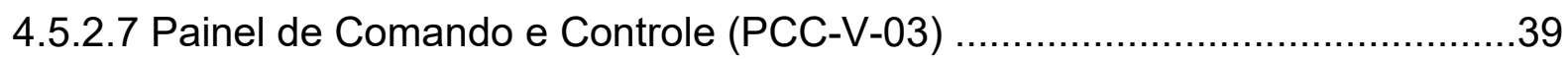

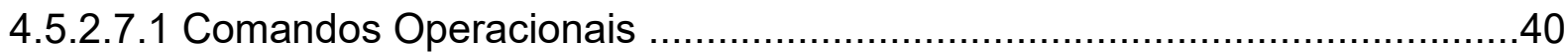

4.5.3 Conjunto "No-Break" estático de 220 Volts (CNB-V-01) ...............................40

4.5.3.1 Retificador / Carregador de Bateria .......................................................

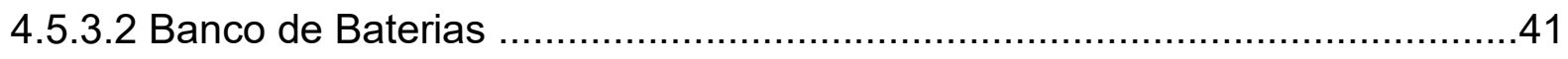

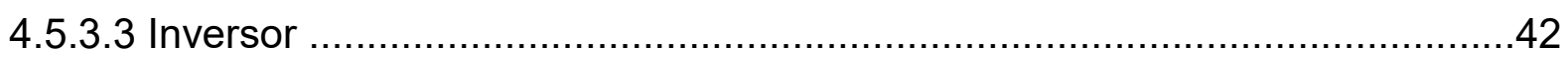

4.5.3.4 Chave Estática Inversor / Rede ......................................................

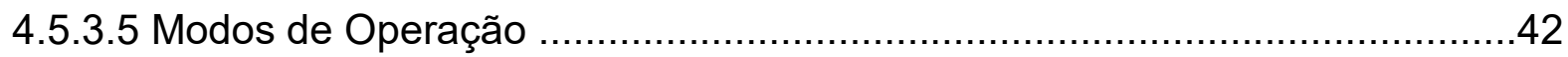

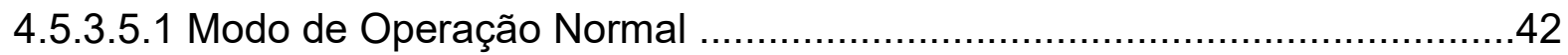

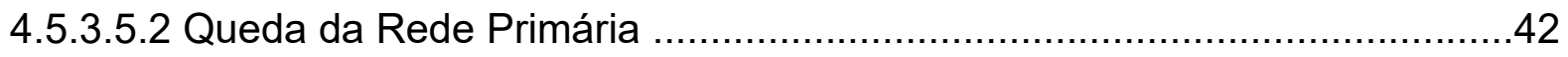




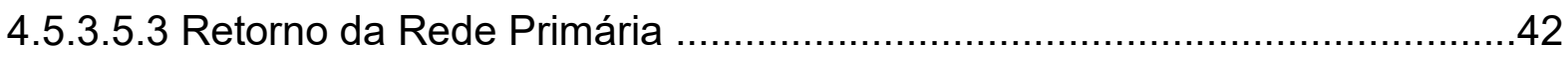

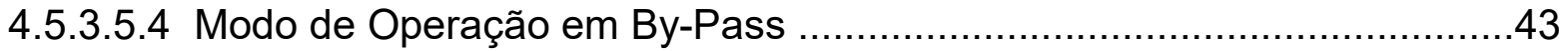

4.5.3.6 Especificações Técnicas ………..................................................................

4.5.4 Quadros de Distribuição de Força (QDF) ……….................................43

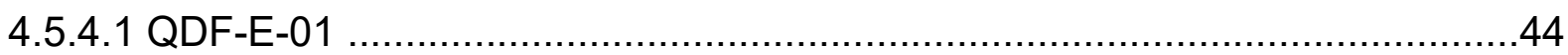

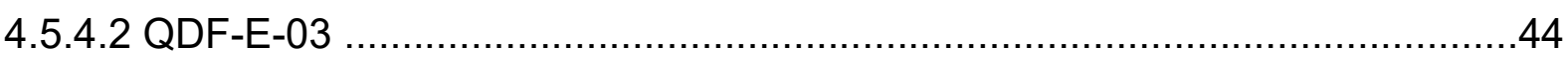

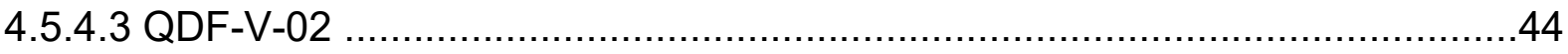

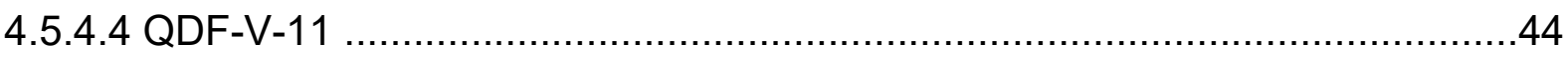

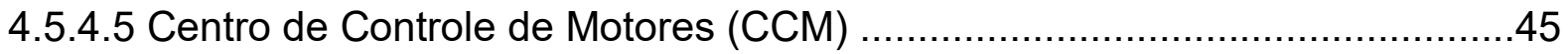

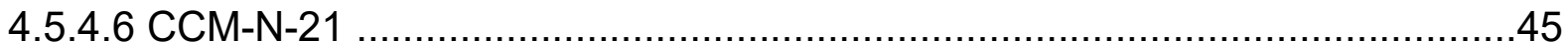

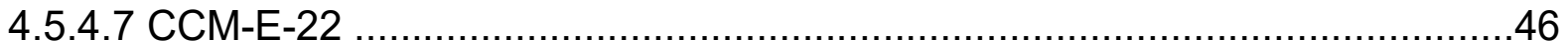

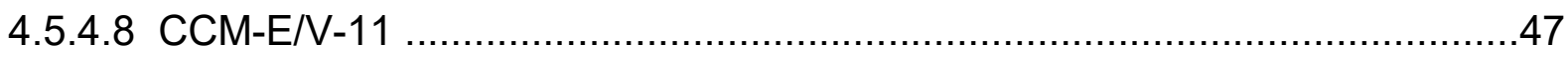

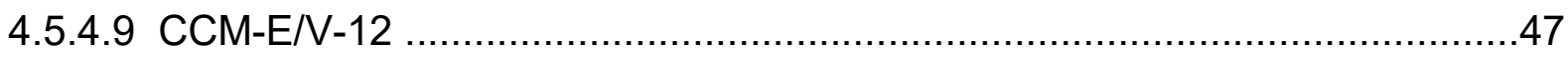

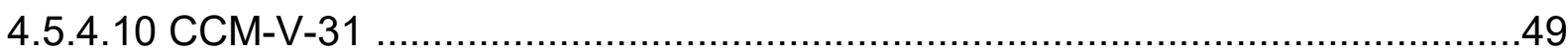

4.5.4.11 Quadros de Corrente Alternada (QCA) ……....................................50

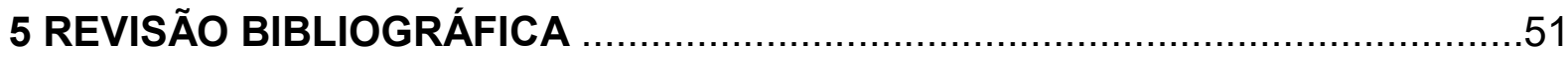

6 METODOLÔGIA

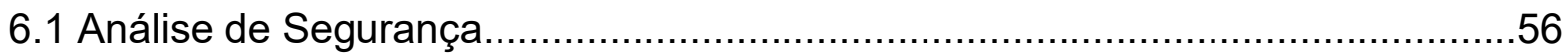

6.1.1 Métodos e Abordagens Utilizados na Análise de Segurança do

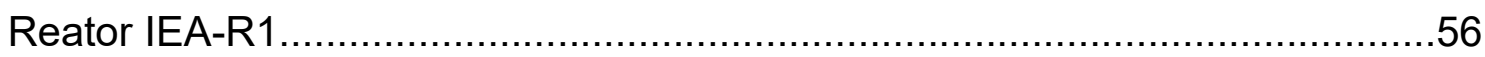

6.1.2 Métodos de Identificação e Seleção de Eventos Iniciadores ..........................56

6.1.2.1 Seleções de Eventos Iniciadores de Acidentes .........................................57

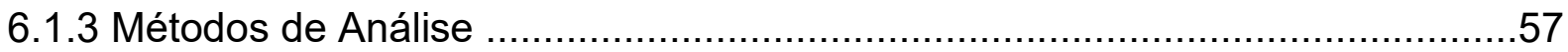

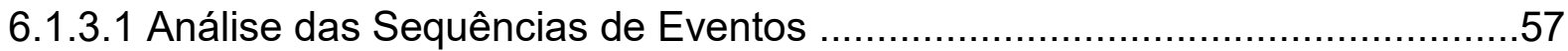

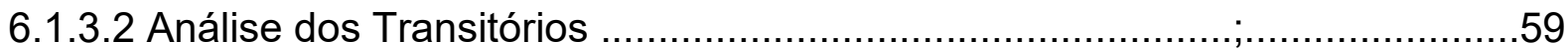

6.1.3.3 Análise das Consequências Radiológicas ..............................................60

6.1.3.3.1 Critérios de Aceitação de Doses Radiológicas ........................................61

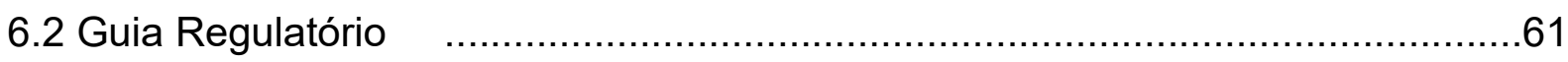

6.2.1 Observações sobre a Base Normativa ......................................................63

7 RESULTADOS

7.1 Modificações Feitas no Sistema Elétrico do Reator IEA-R1 ...............................65 


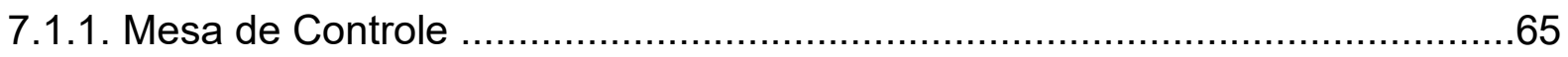

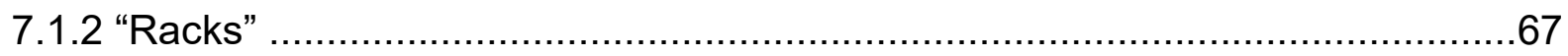

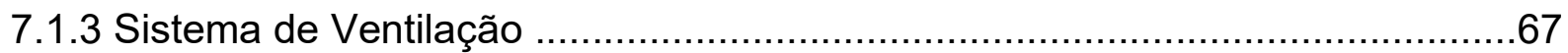

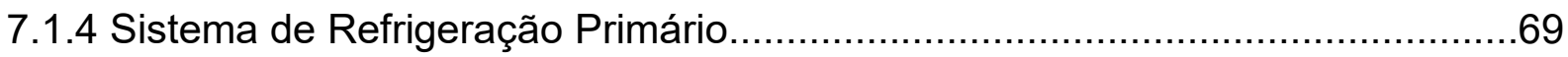

7.1.4.1 Sistema de Isolamento da Piscina ........................................................

7.1.4.2 Sistema de Resfriamento de Emergência (SRE) ….................................71

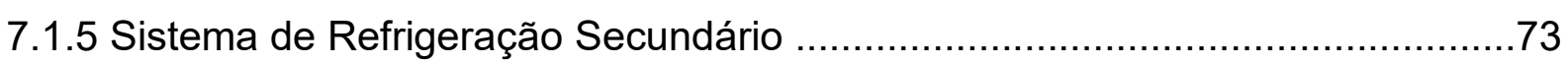

7.1.6 Cabos, Fiações e Dispositivos de Proteção ................................................74

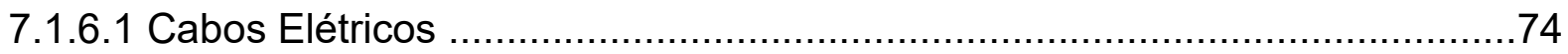

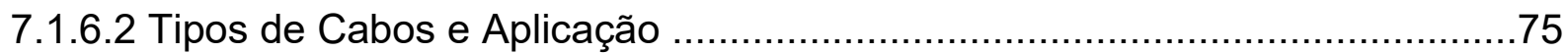

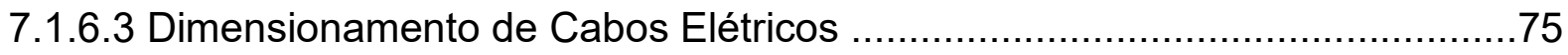

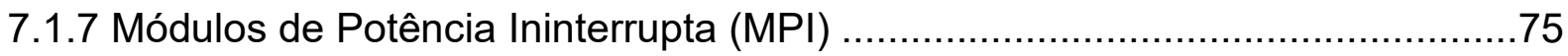

7.1.8 Atualização dos Diagramas e Esquemas Elétricos .....................................77

7.2 Ocorrências Devido a Perda de Alimentação Elétrica........................................77

7.2.1 Falha do Sistema de Distribuição Elétrica Normal ......................................77

7.2.2 Falha do Sistema de Distribuição Elétrica Essencial ...................................78

7.2.3 Falha do Sistema de Distribuição Elétrica Vital ...........................................78

7.2.4 Falha do Sistema de Isolamento da Piscina do Reator ................................79

7.2.5 Falha do Sistema de Resfriamento de Emergência (SRE)...........................79

7.2.6 Falha na Alimentação Elétrica para os Quadros de Segurança e

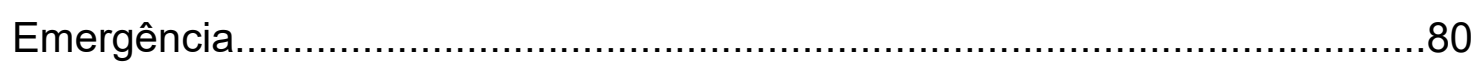

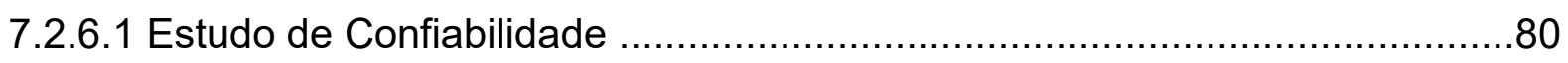

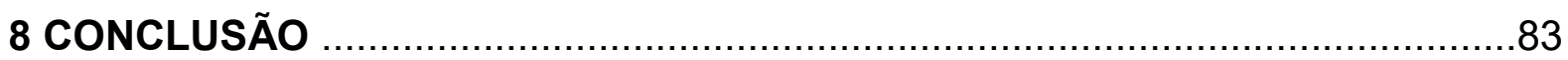

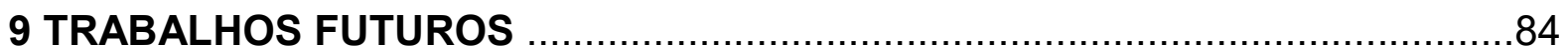

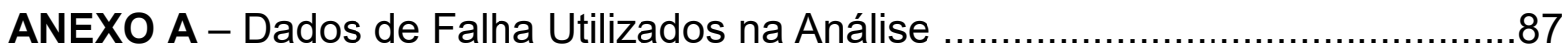

ANEXO B - Probabilidade de Falha dos Sistemas Analisados Obtidos nas

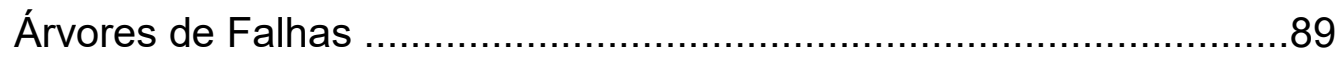

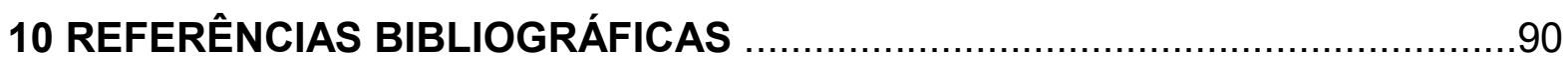




\section{LISTA DE FIGURAS}

Página

FIGURA 1 - Desenho Esquemático da Piscina do Reator IEA-R1 ....................17

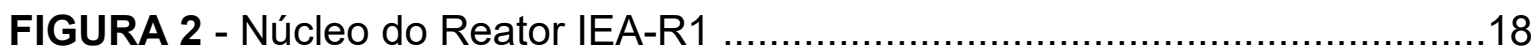

FIGURA 3 - Configuração Típica do Reator na Placa Matriz .............................19

FIGURA 4 - Desenho Esquemático do Sistema Elétrico do Reator IEA-R1 ........23

FIGURA 5 - Layout do Prédio de Distribuição e Geração de Energia Elétrica .....27

FIGURA 6 - Esquema Simplificado do Sistema Elétrico do Reator IEA-R1 ........66

FIGURA 7 - Diagrama Unifilar de Alimentação Elétrica para a Mesa de Controle .67

FIGURA 8 - Comando do Sistema de Ventilação...........................................69

FIGURA 9 - Sistema de Refrigeração do Reator IEA-R1 ................................70

FIGURA 10 - Sistema de Resfriamento de Emergência e Sistema de Isolamento da Piscina ......................................................... 73

FIGURA 11 - Fluxo de Calor X Tempo Após Desligamento do Reator IEA-1 ......74

FIGURA 12 - Diagrama Unifilar: QCA-V-21, QCA-V-31 e CCM-E/V-11..............82

\section{LISTA DE TABELAS}

Página

TABELA 1 - Ano X Número de Falhas no Fornecimento de Energia 86

\section{LISTA DE ABREVIATURAS E SIGLAS}

$\begin{array}{ll}\text { PWR } & \text { Pressurized Water Reactor } \\ \text { IEA-R1 } & \text { Instituto de Energia Atômica - Reator1 } \\ \text { ABNT } & \text { Associação Brasileira de Normas Técnicas } \\ \text { CNEN } & \text { Comissão Nacional de Energia Nuclear } \\ \text { IPEN } & \text { Instituto de Pesquisas Energéticas e Nucleares } \\ \text { CEN } & \text { Centro de Engenharia Nuclear } \\ \text { MTR } & \text { Materials Testing Reactor } \\ \text { SRE } & \text { Sistema de Refrigeração de Emergência } \\ \text { SCRAM } & \text { Desligamento Rápido do Reator }\end{array}$




$\begin{array}{ll}\text { LEN } & \text { Laboratório de Experimentação Nuclear } \\ \text { SDEN } & \text { Sistema de Distribuição Elétrica Normal } \\ \text { SDEE } & \text { Sistema de Distribuição Elétrica Essencial } \\ \text { SDEV } & \text { Sistema de Distribuição Elétrica Vital } \\ \text { MPI } & \text { Módulo de Potência Ininterrupta } \\ \text { TP } & \text { Transformador de Potencial } \\ \text { TRF } & \text { Transformador de Força } \\ \text { CBT } & \text { Conjunto de Manobra e Controle de Baixa Tensão } \\ \text { CAP } & \text { Capacitor } \\ \text { CCM } & \text { Centro de Controle de Motores } \\ \text { CC } & \text { Corrente Contínua } \\ \text { CA } & \text { Corrente Alternada } \\ \text { PCC } & \text { Painel de Comando e Controle } \\ \text { QDF } & \text { Quadro de Distribuição de Força } \\ \text { QFL } & \text { Quadro de Força e Luz } \\ \text { QFF } & \text { Quadro de Força } \\ \text { GDG } & \text { Grupo Diesel Gerador } \\ \text { CNB } & \text { Conjunto Gerador "No-break" } \\ \text { QCA } & \text { Quadro de Corrente Alternada } \\ \text { VG } & \text { Motor do Ventilador de Exaustão } \\ \text { SC } & \text { Condicionador de Ar tipo "Self-Contained" } \\ \text { RS } & \text { Resistor de Aquecimento } \\ \text { CP } & \text { Compressor } \\ \text { SUMP } & \text { Coletor de Água do Prédio do Reator } \\ \text { BLOWER } & \text { Motor do Sistema Pneumático de Irradiação de Amostras } \\ \text { ELV } & \text { Elevador } \\ \text { TE } & \text { Talha Elétrica } \\ \text { NRC } & \text { Nuclear Regulatory Commission } \\ \text { SAPHIRE } & \text { Systems Analysis Programs for Hands-on Integrated Reliability } \\ & \text { Evaluations } \\ & \end{array}$




\section{INTRODUÇÃO}

As centrais nucleares requerem energia elétrica em corrente alternada para executar suas funções de segurança em condições normais de operação e durante ou após a ocorrência de um acidente.

Até o final da década de 60 , o foco principal da segurança de reatores nucleares era predominantemente voltado para o núcleo do reator. Após a publicação, em 1975, de um estudo encomendado pela antiga Comissão de Energia Atômica dos Estados Unidos [1], o qual mostrou que a perda total do fornecimento de energia elétrica em corrente alternada poderia ter uma grande contribuição no risco total de acidentes em centrais nucleares, as atenções sobre os problemas de segurança deslocaram-se para os sistemas periféricos das centrais nucleares. Este estudo mostra que um dos tipos mais sérios de acidente, em um reator tipo PWR - Pressurized Water Reactor ocorreria se em um determinado momento e por um período de tempo de vários minutos, houvesse falha total do suprimento de energia elétrica da Usina. Em geral, o Sistema Elétrico de uma central nuclear é similar ao Sistema Elétrico de uma central térmica convencional, exceto pela maior preocupação com suprimento de energia elétrica das cargas necessárias para a operação segura do reator.

A necessidade de fontes de energia independentes e redundantes tem origem nas características que envolvem a operação de reatores nucleares.

O calor do decaimento radioativo, gerado logo após o desligamento do reator, deve ser removido de modo a evitar que o calor gerado eleve a temperatura do núcleo do reator a níveis não permitidos, que poderiam danificar o combustível nuclear.

Acidentes, como a perda de refrigerante ou a falha das bombas de refrigeração do circuito primário, criam a necessidade de fornecimento de refrigeração de emergência provido por bombas e válvulas acionadas por motores que dependem da disponibilidade de eletricidade para a sua operação.

A fonte principal de energia elétrica de uma central nuclear é composta pelo sistema elétrico conectado a central por linhas de transmissão. Na ocorrência de acidentes coincidentes com a perda das linhas de transmissão um Sistema de 
Emergência Local, em geral composto por geradores diesel, tem a função de prover a energia elétrica necessária aos Sistemas de Segurança e equipamentos necessários para manter o reator numa condição segura.

A autoridade regulatória nuclear exige que seja estudado o comportamento previsto de uma central nuclear em situações normais, transitórias e de acidentes postulados, de modo a se determinar as margens de segurança previstas e a adequação de itens e sistemas para prevenir acidentes e atenuar as consequências dos acidentes que possam ocorrer.

Também devem ser objeto de atenção os acidentes com baixa probabilidade de ocorrência, visto que os mesmos podem ser mais severos do que aqueles considerados no projeto.

As condições consideradas para a avaliação da confiabilidade do Sistema Elétrico pertencem ao grupo de acidentes severos, uma vez que a perda do suprimento de energia elétrica em corrente alternada dos barramentos de segurança pode conduzir a um cenário de múltiplas falhas.

Acidentes severos são aqueles associados a cenários de múltiplas falhas, além daqueles considerados na base de projeto, que podem envolver danos substanciais ao núcleo do reator e ou liberações de produtos radioativos em quantidades que possam afetar a saúde do público e do meio ambiente [2].

Segundo o "Safety Series" 50-SG-D7 [2], uma central nuclear pode se enquadrar em duas condições possíveis, a saber: "Estados Operacionais" e "Acidentes". A condição de "Estados Operacionais" pode ser entendida como a operação da central em condições normais e em condições de pequenos desvios das condições normais de operação. A condição de "Acidentes" caracteriza que a central opera com desvios das condições normais de operação onde liberações de material radioativo são mantidas dentro dos limites aceitáveis.

Dentro da condição de "Acidentes", a ocorrência de acidentes severos está associada à probabilidade da ocorrência simultânea de múltiplas falhas de sistemas e barreiras de segurança, tornando remota a chance de esses cenários serem considerados além da base de projeto. Sua baixa probabilidade não significa que os mesmos não possam ocorrer, devendo-se, portanto, prover medidas ou procedimentos para gerenciar seu curso e mitigar suas consequências. 
A meta, com o objetivo de segurança técnica, para as plantas existentes é que a ocorrência de acidentes com danos severos ao núcleo tenha uma probabilidade de no máximo $10^{-4}$ eventos por ano de operação. A implementação de todos os princípios de segurança, para plantas futuras, devem levar a uma melhora na meta, de forma que a mesma não seja superior a $10^{-5}$ eventos por ano [3].

Cada central nuclear possui sistemas, componentes e procedimentos que contribuem significativamente para a redução do risco de acidentes severos.

A falta de suprimentos de energia adequados, com consequente incapacidade dos sistemas de executar as funções de segurança necessárias, pode levar a planta a um cenário de acidente, podendo resultar em liberações inaceitáveis de radioatividade.

Nessa condição, os geradores diesel de emergência desempenham papel de fundamental importância, tendo sido objeto de vários estudos visando melhorar suas características de confiabilidade. 


\section{OBJETIVO}

Este trabalho tem por objetivo estudar o relacionamento entre 0 Sistema de Alimentação Elétrica e a Segurança do Reator IEA-R1. Demonstrar que a falta de energia elétrica, fornecida pela concessionária, durante a operação do reator não irá provocar um evento iniciador de acidente.

\subsection{Motivação do Trabalho}

A motivação deste trabalho surgiu devido à necessidade de avaliar a segurança do Sistema Elétrico do Reator IEA-R1 para aumentar a potência a $5 \mathrm{MW}$ e da necessidade de regulamentação do sistema de acordo com o Guia Regulatório. 


\section{DESCRIÇÃO DO REATOR IEA-R1 [4]}

O reator IEA-R1 do Instituto de Pesquisas Energéticas e Nucleares (IPEN) é um reator de pesquisa do tipo piscina aberta, construído e projetado pela firma norte-americana "Babcox \& Wilcox", tendo como refrigerante e moderador a água leve desmineralizada e berílio e grafite como refletores.

Os principais propósitos do reator IEA-R1 são a produção de radioisótopos para uso na medicina, testes de materiais e combustíveis nucleares, irradiação de amostras com nêutrons, realização de pesquisas fundamentais em diversas áreas tais como em física, radioquímica, radiobiologia, análise por ativação, auxílio à formação de recursos humanos em nível de pós-graduação e treinamento de pessoal especializado para operação de reatores.

A primeira criticalidade do reator ocorreu em setembro de 1957. Originalmente, o reator foi projetado para operação à potência de $5 \mathrm{MW}$, mas a maioria das operações ocorreu à potência de 2 MW até 1997. Entre 1995 e 1997, o reator recebeu uma série de modificações para adequá-lo, em termos de segurança, à operação na potência de 5MW. Em 1997, o reator recebeu uma autorização provisória para operação nesta potência.

A piscina do reator está situada no interior do prédio do reator. Ela possui um volume total de $272 \mathrm{~m}^{3}$, estando dividida em dois compartimentos: compartimento de operação e compartimento de estocagem dos elementos combustíveis irradiados. Os dois compartimentos podem ser eventualmente isolados com a utilização de uma comporta. Na FIG. 1 é apresentado o desenho esquemático da piscina do reator. 


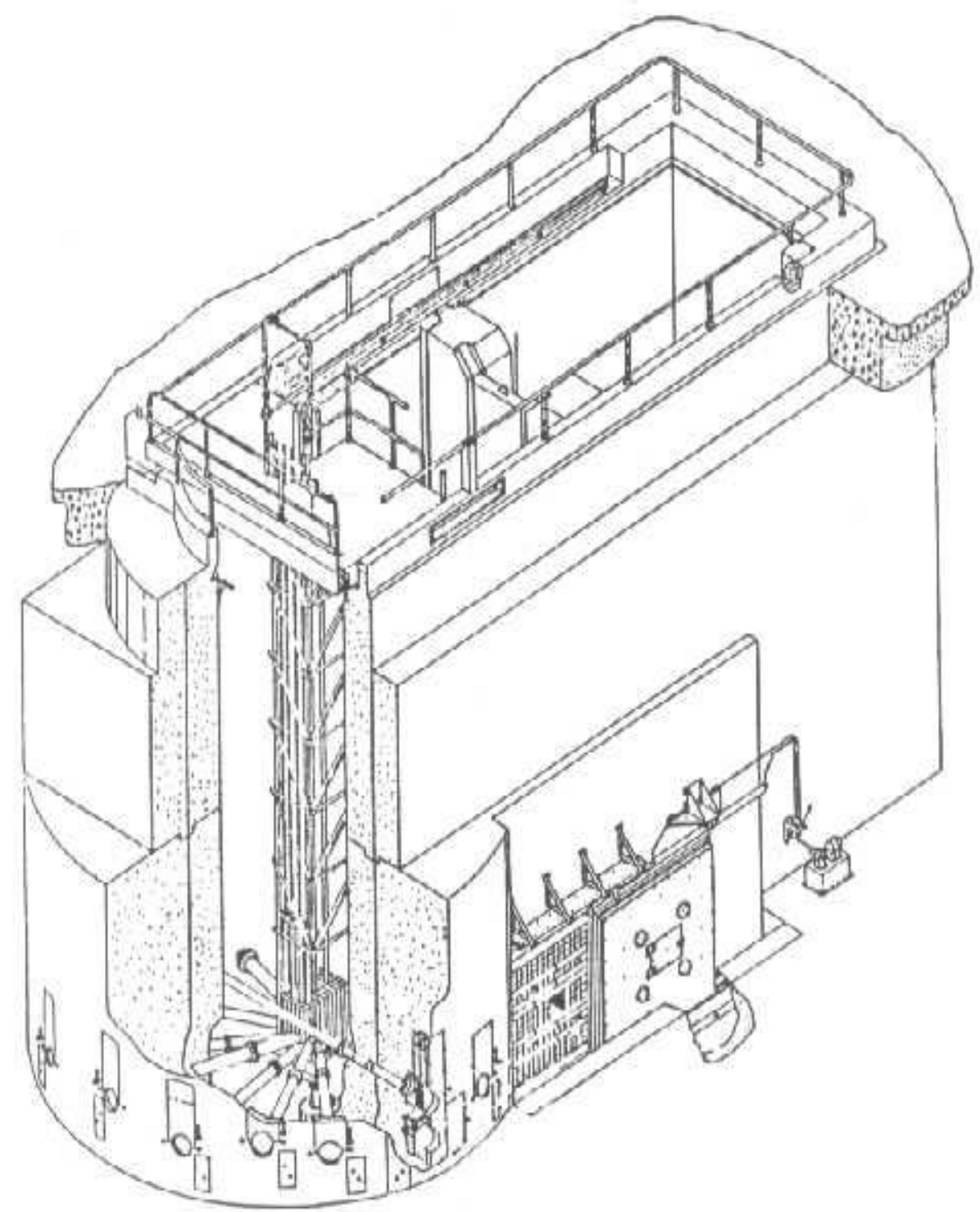

FIGURA 1 - Desenho Esquemático da Piscina do Reator IEA-R1 [4]

O núcleo do reator IEA-R1, mostrado na FIG. 2, é constituído basicamente por um conjunto de elementos combustíveis do tipo MTR que fica submerso na piscina, e suspenso por meio de uma estrutura metálica. 


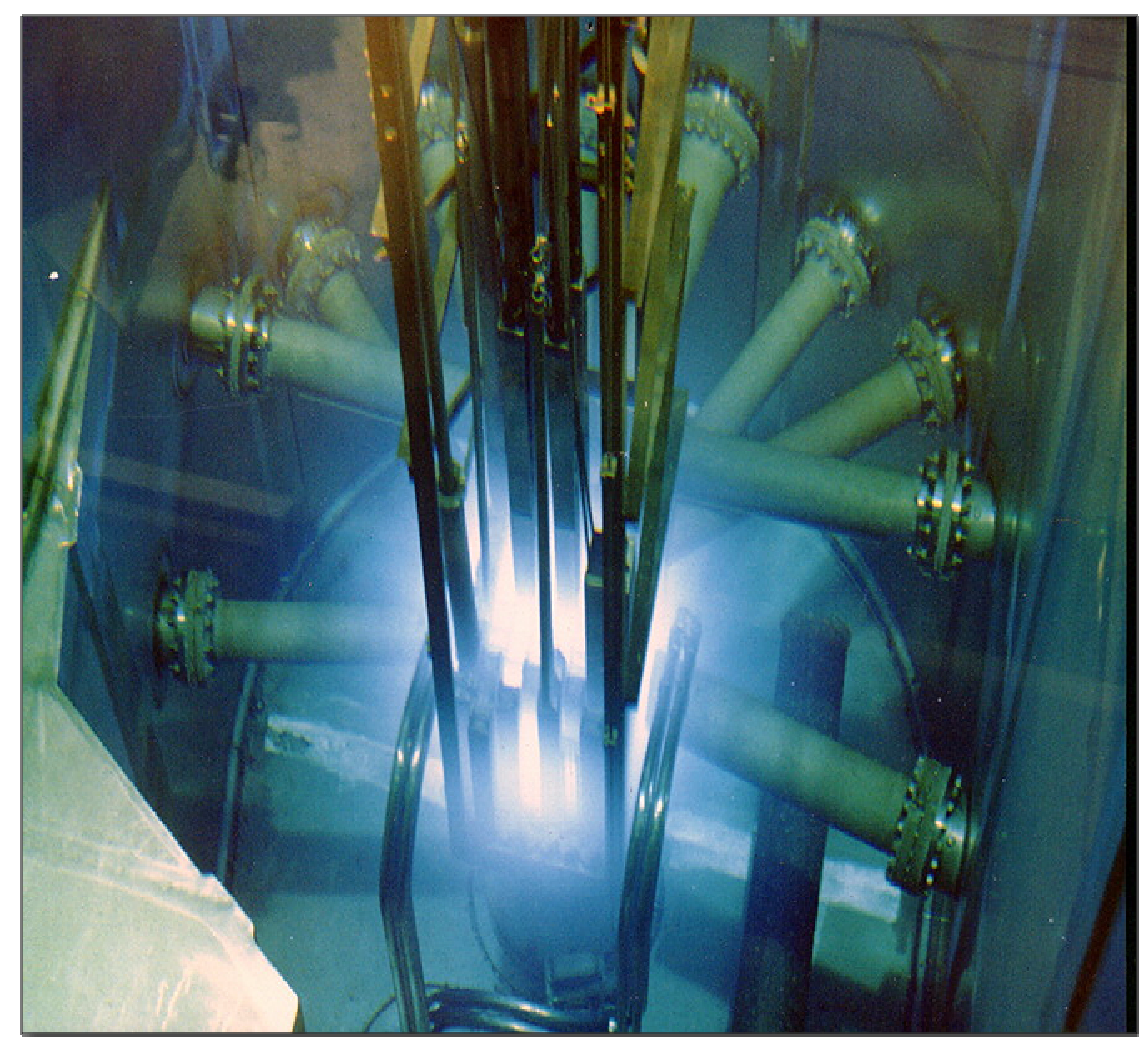

FIGURA 2 - Núcleo do reator IEA-R1 (fonte própria)

O controle da potência do reator é realizado pela movimentação dos elementos absorvedores de nêutrons no interior do reator. O reator possui quatro elementos de controle. Cada elemento absorvedor (elemento de controle) contém duas lâminas da liga de Prata-Índio-Cádmio revestidas de Níquel. O acionamento dos elementos absorvedores, para controle do reator, é feito por mecanismos eletromecânicos, independentes por elemento absorvedor. Estes elementos absorvedores também têm a função de garantir o desligamento seguro do reator quando necessário, o qual se dá por meio da queda livre de todos os elementos absorvedores, através da desenergização de eletroímãs que sustentam esses elementos. O reator possui somente este meio de controle de reatividade com as duas funções (controle e segurança). Um elemento absorvedor exerce as funções de controle e de segurança e os outros três exercem somente a de segurança.

\subsection{Núcleo}

O núcleo contém um arranjo de elementos combustíveis típicos e de elementos combustíveis de controle encaixados na placa matriz. Ao redor dos elementos combustíveis são posicionados elementos refletores de nêutrons e 
elementos para irradiação de materiais. No arranjo da placa matriz também são posicionados os detectores para controle do reator, a fonte de nêutrons para partida do reator e as posições não ocupadas são obstruídas com tampões especiais. Na FIG. 3 é apresentada a configuração típica do núcleo do reator na placa matriz.

\section{CDNFIGURACĀD - 25EA}

22 - 28 DEZEMBRD 2015

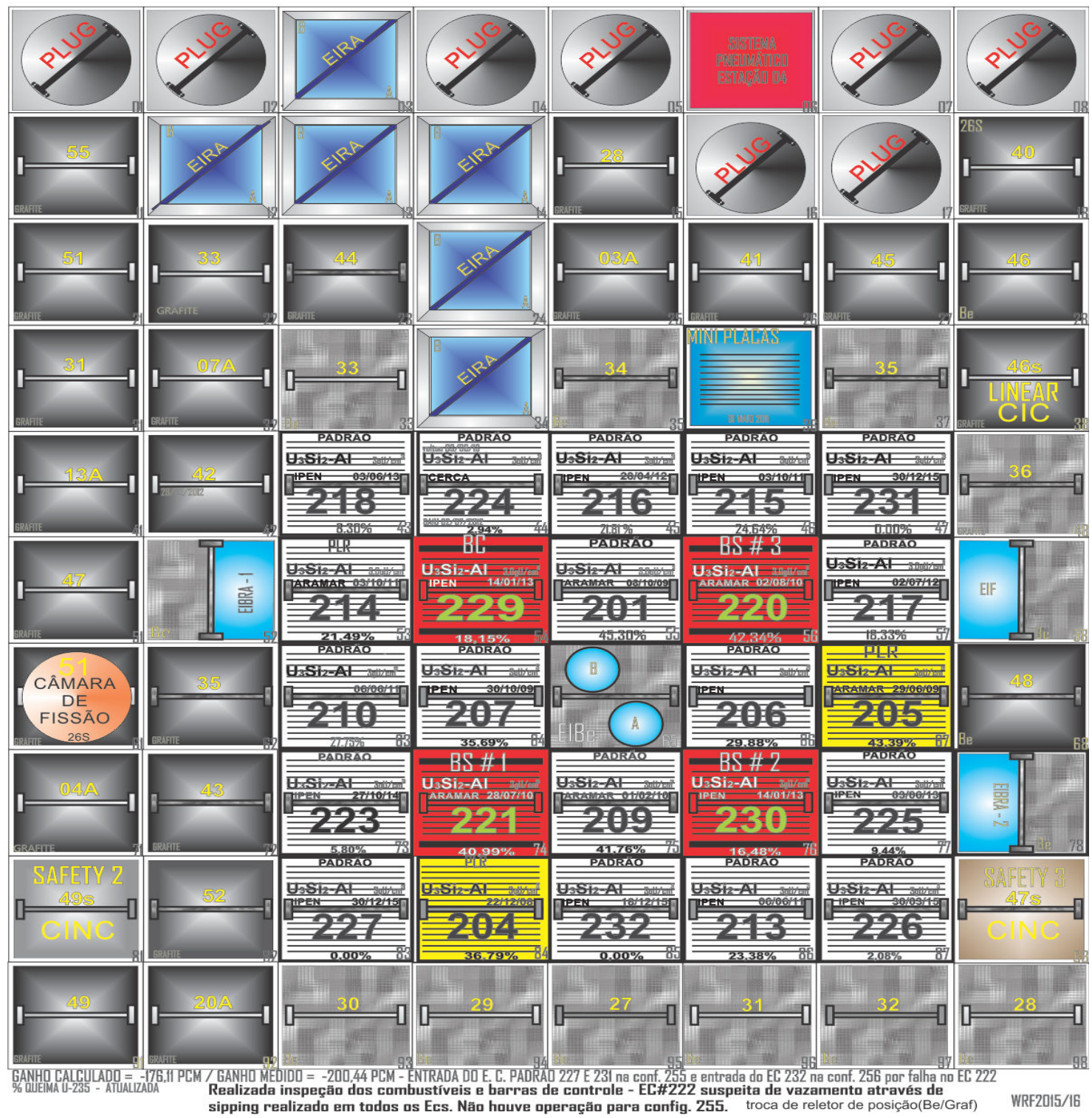

FIGURA 3 - Configuração Típica do Reator na Placa Matriz (fonte própria)

O elemento combustível padrão utilizado no reator IEA-R1 é formado por placas combustíveis. As placas combustíveis são constituídas de liga metálica (U-Al) ou na forma de dispersões (U3O8-Al ou U3Si2-Al ou UAlx), com revestimento de alumínio. Cada elemento é constituído de 18 placas 
combustíveis, intercaladas por canais por onde circula o fluido refrigerante (canal de refrigeração).

O núcleo é refrigerado pelo Sistema de Resfriamento do Reator. Este sistema e sistemas conectados compreendem o circuito primário que é responsável pela remoção do calor gerado no núcleo através da circulação do refrigerante; o circuito secundário, responsável pela dissipação do calor retirado do primário ao ambiente, através de torres de resfriamento; o Sistema de Resfriamento de Emergência (SRE), responsável pelo resfriamento do núcleo após um acidente postulado de perda de refrigerante; o Sistema de Tratamento de Água, responsável pelo suprimento normal de refrigerante ao Circuito Primário; e o Sistema de Retratamento, responsável pela manutenção da qualidade da água da piscina.

\subsection{Sistemas de Proteção e Emergência}

O Sistema de Proteção do Reator atua basicamente no circuito de desligamento (SCRAM) do reator, interrompendo, sempre que necessário, a corrente que alimenta os magnetos responsáveis pelo acoplamento das barras de controle/segurança aos respectivos mecanismos de movimentação. Desta forma se as barras de controle ainda estiverem inseridas no núcleo são impedidas de serem removidas e no caso de estarem fora do núcleo são imediatamente inseridas pela ação da gravidade.

O sistema atua automaticamente iniciando o processo de desligamento do reator sempre que uma das variáveis do sistema atinge um valor pré-definido, e, uma vez iniciado o processo, é impossível evitar-se o desligamento. Para assegurar o desligamento são utilizadas três barras de segurança e uma de controle.

Fazem parte do Sistema de Proteção do reator todos os canais que monitoram parâmetros relacionados com a segurança da instalação que permitem identificar situações em que deve ser providenciado o desligamento do reator. Fazem parte, também, o circuito de desligamento, os dispositivos de sinalização e alarme, e os dispositivos para acionamento manual do sistema.

O Sistema é composto por quatro canais nucleares, que fazem parte do subsistema de instrumentação nuclear e permitem monitorar a potência e o período do reator; três monitores de área (radiação), que permitem monitorar o 
nível de radiação na superfície da piscina e no salão de experimentos da física nuclear; um monitor de vazão no circuito primário do Sistema de Resfriamento do Reator; um transmissor de pressão diferencial utilizado para medir a diferença de pressão no núcleo; um termômetro bimetálico utilizado para monitorar a temperatura da água na saída da piscina; um transmissor de pressão diferencial e uma chave de nível para monitorar o nível de água na piscina; três botões de desligamento manual; e vários contatos, do tipo on / off, para monitorar que alguns equipamentos estejam na posição correta para habilitar a partida do reator. 


\section{SISTEMA DE ENERGIA ELÉTRICA DO REATOR IEA-R1 [5]}

O Sistema de Energia Elétrico do Reator IEA-R1 é projetado para suprir a demanda de energia elétrica requerida pelas cargas do reator (Sistemas de Segurança e Sistemas não relacionados com a segurança), nas diferentes situações em que a planta possa se encontrar, tais como: durante a partida, operação normal em potência, desligamento, manutenção, troca de elementos combustíveis e situações de acidente. O Sistema também alimenta o Laboratório de Experimentação Nuclear - LEN, e experimentos da física nuclear (bancadas experimentais).

O Sistema de Energia Elétrica é normalmente alimentado pela rede da concessionária de eletricidade (ELETROPAULO), via subestação Jaguaré. Este ramal está conectado à rede subterrânea de distribuição do IPEN, que se configura com dois anéis interligados. No caso de falha deste fornecimento de energia elétrica, as cargas que devem manter a continuidade da operação do reator, inclusive das bancadas experimentais, passam a ser alimentadas por fontes locais de energia elétrica (grupo diesel gerador, conjunto "no-break" ou módulo de potência ininterrupta). Na FIG. 4 é mostrado o desenho esquemático do Sistema Elétrico do Reator IEA-R1. Neste capitulo serão descritos os componentes do Sistema de Energia Elétrica. 


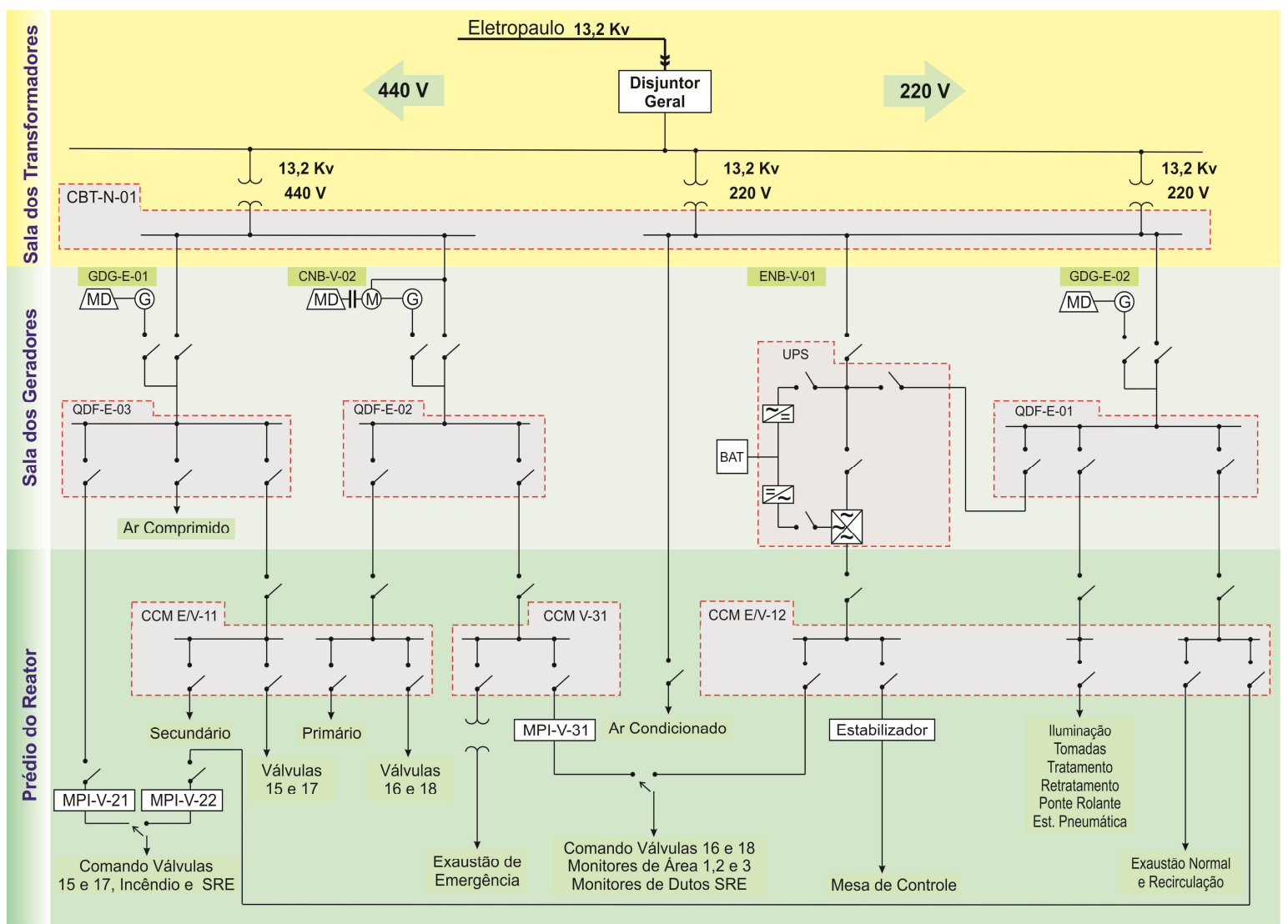

FIGURA 4 - Desenho Esquemático do Sistema Elétrico do Reator IEA-R1 (fonte própria)

\subsection{Configuração}

O Sistema de Energia Elétrica é subdividido em 3 (três) Sistemas de Distribuição. Cada Sistema leva em consideração o nível de disponibilidade pretendido no fornecimento de energia elétrica para as cargas do reator, a fim de manter a continuidade da operação do mesmo. Tais sistemas de distribuição são:

\subsubsection{Sistema de Distribuição Elétrica Normal (SDEN)}

O SDEN pode tolerar interrupções de longo período no fornecimento de energia elétrica, sem causar riscos à segurança e continuidade da Operação. $O$ SDEN é alimentado exclusivamente pela rede da concessionária.

Principais cargas:

- Sistema de Ar Condicionado do Prédio do Reator.

- Bombas do Tanque de Retenção.

- Quadro de Força da Física Nuclear.

- Iluminação externa. 


\subsubsection{Sistema de Distribuição Elétrica Essencial (SDEE)}

O SDEE pode tolerar interrupções de curta duração no fornecimento de energia elétrica, mas são imprescindíveis à segurança e continuidade da operação. O SDEE é alimentado pela rede normal e no caso de ocorrer falha no fornecimento o sistema é alimentado por grupo geradores convencionais.

Principais cargas em 220V:

- lluminação normal do prédio do reator.

- Sistema de Exaustão e Ventilação Normal.

- Ponte rolante.

Principais cargas em 440V:

- Bombas do Circuito Secundário de Refrigeração do Reator.

- Ventiladores das Torres de Refrigeração.

- Compressores do Sistema de Ar Comprimido.

- Válvulas do Sistema de Isolamento da Piscina.

\subsubsection{Sistema de Distribuição Elétrica Vital (SDEV)}

O SDEV não pode tolerar interrupções no fornecimento de energia elétrica, pois, são imprescindíveis à segurança e continuidade da operação.

O SDEV é alimentado pela rede normal e no caso de ocorrer falha no fornecimento o sistema é alimentado por grupo geradores "no- break's" e por Módulos de Potência Ininterrupta (MPI).

Principais cargas em 220V:

- Mesa de Controle.

- Sistema de Combate a Incêndio.

- Quadro da Física Nuclear.

Principais cargas em 440V:

- Bombas do Circuito Primário de Refrigeração do Reator.

- Sistema de Exaustão de Emergência.

- Válvulas do Sistema de Resfriamento de Emergência (SRE).

\subsection{Classificação das Cargas Elétricas}

As cargas conectadas a cada sistema de distribuição de energia elétrica são também classificadas em 3 (três) categorias: 
- Cargas Normais (ou não Essenciais) - São as cargas que, em caso de interrupção no fornecimento normal de energia elétrica (rede da concessionária), não serão religadas após a partida dos grupos diesel geradores de emergência.

- Cargas Essenciais - São as cargas que, em caso de interrupção no fornecimento normal de energia elétrica (rede da concessionária), serão religadas imediatamente após a partida dos grupos diesel geradores de emergência.

- Cargas Vitais - São as cargas que, em caso de interrupção no fornecimento normal de energia elétrica, serão mantidas em operação através dos conjuntos "no-breaks" ou módulos de potência ininterrupta.

\subsection{Descrição do Sistema de Distribuição Elétrica Normal (SDEN)}

Conforme é mostrado no diagrama unifilar da FIG. 4 - Desenho Esquemático do Sistema Elétrico do Reator IEA-R1, o suprimento de energia elétrica para as cargas do reator é feito usualmente pelo sistema de distribuição elétrica normal, o qual é alimentado a partir de um circuito subterrâneo da rede de distribuição do IPEN (13,2 kV).

O SDEN engloba:

- Um circuito ramal de média tensão (cabo trifásico com muflas terminais) e seus dispositivos de seccionamento, manobra e proteção, bem como dispositivos para medição da energia fornecida.

- Três transformadores de potencial, TP-01, TP-02 e TP-03, para alimentação do controle do disjuntor geral de entrada e da sinalização da falta de fase (Sala de Controle).

- Três transformadores de força, TRF-N-01, TRF-N-02 e TRF-N-03, com neutros solidamente aterrados. Os transformadores TRF-N-02 e TRF-N-03 estão ligados em paralelo.

- Um conjunto de manobra e controle de baixa tensão, CBT-N-01, constituído de dois barramentos eletricamente independentes, sendo um (barramento N1) alimentado pelo transformador TRF-N- 
01 e o outro (barramento N2) alimentado pelos transformadores TRF-N-02 e TRF-N-03.

- Dois capacitores de potência trifásicos, CAP-N-01 e CAP-N-02, para correção do fator de potência da instalação, um conectado ao barramento $\mathrm{N} 1$ e o outro ao barramento N2 do CBT-N-01.

- Um centro de controle de motores, CCM-N-21 (ver item 4.5.4.6).

- Circuitos ramais de saída, originados nos barramentos N1 e N2 do CBT-N-01, para os sistemas de distribuição elétrica essencial e vital, bem como para o CCM-N-21 e outras cargas normais da planta.

- Circuitos ramais de saída, originados no $\mathrm{CCM}-\mathrm{N}-21$, destinados às cargas normais do Sistema de Ventilação e Ar Condicionado do Prédio do Reator.

\subsubsection{Arranjo e Características dos Equipamentos}

Os equipamentos ou componentes principais do SDEN estão instalados no Prédio de Distribuição e Geração de Energia Elétrica na área denominada Sala dos Transformadores, conforme é mostrado a FIG. 5 - Layout do Prédio de Distribuição e Geração de Energia Elétrica, bem como no $2^{\circ}$ andar do Prédio do Reator (CCM-N-21).

A Sala dos Transformadores, por sua vez, está dividida em duas partes: uma parte contém sete compartimentos (ou celas), cujos acessos são providos de grades de proteção com telas metálicas removíveis, e onde estão instalados os transformadores e equipamentos de média tensão; a outra parte é destinada aos equipamentos ou componentes de baixa tensão, isto é conjunto de manobra e controle de baixa tensão (CBT-N-O1) e unidades de capacitores (CAP-N-01 e CAP-N-02).

\subsubsection{Equipamentos de Média Tensão}

A FIG. 5, layout do prédio de distribuição e geração de energia elétrica, mostra as celas onde estão instalados os equipamentos ou componentes de média tensão, contendo cada uma destas celas: 


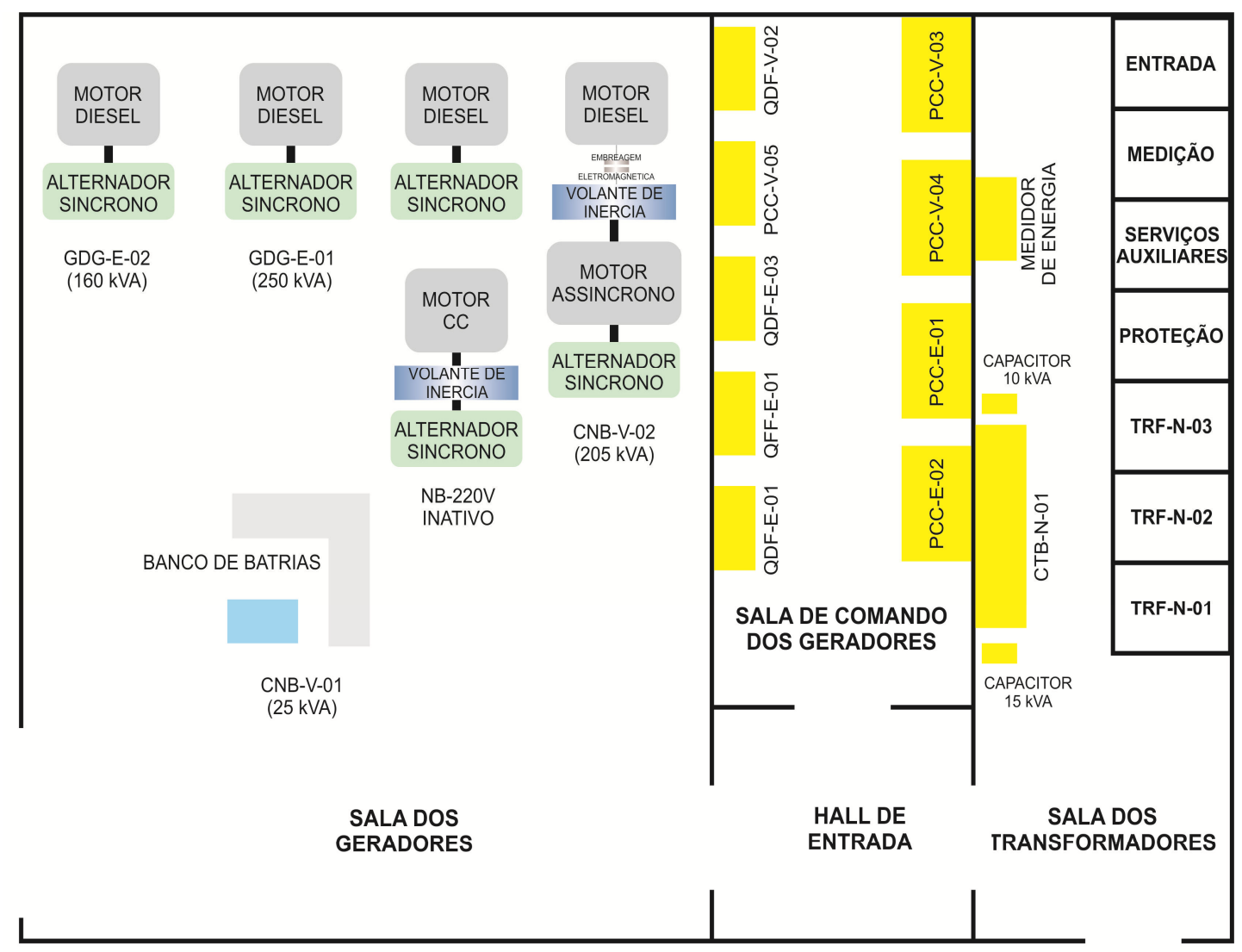

FIGURA 5 - Layout do Prédio de Distribuição e Geração de Energia Elétrica [5]

\subsubsection{Cela de Entrada}

- Uma mufla trifásica de $15 \mathrm{kV}$ no terminal do cabo derivado da rede de distribuição do IPEN.

- Uma chave seccionadora tripolar de 15 kV-200 A, operação manual, comando de ação simultânea, com alavanca para manobra, fabricação AEG.

\subsubsection{Cela de Medição}

- Um transformador de medição tipo WCT 645/15, fabricação Hitachi Line.

\subsubsection{Cela de Serviços Auxiliares}

- Dois transformadores de potencial monofásicos (TP-1 e TP-2), 400VA, 13200/110 Volts, fabricação Hohl. 
- Um transformador de potencial monofásico (TP-3), 3500 VA, 13200/110 Volts, fabricação EASA.

\subsubsection{Cela de Proteção}

- Um disjuntor tripolar de pequeno volume de óleo, motorizado, montagem extraível, $500 \mathrm{MVA}, \quad 24 \mathrm{kV}-800 \mathrm{~A}, \quad 60 \mathrm{~Hz}$, tipo HPTW-306 E, fabricação Sprecher e Schuhl.

\subsubsection{Cela de Transformador - 500 kVA}

- Um transformador de força (TRF-N-01), trifásico, 500 kVA, $13.200 / 440 \mathrm{~V}, 60 \mathrm{~Hz}$, resfriamento natural, líquido isolante óleo mineral, tipo TL-500/15, fabricação AEG.

- Uma chave seccionadora tripolar de 15 kV-200 A, operação manual, comando de ação simultânea, com alavanca para manobra, fabricação AEG.

\subsubsection{Cela de Transformador-150kVA}

- Um transformador de força (TRF-N-02), trifásico, 150 kVA, $13.200 / 220 \mathrm{~V}, 60 \mathrm{~Hz}$, resfriamento natural, líquido isolante óleo mineral, tipo TL-150/15, fabricação AEG.

- Uma chave seccionadora tripolar de 15 kV-200 A, operação manual, comando de ação simultânea, com alavanca para manobra, fabricação AEG.

\subsubsection{Cela de Transformador - 150 kVA}

- Um transformador de força (TRF-N-03), trifásico, 150 kVA, $13.200 / 220 \mathrm{~V}, 60 \mathrm{~Hz}$, resfriamento natural, líquido isolante óleo mineral, tipo TL-150/15, fabricação AEG.

- Uma chave seccionadora tripolar de 15 kV-200 A, operação manual, comando de ação simultânea, com alavanca para manobra, fabricação AEG. 


\subsubsection{Conjunto de Manobra e Controle de Baixa Tensão (CBT-N-01)}

O CBT-N-01 é do tipo armário de aço, fixo (componentes em montagem não extraíveis), autoportante, constituído de seções verticais justapostas para os barramentos principais, dispositivos de proteção e manobra dos alimentadores de entrada e circuitos ramais de saída, bem como para outros componentes ou acessórios auxiliares.

O CBT-N-01 é constituído de dois barramentos trifásicos eletricamente independentes (barramento $\mathrm{N} 1$ e barramento $\mathrm{N} 2$ ). $\mathrm{O}$ barramento $\mathrm{N} 1$ é alimentado pelo transformador TRFN-01 (440 V) e o barramento N2 pelos transformadores TRF-N-02 (220 V) e TRF-N-03 (220 V), ligados em paralelo. Os alimentadores de entrada (ou seja, os cabos vindos dos transformadores), bem como os circuitos ramais de saída, chegam e partem respectivamente do quadro pela parte inferior através de canaleta. Para cada alimentador de entrada é provida uma chave seccionadora, abertura sob carga, e fusíveis tipo $\mathrm{NH}$; enquanto nos circuitos ramais de saída são providos disjuntores termomagnéticos de caixa moldada ou chaves seccionadoras com fusíveis tipo $\mathrm{NH}$. Estes dispositivos de proteção e manobra possuem capacidades nominais de condução de corrente e de ruptura adequadas.

Os circuitos ramais de saída, derivados dos barramentos N1 e N2 são:

\subsubsection{Barramento N1 (440 Volts)}

- Alimentador para o Painel de Comando e Controle, PCC-V-03, do conjunto "no-break" (CNB-V-02) do Sistema de Distribuição Elétrica Vital.

- Alimentador para o Painel de Comando e Controle, PCC-E-01, do grupo diesel gerador (GDG-E-01) do Sistema de Distribuição Elétrica Essencial.

\subsubsection{Barramento N2 (220 Volts)}

- Alimentador para o Painel de Comando e Controle, PCC-V-05, do grupo diesel gerador (GDG-V-03) do Sistema de Distribuição Elétrica Vital. 
- Alimentador para o Painel de Comando e Controle, PCC-E-02, do grupo diesel gerador (GDG-E-02) do Sistema de Distribuição Elétrica Essencial.

- Alimentador do Quadro de Força e Luz, QFL-N-01, do galpão do Laboratório de Experimentação Nuclear - LEN.

- Alimentador do Quadro de Força, QFF-N-13, destinado aos experimentos da física nuclear.

- Alimentador do Centro de Controle de Motores, CCM-N-21, destinado às cargas normais do Sistema de Ventilação e $\mathrm{Ar}$ Condicionado do Prédio do Reator.

- Alimentador do quadro de força, QFF-N-06, das duas bombas de drenagem do tanque de retenção pertencentes ao Sistema de Drenagem do Prédio do Reator.

- Alimentador do quadro de força, QFF-N-04, destinado à iluminação externa (postes) do Prédio do Reator.

\subsubsection{Capacitores de Potência Trifásicos}

As características dos capacitores de potência trifásicos conectados aos barramentos N1 e N2 do CBT-N-01 são:

Capacitor do Barramento N1 (CAP-N-01)

- Potência 15 kVAr.

- Tensão 440 V.

- Corrente 19,7 A.

- Frequência $60 \mathrm{~Hz}$.

- Isolamento $3 \mathrm{kV}$.

- Ligação triângulo.

- Fabricante INEPAR.

Capacitor do Barramento N2 (CAP-N-02)

- Potência 10 kVAr.

- Tensão 220 V.

- Corrente 26,2 A.

- Frequência $60 \mathrm{~Hz}$.

- Isolamento $3 \mathrm{kV}$. 
- Ligação triângulo.

- Fabricante INEPAR.

\subsection{Descrição do Sistema de Distribuição Elétrica Essencial (SDEE)}

O Sistema de Distribuição Elétrica Essencial é alimentado usualmente pelo Sistema de Distribuição Elétrica Normal (SDEN), como mostrado no diagrama unifilar da FIG. 4 (ver pág. 22); no caso de ocorrer falha deste fornecimento os dois grupos diesel geradores do SDEE entram automaticamente em serviço para assumirem as cargas essenciais da planta.

A partida de cada grupo diesel gerador é feita por um dos seguintes modos:

- Partida Automática: feita em caso de falha no suprimento de energia elétrica para o SDEN pela rede da concessionária de eletricidade. Convém ressaltar que na eventualidade de falha na partida inicial a mesma será repetida mais 2 vezes; ou

- Partida Manual: feita em caso de falha da partida automática, após as manutenções preventivas e para testes periódicos.

No modo de partida automática um relé de supervisão de tensão da rede aciona, com um atraso de tempo para absorção de eventuais quedas momentâneas de tensão na rede, o comando de partida para o motor diesel. Após a partida do motor diesel e estando o alternador na condição de tensão e frequência nominais (10 segundos, aproximadamente), é feita a aplicação de carga no grupo. A aplicação de carga, particularmente os motores dos sistemas de processo, é feita manualmente pelo operador do reator da sala de controle ou do próprio centro de controle de motores; a sequência deste carregamento é executada de tal forma que são inicialmente conectadas as cargas de maior demanda de corrente. Com o retorno da rede as cargas serão religadas automaticamente à mesma, (exceto os motores dos sistemas de processo que serão religados manualmente pelos operadores do reator), porém com certo atraso a fim de possibilitar a regularização das variações transitórias de tensão da rede durante este retorno. O grupo será então desligado, após um determinado tempo, para arrefecimento do motor diesel. 
Vale ainda enfatizar que cada grupo diesel gerador tem potência nominal suficiente para suprir continuamente a demanda solicitada pelos equipamentos conectados, inclusive durante a partida de cargas motóricas, sem causar flutuações de tensão e frequência fora dos limites permissíveis.

O SDEE engloba:

- Dois Grupos Diesel Geradores eletricamente independentes, GDGE-01 e GDG-E-02.

- Um quadro de distribuição de força, QDF-E-01 (ver item 4.5.4.1), alimentado pelo painel de comando e controle (PCC-E-02) do grupo GDG-E-02.

- Um quadro de distribuição de força, QDF-E-03 (ver item 4.5.4.2), alimentado pelo painel de comando e controle (PCC-E-01) do grupo GDG-01.

- Uma parte eletricamente independente do centro de controle de motores, barramento E (440 V) do CCM-E/N-11 (ver item 4.5.4.8), alimentado pelo QDF-E-03.

- Uma parte eletricamente independente do centro de controle de motores, barramento E $(220 \mathrm{~V})$ do CCM-E/V-12 (ver item 4.5.4.9), alimentado pelo QDF-E-01.

- Um centro de controle de motores, CCM-E-22 (ver item 4.5.4.7), para o Sistema de Ventilação e Ar Condicionado do Prédio do Reator.

- Um transformador de força seco (TRF-E-21), bifásico, 5 kVA, 440/220 V para alimentar exclusivamente o MPI-V-21.

- Circuitos ramais de saída, originados nos QDFs e CCMs, para as cargas essenciais da planta.

\subsubsection{Arranjo e Características dos Equipamentos}

Os equipamentos ou componentes principais do SDEE estão instalados no Prédio de Distribuição e Geração de Energia Elétrica, nas áreas denominadas Sala dos Geradores (grupos diesel geradores) e Sala de Comando dos Geradores (painéis de comando e controle e quadros de distribuição de força), conforme é mostrado na FIG 5 (ver pag. 26), bem como nos $1^{\circ}$ e $2^{\circ}$ 
andares do Prédio do Reator (centro de controle de motores e quadros de distribuição).

\subsubsection{Grupo Diesel Gerador de 440 Volts (GDG-E-01)}

O grupo GDG-E-01 é constituído de um motor diesel, um alternador síncrono trifásico, um painel de comando e controle, e componentes auxiliares para: partida, arrefecimento, lubrificação, admissão e exaustão de ar, bem como tanque diário para óleo combustível (500litros). As características principais de cada grupo diesel gerador são:

\subsubsection{Motor Diesel}

Motor MWM, turbo alimentado, ciclo de 4 tempos, 12 cilindros dispostos em $\mathrm{V}$, resfriado a água, e tendo ainda as seguintes características:

- Potência em regime contínuo de serviço: 328 HP à 1.800 rpm, operando em pressão atmosférica de $736 \mathrm{mmHg}$ (300 metros, aproximadamente, acima do nível do mar), temperatura ambiente de $20^{\circ} \mathrm{C}$ e umidade relativa do ar de $60 \%$.

- Sobrecarga permitida por hora: $10 \%$ a cada ciclo de 6 horas.

- Partida através de motor de arranque acionado por bateria.

\subsubsection{Alternador Síncrono}

Alternador síncrono com 4 polos, trifásico, neutro acessível tipo roda polar, enrolamento elétrico amortecedor e mancais com rolamentos auto ventilados; a excitação é estática com regulador eletrônico automático de tensão.

Os dados de placa são:

- Potência nominal: 250 kVA.

- Tensão: 440/380 Volts.

- Número de fase: 3.

- Ligação estrela (neutro solidamente aterrado).

- Frequência: $60 \mathrm{~Hz}$.

- Rotação: 1800 rpm.

- Fator de potência: 0,80.

- Tipo de excitação: estática. 
- Regime de serviço: contínuo.

- Isolação: classe B.

- Fabricante: Toshiba.

\subsubsection{Painel de Comando e Controle (PCC-E-01)}

No PCC-E-01 é feita a seleção dos modos de operação, os comandos requeridos no modo de operação manual, a supervisão dos diversos itens de proteção, a sinalização de operação, a sinalização de defeitos, bem como as medições de tensão, corrente e frequência do circuito de força.

O circuito de força é composto por dois contatores: um, denominado contator da rede, conectado ao sistema de distribuição elétrica normal (SDEN) através do alimentador derivado do CBT-N-01; e o outro, denominado contator do gerador, conectado ao alimentador vindo do alternador síncrono.

A chave seletora (manual/automática), instalada no módulo de comando automático digital do painel, permite selecionar os seguintes modos de operação:

\subsection{Modo de Operação Manual}

- Partida do grupo.

- Desconexão da carga da rede.

- Conexão da carga no grupo.

- Desconexão da carga do grupo.

- Conexão da carga na rede.

- Parada do grupo.

- Regulagem da tensão do grupo; ou

- Regulagem da frequência do grupo.

\subsection{Modo de Operação Automática}

Neste modo as operações de partida do grupo, conexão e desconexão da carga, bem como de parada serão realizadas automaticamente.

\subsubsection{Grupo Diesel Gerador de 220 Volts (GDG-E-02)}

O grupo GDG-E-02 é constituído de um motor diesel, um alternador síncrono trifásico, um painel de comando e controle, e componentes auxiliares 
para: partida, arrefecimento, lubrificação, admissão e exaustão de ar, bem como tanque diário para óleo combustível.

\subsubsection{Motor Diesel}

- Motor MWM, turbo alimentado, ciclo de 4 tempos, 8 cilindros dispostos em $\mathrm{V}$, resfriado a água, e tendo as seguintes particularidades:

- Potência em regime contínuo de serviço: $210 \mathrm{HP}$ à 1.800 rpm, operando em pressão atmosférica de $736 \mathrm{mmHg}$ (300 metros, aproximadamente, acima do nível do mar) temperatura ambiente de $20^{\circ} \mathrm{C}$ e umidade relativa do ar de $60 \%$.

- Sobrecarga permitida por hora: $10 \%$ a cada ciclo de 6 horas.

- Partida através de motor de arranque acionado por bateria.

\subsubsection{Alternador Síncrono}

Alternador síncrono com 4 polos, trifásico, neutro acessível tipo roda polar, enrolamento elétrico amortecedor e mancais com rolamentos auto ventilados; a excitação é estática com regulador eletrônico automático de tensão.

Os dados de placa são:

- Potência nominal: 160 kVA.

- Tensão: 220/127 Volts.

- Número de fases: 3 .

- Ligação estrela (neutro solidamente aterrado).

- Freqüência: $60 \mathrm{~Hz}$.

- Rotação: 1800 rpm.

- Fator de potência: 0,80.

- Tipo de excitação: estática.

- Regime de serviço: contínuo.

- Isolação: classe B.

- Fabricante: Toshiba. 


\subsubsection{Painel de Comando e Controle (PCC-E-02)}

As características de projeto e operacionais do PCC-E-02 são similares às descritas no item 4.4.2.3 para o PCC-E-01.

\subsection{Descrição do Sistema de Distribuição Elétrica Vital (SDEV)}

O sistema de distribuição elétrica vital é alimentado usualmente pelo sistema de distribuição elétrica normal, como mostrado no diagrama unifilar da FIG.4 (Ver pag. 23); no caso de ocorrer a falha deste fornecimento os conjuntos "no-breaks" e módulos de potência ininterrupta (MPIs) do SDEV asseguram a continuidade do suprimento de energia elétrica às cargas vitais da planta, até que passem a serem alimentados pelas fontes locais de energia disponíveis para esses conjuntos "no-breaks" e MPIs.

O SDEV engloba:

- Dois conjuntos "no-break's" eletricamente independentes, CNB-V-01 e CNB-V-02.

- Três módulos de potência ininterrupta, MPI-V21, MPI-V-22 e MPIV-31.

- Dois quadros de corrente alternada, QCA-V-21 (alimentado pelo MPI-V-21 ou MPI-V-22) e QCA-V-31 (alimentado pelo MPI-V-31 ou QDF-V-11).

- Um quadro de distribuição de força, QDF-V-02 (ver item 4.5.4.3), alimentado pelo painel de comando e controle (PCC-V-03) do CNB-V-02.

- Um quadro de distribuição de força, QDF-V-11 (ver item 4.5.4.4), alimentado pelo painel de comando e controle (PCC-V-04) do CNB-V-01.

- Um centro de controle de motores, CCM-V-31 (ver item 4.5.4.10), para o Sistema de Ventilação e Ar Condicionado do Prédio do Reator.

- Um transformador de força seco (TRF-V-31), trifásico, 60 kVA, 440/220 V para alimentar exclusivamente o CCM-V-31. 
- Uma parte eletricamente independente do centro de controle de motores, CCM-E/V11 barramento $V$ (ver item 4.5.4.8), alimentado pelo QDF-V-02.

- Uma parte eletricamente independente do centro de controle de motores, CCM-E/V12 barramento $V$ (ver item 4.5.4.9), alimentado pelo QDF-V-11.

- Circuitos ramais de saída, originados nos QDF, CCM e QCA, para as cargas vitais da planta.

\subsubsection{Arranjo e Características dos Equipamentos}

Os equipamentos ou componentes principais do SDEV estão localizados, conforme é mostrado na FIG. 5 (ver PAG. 26), no Prédio de Distribuição e Geração de Energia Elétrica nas áreas denominadas Sala dos Geradores ( conjuntos "no-break's" ) e Sala de Comando dos Geradores (QDF-V-02 e painéis de comando e controle).

\subsubsection{Conjunto "No-Break" de 440 Volts (CNB-V-02)}

O CNB-V-02 consiste de um moto gerador (motor assíncrono e alternador síncrono), um volante de inércia com mancais de rolamentos, uma embreagem de acoplamento eletromagnético, um motor diesel no mesmo eixo do moto gerador, e um painel de comando e controle (PCC-V-03) com chave de transferência manual ("by-pass") para possibilitar a alimentação das cargas vitais diretamente pela rede externa (ou seja, alimentação provida pelo CBT-N-01) durante a execução dos trabalhos de manutenção no conjunto "no-break".

Em condição usual de operação o motor assíncrono, alimentado pelo sistema de distribuição elétrica normal (SDEN) via alimentador derivado do CBT$\mathrm{N}-01$, aciona o alternador síncrono que supre as cargas vitais conectadas. Em caso de falha deste fornecimento de energia elétrica a energia mecânica acumulada no volante de inércia manterá o moto gerador funcionando e, adicionalmente, aciona após o fechamento da embreagem eletromagnética o motor diesel que se encontra parado; o motor diesel agora em funcionamento fornece a energia mecânica necessária para levar o moto gerador à rotação nominal, garantindo deste modo a continuidade sem interrupção do suprimento de 
energia elétrica. A flutuação transitória de frequência no alternador durante essa transferência é 4\%, no máximo.

No retorno da rede externa a embreagem eletromagnética é desligada, porém com certo atraso para possibilitar a regularização das possíveis variações de tensão que possam ocorrer durante o retorno da rede, e o motor assíncrono novamente ligado à rede. Após um período de funcionamento para arrefecimento do motor diesel, o mesmo será desligado.

Os equipamentos principais do CNB-V-02 possuem as seguintes características:

\subsubsection{Moto gerador}

Constituído de um motor trifásico assíncrono com rotor de gaiola, pontas de eixo em ambas as extremidades, e de um alternador síncrono. Os dados de placa concernentes a cada um destes equipamentos são:

\subsubsection{Motor Assíncrono}

- Potência nominal 187 kW.

- Fator de potência 0,85.

- Rendimento $94 \%$..

- Tensão 440 Volts.

- Número de fases 3.

- Frequência $60 \mathrm{~Hz}$.

- Isolação classe B.

- Rotação 1800rpm Regime de serviço contínuo.

- Fabricante Anel.

\subsubsection{Alternador Síncrono}

- Potência nominal 205 kVA.

- Fator de potência 0,80.

- Tensão 440 Volts.

- Número de fases 3.

- Ligação estrela (neutro solidamente aterrado).

- Frequência $60 \mathrm{~Hz}$. 
- Isolação classe B .

- Rotação 1800rpm

- Tipo de excitação estática.

- Regime de serviço contínuo.

- Fabricante Anel.

\subsubsection{4 - Volante de Inércia}

Dimensionado de modo que a flutuação transitória de frequência no alternador não seja superior a $4 \%$, durante a transferência de alimentação da rede externa para o motor diesel.

\subsubsection{Embreagem Eletromagnética}

Dimensionada para acionar o motor diesel desde a condição parado até a condição de rotação nominal (1.800rpm); ela é provida de proteção contra sobretensão.

\subsubsection{Motor Diesel}

Motor Caterpillar, turbo alimentado, ciclo de 4 tempos, 12 cilindros dispostos em $\mathrm{V}$, resfriado a água, e tendo as seguintes particularidades:

- Potência em regime contínuo de serviço: $210 \mathrm{HP}$ a 1.800 rpm, operando em pressão atmosférica de $736 \mathrm{mmHg}$ (300 metros, aproximadamente, acima do nível do mar), temperatura ambiente de $20^{\circ} \mathrm{C}$ e umidade relativa do ar de $60 \%$.

- Sobrecarga permitida por hora: $10 \%$ a cada ciclo de 6 horas.

- Partida manual para estado de prontidão por meio de motor de arranque acionado por bateria.

\subsubsection{Painel de Comando e Controle (PCC-V-03)}

No PCC-V-03 são executados os comandos operacionais manuais, a supervisão dos diversos itens de proteção, a sinalização de operação, a sinalização de defeitos, as medições de tensão, corrente e frequência do circuito de força. 


\subsection{Comandos Operacionais}

Os comandos são executados na parte frontal do painel por meio de botoeiras ou chaves seletoras que permitem as seguintes operações:

- Conexão ou desconexão da rede.

- Liga / desliga bateria do motor diesel.

- Desliga motor diesel.

- Liga / desliga embreagem eletromagnética.

- Seleção do modo de operação (manual ou automático).

- Liga / desliga alternador síncrono.

- Reativação de alarme.

- Desenergização do painel em situações de emergência.

\subsubsection{Conjunto "No-Break" Estático de 220 Volts (CNB-V-01)}

O CNB-V-01 consiste de um retificador/carregador de baterias, um banco de baterias, um inversor e uma chave estática inversor /rede para possibilitar a alimentação das cargas vitais diretamente pela rede externa (ou seja, alimentação provida pelo CBT-N-01) durante a execução dos trabalhos de manutenção no conjunto "no-break".

Em condição usual de operação o sistema de energia ininterrupta, fornecida pelo "no-break", isola totalmente a carga da fonte de corrente alternada da rede quando alimentado pelo Inversor, protegendo-se de quedas de tensão, picos, transitórios e variações de frequência.

O "no-break" é alimentado por um ramal que é atendido tanto pela rede normal de alimentação como também pelo Grupo Diesel Gerador de 220V (GDG-E-02).

Na ocorrência de queda de força parcial ou total da rede, o "no-break" continuará sem interrupção a fornecer energia à carga a partir das baterias do sistema até que o Grupo Diesel Gerador (GDG-E-02) entre em funcionamento e passe a assumir a alimentação da carga.

A previsão de duração das baterias à plena carga é de 1 (uma) hora. Quando a fonte da rede ou do Grupo Diesel Gerador é restaurada, o "no-break" automaticamente recarrega as baterias, a fim de deixá-las prontas para uma nova 
atuação. A indicação da tensão e corrente de carga e outras informações podem ser vistas no display localizado na porta frontal do quadro.

A fonte trifásica de CA é retificada para fornecer corrente contínua para manter a carga da bateria e também para fornecer energia ao inversor. $O$ inversor converte a tensão contínua em tensão de CA.

A carga pode ser alimentada por duas fontes: pelo Inversor ou pela entrada reserva. O Inversor é a fonte preferencial e por meio da "chave estática", permite que a carga seja alimentada pela rede reserva. A transferência neste caso é feita sem interrupção e acontece quando a preferencial cai por algum motivo.

Os equipamentos principais do CNB-V-01 possuem as seguintes características:

\subsubsection{Retificador / Carregador de bateria}

O retificador-carregador de bateria converte a tensão alternada da rede de alimentação primária em tensão contínua, assim mantendo a bateria em ótimo estado de carga e alimentando o Inversor.

\subsubsection{Banco de Baterias}

Constituído de baterias automotivas de chumbo-ácido, livres de manutenção, isto é, dispensa adição de água, e montadas em duas estantes de ferro perfilado na configuração de duas filas sobrepostas; nestas estantes as baterias estão apoiadas sobre longarinas revestidas por canaletas de PVC. O banco possui as seguintes características:

- Quantidade de baterias: 36.

- Capacidade nominal: 185 Ah.

- Tensão nominal: 12 Vcc.

- Tensão mínima: 10,5 Vcc.

- Tensão de flutuação: 13,5 Vcc.

- Tensão de equalização: 15,5 Vcc.

- Autonomia: 60 minutos.

- Fabricante: FREEDOM DF 3000. 
A bateria é um reservatório de energia usado pelo inversor e pela carga na ocorrência de falha na energia da rede.

\subsubsection{Inversor}

O inversor converte a tensão contínua do retificador ou da bateria em tensão senoidal para fornecimento externo.

\subsubsection{Chave Estática Inversor/Rede}

As duas fontes de tensão fornecidas à chave estática são a saída do inversor e a fonte principal/reserva. A função da chave estática consiste em selecionar a saída do inversor como fonte preferencial e fornecer energia à carga externa.

\subsubsection{Modos de Operação}

\subsection{Modo de Operação Normal}

Durante a operação normal, a carga é alimentada pela rede através do retificador e do inversor. O retificador também fornece a energia para recarregar e manter a bateria em flutuação. Nestas condições no painel frontal estarão acesas as seguintes sinalizações: rede Ok, carga no inversor e sincronizado.

\subsection{Queda da Rede Primária}

Quando a tensão da rede está fora da tolerância permitida, a bateria alimenta o inversor e o painel deve indicar as seguintes sinalizações: bateria em descarga e carga no inversor. A duração desse período de funcionamento depende da capacidade da bateria e da magnitude da carga. A autonomia pode ser prolongada desconectando-se cargas de importância secundária. Ao final da autonomia o inversor é desligado automaticamente e é sinalizado no painel frontal "Vcc Baixa".

\subsection{Retorno da Rede Primária}

Quando a rede primária retorna aos limites admitidos, o "no-break" automaticamente volta ao modo normal de operação (como descrito no item 
4.5.3.5.2) e o retificador inicia a recarga da bateria. Nesta condição estará sinalizado "Rede OK", carga no Inversor e Sincronizado.

\subsection{Modo de Operação em By-Pass}

Em casos de manutenção pode-se realizar esta operação para isolar o "no-break". Nesta condição estarão ativas as indicações de "Rede Ok" e "By-Pass Ligado".

\subsubsection{Especificações Técnicas:}

- Potência Continua (Fator de Potência 0,8) 30,0 kVA.

- Sobrecarga no inversor (15 minutos) FP 0,8 37,5 kVA.

Tensão de saída do retificador:

- Nominal 216 Vcc.

- Flutuação (recarga) 245 Vcc.

- Desligamento do inversor por baixa tensão 189 Vcc.

- Corrente máxima de descarga da bateria 125 Acc.

- Rendimento (a plena carga):

- CC-CA 92\%.

- CA-CA $85 \%$.

- Dissipação (a plena carga) $3096 \mathrm{kcal} / \mathrm{h}$.

- Ruído Acústico (a 1,5m do equipamento) 68 DBA (máximo).

\subsubsection{Quadros de Distribuição de Força (QDF)}

Os QDF são do tipo armário de aço, fixo, ou seja, componentes em montagem não extraíveis, auto-portante, com grau de proteção do invólucro IP-52, conforme norma ABNTNBR- 6146 [6]. Os quadros são constituídos de uma seção vertical equipada com um barramento trifásico, chave seccionadora sob carga para o alimentador de entrada e disjuntores termomagnéticos de caixa moldada para os circuitos ramais de saída. Estes dispositivos de proteção e manobra possuem capacidades nominais de condução de corrente e de ruptura adequadas.

Os requisitos de projeto e fabricação dos QDF's seguem, basicamente, as recomendações da norma ABNT-NBR-6808 [7]. 


\subsubsection{QDF-E-01}

O QDF-E-01, instalado na Sala de Comando dos Geradores, é alimentado pelo PCC-E-02. Os circuitos ramais de saída derivados deste quadro são:

- Alimentador do CCM-E-22.

- Alimentador do CCM-E/N-12 (Barramento V).

- Alimentador do QFF-E-01 (Quadro da Exaustão da Sala dos Geradores).

- Alimentador do QFF-03 (Quadro do Prédio de Distribuição e Geração de Energia Elétrica).

- Alimentador alternativo do QDF-V-11.

\subsubsection{QDF-E-03}

O QDF-E-03, instalado na Sala Comando dos Geradores, é alimentado pelo PCC-E-01. Os circuitos ramais de saída derivados deste quadro são:

- Alimentador do CCM-E/V-11 (barramento V).

- Alimentador do QFL-E-02 (quadro do galpão do Laboratório de Experimentação Nuclear - LEN) via transformador de força TRF-E-01 (a seco, trifásico, 20 kVA-440/220 V).

- Alimentador do QFF-E-03 (quadro do Sistema de Ar Comprimido).

- Alimentador do QFF-E-02 (quadro da bomba da caixa d'água).

\subsubsection{QDF-V-02}

O QDF-V-02, instalado na Sala de Comando dos Geradores, é alimentado pelo PCC-V-03. Os circuitos ramais de saída derivados deste quadro são:

- Alimentador do CCM-E/V-11 (barramento V).

- Alimentador do CCM-V-31 via transformador de força TRF-V-31 (a seco, trifásico, 60kVA-440/220 V).

\subsubsection{QDF-V-11}

O QDF-V-11, instalado no 10 andar do Prédio do Reator, é alimentado pelo PCC-V-04. Os circuitos ramais de saída derivados deste quadro são: 
- Alimentador do CCM-E/V-12 (barramento V).

- Alimentador do estabilizador de tensão, EST-V-11, da Mesa de Controle.

- Alimentador do QFF-V-05 (quadro do galpão do Laboratório de Experimentação Nuclear - LEN).

- Alimentador alternativo do QCA-V-31 (ver item 4.5.4.11).

\subsubsection{Centro de Controle de Motores (CCM)}

Os CCM são do tipo armário de aço, fixo, ou seja, componentes em montagem não extraíveis, autoportante, com grau de proteção do invólucro IP-52. Os CCM são constituídos de duas ou mais seções verticais justapostas equipadas com um barramento trifásico horizontal comum, unidades de comando de motores (ou demarradores) e unidades de circuitos alimentadores. Cada uma destas unidades é provida, quando necessário, de bloqueios elétricos, botoeiras de comando, instrumentos de medição com chaves seletoras e lâmpadas de sinalização.

Os requisitos de projeto e fabricação dos $\mathrm{CCM}$ seguem, basicamente, as recomendações da norma ABNT-NBR-6808 [7].

\subsubsection{CCM-N-21}

O CCM-N-21, instalado na Sala de Ventilação e Ar Condicionado ( $2^{\circ}$ andar do Prédio do Reator), é destinado exclusivamente às cargas normais do Sistema de Ventilação e Ar Condicionado; é constituído de um barramento trifásico horizontal (barramento $\mathrm{N}$ ) alimentado pelo CBT-N-01. O alimentador de entrada e os circuitos ramais de saída, chegam e partem respectivamente do CCM pela parte inferior através de eletrodutos. No alimentador de entrada é provida uma chave seccionadora de abertura sob carga; enquanto em cada alimentador do circuito ramal de saída é provido um disjuntor termomagnético de caixa moldada ou um disjuntor eletromagnético de caixa moldada mais um contator magnético com relé térmico (demarradores de motores). Estes dispositivos de proteção e manobra possuem capacidades nominais de condução de corrente e de ruptura adequadas.

Os circuitos ramais de saída, originados no barramento $\mathrm{N}$ são: 
- Alimentador do motor do ventilador de exaustão da área fria, VG004 (3,2 kW).

- Alimentadores dos condicionadores de ar tipo "self-contained", SC001 (8,0 kW) e SC-002 (8,0 kW).

- Resistores de aquecimento do saguão da piscina, RS-001A (4,8kW), RS-001B (4,8kW), RS-001C (4,8 kW) e RS-001D (4,8 kW);

- Alimentadores dos compressores CP-001 (78,0 kW) e CP-002 (78,0 $\mathrm{kW})$.

- Alimentadores das bombas de condensado B-001 (9,2 kW) e B-002 $(9,2 \mathrm{~kW})$.

\subsubsection{CCM-E-22}

O CCM-E-22, instalado na Sala de Ventilação e $\operatorname{Ar}$ Condicionado ( $2^{\circ}$ andar do Prédio do Reator) é destinado exclusivamente às cargas essenciais do Sistema de Ventilação e Ar Condicionado; é constituído de um barramento trifásico horizontal (barramento E) alimentado pelo QDF-E-01. O alimentador de entrada e os circuitos ramais de saída, chegam e partem respectivamente do CCM pela parte inferior através de eletrodutos. No alimentador de entrada é provida uma chave seccionadora de abertura sob carga; enquanto em cada alimentador do circuito ramal de saída é provido um disjuntor termomagnético de caixa moldada ou um disjuntor eletromagnético de caixa moldada mais um contator magnético com relé térmico (demarradores de motores). Estes dispositivos de proteção e manobra possuem capacidades nominais de condução de corrente e de ruptura adequadas. Os circuitos ramais de saída, originados no barramento E são:

- Alimentador do motor do ventilador de insuflamento da área quente, VG-001 (48,75kW).

- Alimentador do motor do ventilador de exaustão da área quente, VG$002(22,12 \mathrm{~kW})$.

- Alimentador do. motor .do .ventilador de .exaustão .da .área fria, VG$005(4,02 \mathrm{~kW})$.

- Alimentador do condicionador de ar tipo "self-contained", SC 003 $(10,83 \mathrm{~kW})$. 
- Alimentadores dos resistores de aquecimento da Sala de Controle, RS-111A (2,28kW) e RS-111B (2,28 kW).

- Alimentador do MPI-V-22 (3kW).

\subsubsection{CCM-E/V-11}

O CCM-E/V-11, instalado no $1^{\circ}$ andar do Prédio do Reator, é constituído de dois barramentos trifásicos horizontais eletricamente independentes (barramento $E$ e barramento $V$ ); o barramento $E$ é alimentado pelo QDF-E-03 e o barramento $V$ pelo QDF-V-02. Os alimentadores de entrada (ou seja, os cabos vindos do QDF-E-03 e QDF-V-02), bem como os circuitos ramais de saída, chegam e partem respectivamente do CCM pela parte inferior através de canaleta. Nos alimentadores de entrada são providos uma chave seccionadora de abertura sob carga e fusíveis tipo $\mathrm{NH}$; enquanto em cada alimentador do circuito ramal de saída é provido um disjuntor eletromagnético de caixa moldada mais um contator magnético com relé térmico. Estes dispositivos de proteção e manobra possuem capacidades nominais de condução de corrente e ruptura adequadas.

Os circuitos ramais, originados no barramento E são:

- Alimentadores das bombas de água de resfriamento, B-102A (37 $\mathrm{kW}$ ) e B-102B (45kW).

- Alimentadores dos ventiladores da torre de resfriamento, VG-001 (22 kW), VG-002 (22 kW), VG-003 (22 kW) e VG-004 (22 kW).

Os circuitos ramais, originados no barramento $V$, são:

- Alimentadores das bombas de circulação de refrigerante, B-101A (75 $\mathrm{kW})$ e B-101B (75kW).

- Alimentador do compressor de ar comprimido reserva, CP-2A (4 $\mathrm{kW})$.

- Alimentador do MPI-V-21 (3kW).

\subsubsection{CCM-E/V-12}

O CCM-E/V-12, instalado no primeiro andar do Prédio do Reator, é constituído de dois barramentos trifásicos horizontais eletricamente independentes (barramento $\mathrm{E}$ e barramento $\mathrm{V}$ ); o barramento $\mathrm{E}$ é alimentado pelo 
QDF-E-01 e o barramento V pelo QDF-V-11. Os alimentadores de entrada (ou seja os cabos vindos do QDF-E-01 e QDF-V-11), bem como os circuitos ramais de saída, chegam e partem respectivamente do CCM pela parte inferior através de canaleta. Nos alimentadores de entrada são providos disjuntores termomagnéticos de caixa moldada; enquanto em cada alimentador de circuito ramal de saída é provido um disjuntor termomagnético de caixa moldada ou um disjuntor eletromagnético de caixa moldada mais um contator magnético com relé térmico (demarradores de motores). Estes dispositivos de proteção e manobra possuem capacidades nominais de condução de corrente e de ruptura adequadas.

Os circuitos ramais originados no barramento $E$ são:

- Alimentador da bomba do coletor de água (SUMP) do Prédio do Reator $(1,5 \mathrm{~kW})$.

- Alimentador do turbo exaustor centrífugo (BLOWER ), EXT-01 (4 $\mathrm{kW})$.

- Alimentador do quadro de força e luz, QFL-E-33, do saguão da piscina $(9,67 \mathrm{~kW})$.

- Alimentador da bomba de retratamento principal, B1-A (2,2 kW).

- Alimentador do quadro de força e luz, QFL-E-11 (0,92kW).

- Alimentador do painel de comando das estações pneumáticas $(0,71 \mathrm{~kW})$.

- Alimentador do quadro de força, QFF-E/V-33 (1kW)

- Alimentador do quadro de força, QFF-E-14 (0,9kW).

- Alimentador do quadro de força, QFF-E-31 (3,2kW).

- Alimentador do quadro de força, QFF-E-07 (Prédio Anexo) (0,92kW).

- Alimentador do elevador, ELV-01 (7,5 kW) do Prédio do Reator.

- Alimentador da talha elétrica, TE-01 (1,2 kW), instalada no primeiro andar do Prédio do Reator.

- Alimentador para os circuitos de iluminação e tomadas da Sala de Emergência $(0,92 \mathrm{~kW})$.

- Alimentador para os circuitos dos refletores da piscina e plataforma móvel do núcleo do reator $(0,92 \mathrm{~kW})$. 
- Alimentador para os circuitos de tomadas da piscina $\left(1^{\circ}\right.$ e $3^{\circ}$ andares) $(0,94 \mathrm{~kW})$.

- Alimentador para os circuitos de iluminação e tomadas da Portaria Externa $(0,91 \mathrm{~kW})$.

Os circuitos ramais de saída, originados no barramento $V$ são:

- Alimentador do alarme de incêndio (Sala de Emergência) (0,64kW).

- Alimentador das bombas de retratamento reservas, B-2A (1,5 kW) e B-3A $(1,5 \mathrm{~kW})$.

- Alimentador do quadro de força, QFF-V-12 (0,93kW)

\subsubsection{CCM-V-31}

O CCM-V-31, instalado na Sala de Ventilação e Ar Condicionado, ( $2^{\circ}$ andar do Prédio do Reator), é destinado exclusivamente às cargas vitais do Sistema de Ventilação e Ar Condicionado. É constituído de um barramento trifásico horizontal (barramento E) alimentado pelo QDF-V-02 via transformador trifásico seco (TRF-V-31). O alimentador de entrada e os circuitos ramais de saída, chegam e partem respectivamente do CCM parte inferior através de eletrodutos. No alimentador de entrada é provida uma chave seccionadora de abertura sob carga; enquanto em cada alimentador do circuito ramal de saída é provido um disjuntor termomagnético de caixa moldada ou um disjuntor eletromagnético de caixa moldada mais um contator magnético com relé térmico (demarradores de motores). Estes dispositivos de proteção e manobra possuem capacidades nominais de condução de corrente e de ruptura adequadas.

Os circuitos ramais de saída originados neste CCM são:

- Alimentador do motor do ventilador de exaustão da área quente, VG$003(22,12 \mathrm{~kW})$.

- Alimentadores dos resistores de aquecimento da exaustão de emergência, RS-044A (4,56 kW), RS-044B (4,56 kW), RS-044C $(4,56 \mathrm{~kW})$ e RS-044D (4,56 kW).

- Alimentador do MPI-V-31 (3kW). 


\subsubsection{Quadros de Corrente Alternada (QCA)}

Os QCA (QCA-V-21 e QCA-V-31) são do tipo armário de aço, fixo, ou seja, componentes em montagem não extraíveis, auto-portante, com grau de proteção do invólucro IP-52, conforme norma ABNT-NBR-6146 [6]. Os quadros são constituídos de uma seção vertical equipada com um barramento bifásico; o alimentador de entrada e os circuitos ramais de saída são providos de disjuntores termomagnéticos de caixa moldada. Estes dispositivos de proteção e manobra possuem capacidades nominais de condução de corrente e de ruptura adequadas.

Os requisitos de projeto e fabricação dos QCA seguem, basicamente, as recomendações da norma ABNT-NBR-6808 [7]. 


\section{REVISÃO BIBLIOGRÁFICA}

A confiabilidade das fontes de energia elétrica de emergência em corrente alternada de centrais nucleares tem sido questionada devido ao número razoável de falhas dos geradores diesel de emergência relatadas e devido a um eventual dano que o núcleo do reator poderia sofrer caso os geradores diesel falhassem durante uma emergência.

A antiga Comissão de Energia Atômica dos Estados Unidos dirigiu um estudo, WASH 1400 [1], publicado em 1975, o qual mostrou que a perda total do fornecimento de energia elétrica em corrente alternada poderia ter uma grande contribuição no risco total de acidentes em centrais nucleares. Nesse trabalho foram analisadas diversas sequências de acidentes possíveis, sendo as consequências de cada acidente avaliadas e comparadas a outros acidentes aos quais está sujeito o homem moderno. A probabilidade de falha do sistema elétrico, do ponto de vista de fornecimento de energia elétrica aos dispositivos de segurança, foi calculada usando-se a técnica de árvore de falhas, utilizada na Avaliação Probabilística de Segurança - Nível 1 [8], com o objetivo de determinar as frequências de ocorrência dos eventos indesejáveis.

Com o decorrer do tempo e com o consequente acúmulo da experiência operacional, foi levantada a suspeita de que a confiabilidade das fontes locais de energia elétrica de emergência em corrente alternada e das fontes externas poderia ser menor do que a originalmente esperada, aumentando a preocupação com o suprimento de energia elétrica.

Em 1979, a NRC - "Nuclear Regulatory Commission" declarou a perda de todas as fontes de energia elétrica como um problema de segurança não resolvido, definindo, em julho de 1980, um plano de ações a serem tomadas para determinar a necessidade de requisitos de segurança adicionais incluindo as tarefas listadas a seguir [9]:

- Estimar a frequência de ocorrência da perda de todas as fontes de energia elétrica das centrais nucleares em operação nos Estados Unidos. 
- Estimar a frequência de perda da alimentação externa de várias centrais.

- Estimar a probabilidade de falha das fontes locais em corrente alternada, na ocorrência de uma perda de alimentação externa.

- Determinar as respostas da central nuclear e o risco associado com as sequências de acidentes iniciados no caso de perda de todas as fontes de energia elétrica.

A pedido da NRC, o ORNL - "Oak Ridge National Laboratory", desenvolveu uma base técnica para auxiliar a resolver o problema de perda de todo suprimento de energia elétrica culminando com a emissão, em julho de 1983, de um estudo sobre a confiabilidade de sistemas de emergência em corrente alternada de centrais nucleares [10]. Esse documento apresenta o resultado dos estudos de confiabilidade das fontes locais de energia elétrica de emergência em corrente alternada, utilizando dados de um total de 120 geradores diesel cobrindo um período entre 1976 e 1980.

Para a execução dos estudos, 18 plantas tidas como típicas quanto aos sistemas locais de energia elétrica em corrente alternada, e dez projetos genéricos foram selecionados para serem modelados por meio de árvores de falhas.

Detectou-se que muitas plantas em operação não tinham metas de confiabilidade para seus geradores diesel de emergência. Considerando o papel crítico que os mesmos desempenham na mitigação de vários transientes e eventos postulados que podem ocorrer durante a perda da fonte externa de energia, foi ressaltada a necessidade de assegurar e manter a confiabilidade dos geradores diesel em níveis aceitáveis.

Segundo esse estudo, os fatores que contribuem para a confiabilidade dos sistemas locais de energia variam de planta para planta, estando entre as mais importantes:

- Probabilidade de falha dos geradores diesel para os quais a média da indústria é $2.5 \times 10^{-2}$ e a faixa varia de $8,0 \times 10^{-3}$ a $1,0 \mathrm{x}$ $10^{-1}$.

- Erro humano e falha de modo comum do "hardware", para os quais a faixa de indisponibilidade varia de $1,0 \times 10^{-4}$ a $4,2 \times 10^{-3}$. 
- Indisponibilidade devido à manutenção programada durante operação do reator para a qual a média da indústria é $6,0 \times 10^{-3}$ e a faixa varia de 0 a $3,7 \times 10^{-2}$.

- Tempo de reparo do gerador diesel, para o qual a média é 20 horas e a faixa varia de 4 a 92 horas.

- Indisponibilidade do sistema de água de serviço da planta, para o qual a probabilidade de falha independente é $2,0 \times 10^{-3}$, a probabilidade de falha de modo comum é $8,0 \times 10^{-5} \mathrm{e}$ a indisponibilidade devido à manutenção programada é $2,0 \times 10^{-3}$.

Como parte do trabalho desenvolvido na NUREG/CR-2989 [10], foram também determinadas as contribuições de cada um dos subsistemas dos geradores diesel no total das falhas apuradas. Para os subsistemas cujas falhas foram mais significativas, foi sumarizada a contribuição de cada componente.

Uma revisão dos relatórios de ocorrência de falhas gerados pelas centrais licenciadas, para o período de 1976 a 1980, identificou 32 ocorrências de falhas de modo comum atribuídas ao hardware e 88 ocorrências nas quais o erro humano causou a indisponibilidade simultânea de dois ou mais geradores diesel.

Considerando que, do ponto de vista de segurança, melhorar a confiabilidade dos geradores diesel teria um significante efeito benéfico, a NRC emitiu a "Generic Letter" 84-15 [11], em julho de 1984, sugerindo o seguinte:

- Reduzir o número dos testes periódicos de partida rápida a frio para os geradores diesel de emergência.

- Solicitar às plantas licenciadas os dados de confiabilidade dos geradores diesel de emergência.

- Solicitar às plantas licenciadas o programa, caso existisse, para atingir e manter o nível de confiabilidade dos geradores diesel de emergência.

Todo o esforço despendido no sentido de reduzir os problemas relacionados com os geradores diesel de emergência levou a uma reavaliação dos dados relativos à experiência operacional dos mesmos para o período de 1981 a 1983, resultando na publicação da NUREG 4347 [12].

Em novembro de 1986 foi publicado o relatório da OECD/NEA - "Loss of Safety System Functions - Pilot Examination of Generic Safety Questions" [13] 
que compila uma série de informações sobre eventos de perda das funções dos sistemas de segurança ocorridos em plantas nucleares dos países membros da "Nuclear Energy Agency" - NEA.

Duas fontes principais foram utilizadas para compilar as informações pertinentes ao assunto: Relatórios dos países membros da NEA que experimentaram eventos de perda de sistemas de segurança e pesquisa na base de dados da NEA.

Foram consideradas duzentas e oitenta ocorrências das quais cento e noventa e nove são relativas a reatores a água leve e oitenta e uma afetaram reatores a água pesada.

O relatório agrupa os eventos de acordo com os sistemas afetados e os eventos relativos ao suprimento de energia elétrica e abordam dois problemas:

- Geração de energia elétrica em corrente alternada por grupos geradores diesel de emergência.

- Distribuição de energia elétrica em corrente alternada ou corrente contínua para a instrumentação e controle através dos barramentos vitais.

As falhas de geração de energia elétrica de emergência em corrente alternada por grupos diesel geradores perfazem uma porção considerável dos eventos de perda de sistemas de segurança, tendo sido relatadas quinze ocorrências.

A maior parte dos eventos ocorreu durante a operação em potência e somente três eventos ocorreram durante paradas para troca de combustível.

Nos acidentes ocorridos durante a operação em potência, somente em duas vezes os geradores diesel de emergência foram realmente necessários, nas demais, fontes alternativas de energia estavam disponíveis.

As discussões apontam duas causas principais para a ocorrência de perda de função dos sistemas de segurança devido aos geradores diesel:

- Falha de um gerador diesel enquanto o gerador diesel redundante estava indisponível devido à manutenção.

- Falha de modo comum dos geradores diesel redundantes.

Sete dos quinze eventos relatados pertencem à primeira categoria, sendo que o gerador diesel em operação falhou cinco vezes devido a uma falha intrínseca e duas vezes por falha humana. 
Sete falhas de modo comum dos geradores diesel foram relatadas, tendo as mesmas causado perda de função dos sistemas de segurança ou contribuído para tal. As falhas observadas foram:

- Trabalhos de modificação executados com documentos errados (listas de cabos e diagramas unifilares/funcionais) tornaram três geradores diesel, do sistema de proteção de segundo nível, inoperáveis. Os geradores diesel falharam em partir na demanda.

- Abertura de chaves erradas, na preparação do teste de partida, (perda do gerador principal e da fonte externa) impediu a partida de quatro geradores diesel.

- Três geradores diesel foram impropriamente borrifados pelo sistema de combate a incêndio.

- Os radiadores dos geradores diesel congelaram devido a adição insuficiente de fluido anti congelante.

- Varas de conexão racharam devido à falha de fabricação.

- Válvulas de verificação defeituosas degradaram a refrigeração do diesel.

- Em um dos casos, um gerador diesel disparou devido a uma falha de projeto na lógica de proteção.

Dada a importância dos geradores diesel de emergência como fontes alternativas de energia e a preocupação com a ocorrência de falhas de modo comum a NEA publicou, em maio de 2000, um relatório [2] que analisa os dados de falha de modo comum visando melhorar o entendimento sobre a ocorrência das mesmas e identificar as medidas que podem ser adotadas para prevenir, ou pelo menos mitigar, o efeito das ocorrências de falhas de modo comum em geradores diesel.

Os dados observados pelo NEA cobrem um período que vai de 1982 a 1997 e, dos dados analisados, um total de 106 eventos foram classificados como de falha de modo comum.

Todos os demais eventos são denominados como "parcial". Um subgrupo é denominado grau de falha "quase completa". Tais eventos são aqueles nos quais todos os componentes falham menos um que fica degradado, sendo que o tempo entre falhas é maior do que o intervalo de inspeção. 


\section{METODOLOGIA}

\subsection{Análise de Segurança}

\subsubsection{Métodos e Abordagens Utilizados na Análise de Segurança do Reator IEA-R1.}

De maneira geral foi utilizada nesta análise a abordagem amplamente disseminada e aceita, de considerar possíveis eventos iniciadores de acidentes e aplicar uma técnica determinística para avaliar as consequências de tais incidentes. Assim, são descritos os métodos utilizados para identificar e selecionar os eventos iniciadores de acidentes, os métodos de análise dos acidentes, incluindo, sequência de eventos, análise de transitórios e consequências radiológicas. Por fim são descritos os critérios de aceitação de doses radiológicas.

\subsubsection{Métodos de Identificação e Seleção de Eventos Iniciadores [14]}

O método utilizado para identificar os eventos iniciadores postulados, isto é as ocorrências que podem conduzir a cenários de acidente, está baseado no "Safety Series" 35-G1 [15] e"Safety Series" 35-S1 [16], e consiste de várias etapas que incluem a identificação de um conjunto preliminar de eventos iniciadores, a eliminação dos eventos inadequados, a reunião dos eventos em categorias e a identificação dos eventos limitantes (eventos de pior consequência de uma categoria), que passarão por estudos detalhados de análise de acidentes. A lista preliminar de eventos iniciadores de acidentes foi obtida a partir da lista genérica, para reatores de pesquisa, apresentada na Tabela I do "Safety Series" 35-G1 [15]. Daquela lista foram eliminados os eventos iniciadores inconsistentes ou inapropriados, os eventos não críveis (impossíveis de ocorrer no IEA-R1); os eventos muito raros (eventos iniciadores cuja frequência de ocorrência é tão baixa que podem ser rejeitados no campo probabilístico) e os eventos que resultam da combinação de eventos mutuamente independentes, com baixa frequência de ocorrência. 
$\mathrm{Na}$ lista reduzida foram incorporados novos eventos a partir da experiência operacional de 39 anos de operação do reator IEA-R1 e do exame de relatórios de segurança de instalações similares, tais como, "Democritos Greek Research Reactor" [17], "Union Carbide Research Reator" [18], "Oak Ridge Research Reactor" [19], "Omega West Reactor" [20] e "MIT Research Reactor" [21]. Após a lista ter sido completada, os eventos iniciadores foram agrupados em categorias que reúnem eventos que exercem influência similar no comportamento do reator e para os quais modelos de cálculo similares podem ser usados. Desta lista foram selecionados, para a análise detalhada, os eventos iniciadores que apresentam indícios de serem limitantes de uma ou mais categorias, isto é, com consequências potenciais superiores aos demais eventos iniciadores de acidentes de um mesmo grupo.

\subsubsection{Seleções de Eventos Iniciadores de Acidentes}

Os eventos postulados iniciadores de possíveis acidentes no Reator IEA-R1, estão divididos em oito categorias, listados a seguir:

- Perda de alimentação elétrica.

- Inserção de excesso de reatividade.

- Perda de vazão no núcleo.

- Perda de refrigerante primário.

- Manobra errada ou falha de equipamento.

- Eventos internos especiais.

- Eventos externos.

- Falhas humanas.

Neste trabalho somente será discutida a categoria de perda de alimentação elétrica.

\subsubsection{Métodos de Análise}

\subsubsection{Análise das Sequências de Eventos}

As sequências de eventos foram avaliadas, desde a ocorrência do evento iniciador, até o estado final de danos no reator, acompanhando todo o desenrolar do acidente. Nestas avaliações foram consideradas tanto as 
interações humanas, quanto os sistemas importantes para a eliminação ou mitigação das consequências do acidente, incluindo o sistema de proteção do reator e os sistemas de segurança. Além disso, foi considerada a barreira primária, constituída pelo revestimento do combustível, a piscina do reator e o confinamento.

Durante o estudo das sequências de eventos foram identificadas ocorrências significativas ao longo do tempo, por exemplo:

- Desligamento do reator.

- Início e final da inserção das barras de segurança.

- Funcionamento correto ou incorreto da instrumentação e controle do reator em condições normais.

- Ações requeridas do operador.

- Condições para o término da análise, incluindo, por exemplo, situações nas quais condições estáveis são alcançadas (sem exposição ou liberação).

Também foram avaliadas as três principais funções de segurança: desligamento do reator, resfriamento do combustível e confinamento dos radionuclídeos, incluindo uma indicação do funcionamento correto do sistema de proteção do reator e dos sistemas de segurança, simultaneamente, e de suas falhas.

A análise foi executada considerando-se:

- Efeito de uma única falha.

- Qualificação do sistema (ou falta de qualificação) sob condições de acidente.

- Sistemas de Proteção e Segurança, incluindo a confiabilidade e parâmetros quantitativos.

- Sistemas de Suporte, tal como Sistema Elétrico de Serviço e de Emergência.

- Parâmetros de desligamento redundantes.

- Ações de sistemas independentes.

- Ações do operador (exemplo: tempos de resposta, apresentação de informações num console). 
As convenções utilizadas para determinar as sequências de eventos que estão além da base de projeto, sendo por isso excluídas da análise detalhada, basearam-se em:

- Argumentos qualitativos justificando a exclusão dos eventos cuja ocorrência é impossível ou que não são críveis para o reator.

- Qualificação da instalação ou dos sistemas do reator para resistir aos efeitos do evento.

- Argumentos probabilísticos.

Os efeitos de erros humanos também foram considerados e incluem:

- Identificação de suas causas.

- Avaliação de seu efeito tanto como iniciador de um acidente, quanto como elemento de agravamento de um acidente em evolução.

- Avaliação crítica das suposições adotadas com respeito à resposta dos sistemas do reator durante as sequências de acidente.

O estudo das sequências de eventos limitantes, isto é, sequências que sofreram análise detalhada com uso de métodos de análise de transitórios, baseou-se em:

- Suposições conservativas feitas na classificação das categorias, como não dar crédito total a ações de mitigação de sistemas ou da resposta do operador.

- Suposições conservativas para assegurar que todas as sequências de uma categoria foram cobertas.

- Em métodos para escolha das sequências limitantes em um grupo de eventos que representa a classe inteira e não somente uma sequência específica, incluindo aquelas que têm as consequências mais severas.

\subsubsection{Análise dos Transitórios}

Após a definição dos eventos limitantes, foi realizada uma análise quantitativa de cada um destes incidentes. Observa-se que a definição destes eventos baseou-se em um estudo detalhado da instalação, estudos realizados em outros reatores similares e dos exemplos apresentados no IAEA-TECDOC-643 [22]. 
Para a análise dos transitórios e análise quantitativa de segurança, foram utilizados métodos determinísticos, baseados, quando possível, em programas computacionais bem disseminados.

Um fator muito importante para a análise dos transitórios é a condição inicial do reator no início do evento. $\mathrm{Na}$ definição da condição inicial foram adotadas hipóteses conservativas. Assim, foram utilizadas as seguintes condições:

- Configuração esperada do núcleo com o menor número de elementos dentro de um prazo de 2 anos.

- Para o cálculo do inventário de radionuclídeos e da potência de decaimento assumiu-se uma queima média do combustível no núcleo de $30 \%$.

- O canal quente foi modelado com fatores de pico nucleares e de engenharia.

- Sobre potência de $10 \%$ antes do início do acidente.

$\mathrm{Na}$ análise dos transitórios de inserção de reatividade e parada de bomba, utilizou-se o código PARET [23], que é adequado para análise destes tipos de eventos em reatores tipo piscina.

\subsubsection{Análise das Consequências Radiológicas}

Para avaliação das consequências radiológicas nos casos dos acidentes com danos no núcleo, foram utilizados métodos conservativos e determinísticos. O IAEA-TECDOC-643 [22] e análises realizadas para reatores similares foram utilizados como referência para modelos e parâmetros.

Para a avaliação da dispersão atmosférica e das consequentes doses radiológicas em torno da instalação, foi utilizado o programa computacional SACARA [24], implantado no Centro de Engenharia Nuclear (CEN) do IPEN. Os modelos utilizados por este código são os recomendados pelos Órgãos Licenciadores e estão baseados nos seguintes guias, "Regulatory Guide" 1.4 [25], "Regulatory Guide" 1.145 [26] e NUREG/CR-3332 [27].

Para avaliação das taxas de dose dentro do prédio do reator e nas suas imediações, devido à radiação direta, foi utilizada a mesma metodologia do Grupo de Física de Reatores do CEN do IPEN para o cálculo de blindagem de reatores nucleares. Esta metodologia consiste de uma rede acoplada de códigos 
nucleares (programas de computador) que são utilizados na solução de transporte da radiação.

\subsection{Critérios de Aceitação de Doses Radiológicas}

Como critério de aceitação das doses radiológicas provocadas por acidentes utilizou-se a RESOLUÇÃO CNEN-09/69 [28], que dita as Normas para Escolha de Locais para Instalação de Reatores de Potência. Nesta resolução são definidas a área de exclusão e a zona de baixa população.

A área de exclusão é a área pertencente ao patrimônio da operadora, que circunda o reator, sendo que nesta área a operadora tem autoridade para determinar todas as atividades, inclusive remoção de pessoal. $\mathrm{Na}$ área de exclusão, em caso de acidente, a dose total de radiação de corpo inteiro não pode exceder 250 mSv e a dose de radiação por inalação na tireóide não pode exceder $3000 \mathrm{mSv}$, para um indivíduo situado em um ponto sobre a linha limítrofe externa durante duas horas a partir do início do acidente máximo postulado.

A zona de baixa população é a área pouco habitada adjacente à área de exclusão. Nesta área, o número total de habitantes deve permitir a existência de medidas protetoras a serem tomadas em caso de acidente grave. Os limites de doses radiológicas para um indivíduo na zona de baixa população são as mesmas para a área de exclusão. Contudo, estas doses não podem ser excedidas para um indivíduo situado sobre um ponto de sua linha limítrofe, durante todo o período de passagem da nuvem radioativa resultante da liberação de radionuclídeos devido ao acidente máximo postulado.

Acidente Máximo Postulado é o acidente resultante de uma possível sequência de eventos, cujas consequências não serão excedidas pelas de nenhum outro acidente possível, exceto aqueles acidentes cuja probabilidade de ocorrência seja tão pequena que possam ser considerados impossíveis de ocorrer.

\subsection{Guia Regulatório}

A CNEN - Comissão Nacional de Energia Nuclear orienta-se nos requisitos e estrutura da NUREG 0800 "Standard Review Plan", na avaliação independente do Relatório de Análise de Segurança. O documento em questão, 
no seu Capítulo 8, estabelece os critérios de aceitação e as diretrizes para os sistemas elétricos [29].

Além dos requisitos específicos para o projeto de sistemas elétricos contemplados na NBR-8671 [30] e na NUREG 0800 [29], a CNEN - Comissão Nacional de Energia Nuclear, tem importantes publicações, entre as quais a "NE1.04 - Licenciamento de Instalações Nucleares" [31] e a "NN - 1.16 - Garantia da Qualidade para Segurança de Usinas Nucleoelétricas e Outras Instalações" [32]. A NE-1.04 [33] estabelece o processo de licenciamento de instalações nucleares aplicado às atividades relacionadas com a localização, a construção e a operação de tais instalações, abrangendo as seguintes etapas:

1. Aprovação de local.

2. Licença de construção (total ou parcial).

3. Autorização para utilização de materiais nucleares.

4. Autorização para operação inicial.

5. Autorização para operação permanente.

6. Cancelamento da autorização para operação.

São apresentadas as informações mínimas que devem estar contidas no relatório preliminar de análise de segurança a ser elaborado visando à emissão da licença de construção, bem como as informações que devem estar contidas no Relatório Final de Análise de Segurança (RFAS), o qual, juntamente com o plano de proteção física, constituem os documentos básicos para a emissão da Autorização para Operação Inicial.

O RFAS deve descrever a instalação, apresentar as bases de projeto, as especificações técnicas, os limites de operação e uma análise de segurança da instalação como um todo, devendo incluir o programa de monitoração ambiental e meteorológica, o programa de garantia da qualidade, o plano de proteção contra incêndio e o plano de emergência, entre outros.

A NN-1.16 [32] determina os requisitos a serem adotados para o estabelecimento e implementação de Sistemas de Garantia da Qualidade para usinas nucleoelétricas, instalações nucleares e, conforme aplicável, também para instalações radiativas. Determina a forma segundo a qual os Programas de Garantia da Qualidade devem ser preparados e submetidos à CNEN. Ela é particularmente aplicável às atividades que influem na qualidade de itens importantes à segurança, desenvolvidos no gerenciamento do empreendimento e 
em cada um dos seus diversos estágios: escolha de local, projeto, construção, comissionamento, operação e descomissionamento.

\subsubsection{Observações sobre a Base Normativa}

Uma análise dos guias e códigos aplicáveis ao desenvolvimento de projetos elétricos mostra que todos eles contemplam, de forma mais ou menos abrangente, os principais critérios de projeto, as principais recomendações e condições de contorno a serem observadas.

Um sistema elétrico externo composto por duas linhas de transmissão fisicamente independentes entre si é uma exigência comum.

O 50-SG-D7 [2] estabelece que uma única linha de transmissão possa ser aceitável nos casos onde a central contribui com uma grande parte da geração do sistema interligado ou onde a estabilidade da rede é tal que a perda da central não ocasionaria o colapso da rede. Nestes casos, é recomendado que o sistema elétrico interno fosse projetado para suportar os efeitos da perda da alimentação externa.

Os requisitos de redundância e separação física também são comuns a todos os guias códigos. O mesmo se aplica para os requisitos de qualificação de componentes e equipamentos.

A exigência de um sistema elétrico de emergência também é abordada em todos os guias códigos. A ABNT-NBR-8671 [30] faz uma exigência adicional caso ocorra perda simultânea de todas as alimentações externas, por um longo período de tempo.

Nesse caso, é recomendado que houvesse uma possibilidade de suprimento de energia elétrica diferente e independente do sistema elétrico de emergência, projetada para suprir as cargas de segurança, após três dias.

Essa recomendação exige especial atenção aos requisitos de redundância e segregação das penetrações de cabos e dutos que conduzem às cargas de segurança, de forma a protegê-las contra a ocorrência de eventos.

Resumindo, os guias e códigos vistos são suficientes para direcionar um projeto elétrico voltado para o atendimento aos requisitos de confiabilidade e disponibilidade. 


\section{RESULTADOS}

No IPEN, o Centro do Reator de Pesquisas (CRPq) é o centro responsável pela operação e manutenção do reator, que desde 1995 teve o seu regime de operação modificado para 64 horas ininterruptas visando a produção de radioisótopos e o atendimento do corpo científico em geral. Visando esse novo ritmo de trabalho e adequação da instalação para num futuro próximo aumentar a potência para 5.0 MW, foi iniciado um projeto de modernização contínua do reator. Como um dos resultados desse esforço, o reator passou a ser o único reator com certificação ABNT NBR ISO 9001:2008 [34], sendo submetido a inspeções rotineiras da própria CNEN, AIEA e ABNT.

É conveniente ressaltar que as informações aqui contidas estão dirigidas para mostrar a adequação funcional do sistema à planta, bem como indicar o grau de conformidade de seus projetos com as normas aplicáveis a instalações industriais, basicamente, normas da Associação Brasileira de Normas Técnicas (ABNT) e atender os critérios de aceitação e as diretrizes para os sistemas elétricos estabelecidos pela Comissão Nacional de Energia Nuclear (CNEN).

O esquema simplificado do Sistema de Energia Elétrica do Reator IEA-R1, com as principais cargas, é mostrado na FIG. 6. 


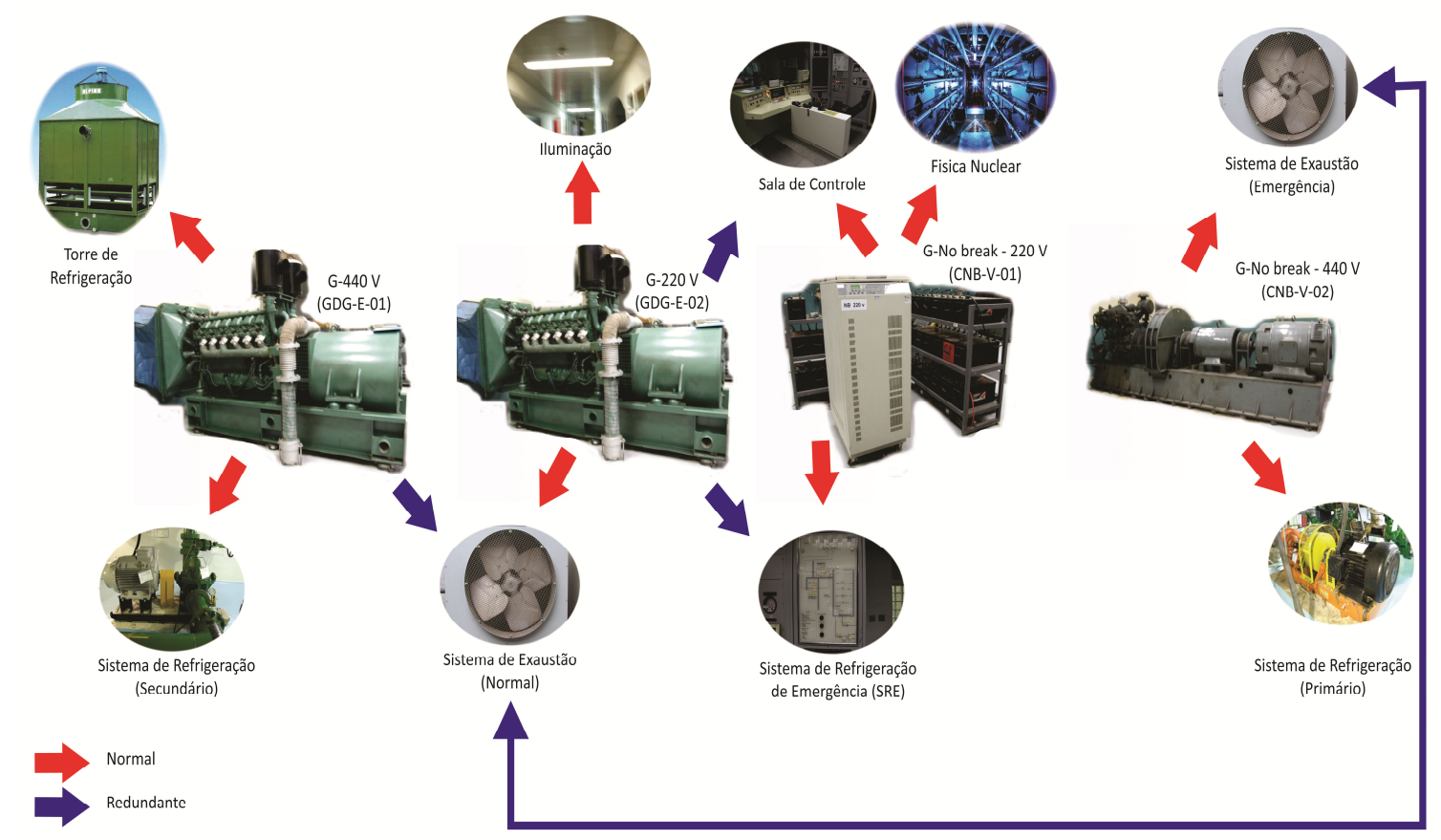

FIGURA 6 - Esquema Simplificado do Sistema Elétrico do Reator IEA-R1 (fonte própria)

\subsection{Modificações Feitas no Sistema Elétrico do Reator IEA-R1}

\subsubsection{Mesa de Controle}

O controle de operação do reator, tanto em manual como em automático, é realizado através da mesa de controle. A operação de um reator de pesquisa consiste em supervisionar as variáveis da planta. As variáveis controladas são de fácil acesso e são visualizadas em um console de controle. As variáveis monitoradas são visualizadas nos sistemas auxiliares e permitem ao operador realizar a partida, os ajustes de controle e o desligamento do reator.

O controle da potência do reator é realizado pela movimentação dos elementos de controle (que contém os absorvedores de nêutrons $\mathrm{Cd}-\mathrm{In}-\mathrm{Ag}$ ). $\mathrm{O}$ acionamento dos elementos é realizado por mecanismos eletromecânicos, independentes por elemento de controle. Estes elementos absorvedores também têm a função de garantir o desligamento seguro do reator quando necessário (SCRAM), o qual se dá por meio da queda livre de todos os elementos de controle, através da desenergização de eletroímãs que sustentam esses elementos. 
A mesa de controle recebia alimentação de um grupo gerador "nobreak" de 220V. Este grupo era constituído por grupo-gerador "no-break" - 25KVA e um grupo de baterias que alimentava a mesa de controle e na queda de energia um grupo-gerador diesel de 65KVA alimentava este conjunto "no-break" - 25KVA. O conjunto "no-break" apresentava muitos problemas com manutenções. Este grupo foi substituído pelo conjunto "no-break" estático de 220 Volts (CNB-V-01) (Ver Cap. 4 - item 4.4.5). Na FIG. 7 é mostrado o diagrama unifilar de alimentação elétrica para a Mesa de Controle

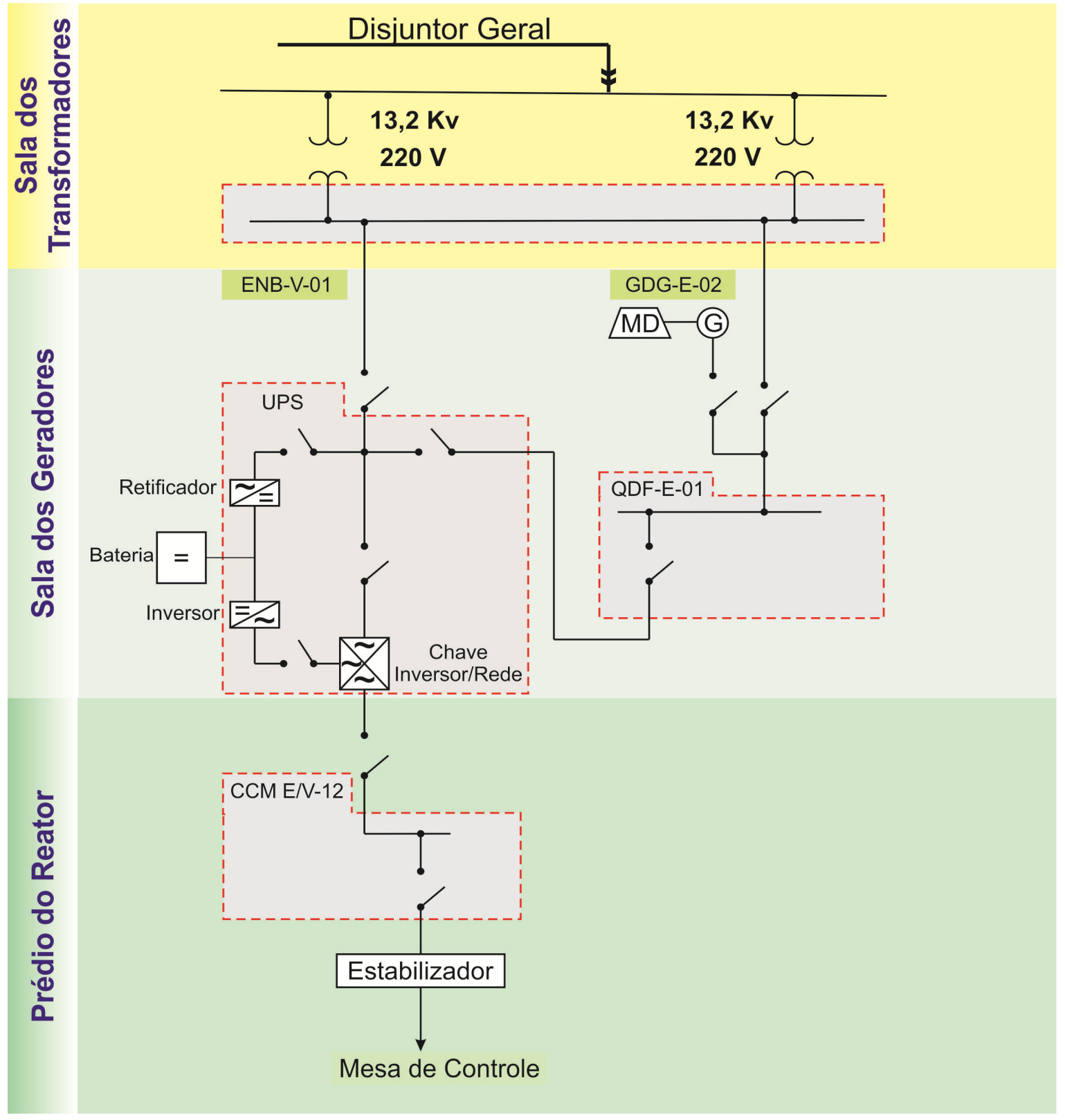

FIGURA 7 - Diagrama Unifilar de Alimentação Elétrica para a Mesa de Controle (fonte própria) 


\subsection{2 "Racks"}

Os "racks", antigos e desatualizados, foram substituídos por um projeto totalmente novo compatível com os padrões de segurança nuclear. Todo projeto de elétrica e instrumentação auxiliar da sala de controle foi refeito. Com isso, os novos racks instalados acompanham medidor de temperatura e vazão, comando para os ventiladores das torres e para as bombas de refrigeração, módulo de controle para a irradiação do silício, equipamento de som ambiente, sistema de irradiação de amostra, sistema de aquisição de dados (SAD) e Projeto "As-Built".

As modernizações permitiram que o IEA-R1 continue a atender às necessidades do IPEN e dos outros usuários, além de permitir aumento na produção de radioisótopos e abrir a possibilidade para a criação de novos projetos.

\subsubsection{Sistema de Ventilação}

O sistema de ventilação e ar condicionado foi projetado para manter as condições de habitabilidade no interior do prédio e manter o controle da liberação da radioatividade dentro de margens apropriadas de segurança durante a operação normal e em condições de acidente.

O sistema visa condicionar o ar insuflado em valores de temperatura e umidade preestabelecidos e prover uma exaustão que, além de manter uma depressão (-20mmc.a ou -200Pa), permite a filtragem do ar de modo a minimizar a liberação de radionuclídeos para o meio ambiente. No caso de ultrapassados os valores limites de exposição para o público, o sistema dispõe de "damper's" de ultra-estanqueidade para isolamento de toda a Área Quente (onde os valores limites de exposição para o público podem ser ultrapassados). A exaustão é efetuada por dois conjuntos de equipamentos e dispositivos de controle que operam conforme a presença ou não de contaminação do ar exaurido por radionuclídeos. Nível de atenção nos monitores de radiação desliga o insuflamento da Área Quente e ativa a exaustão de emergência.

No sistema antigo o comando era feito manualmente no quadro de comando do sistema de ventilação. A mudança de sistema, a troca de equipamentos ou motores era feita manualmente, somente, em caso de acidente ou emergência, haveria a mudança automática do Sistema de Ventilação Normal para o Sistema de Ventilação de Emergência. 
O comando do Sistema foi mudado para comando computadorizado, facilitando a troca de motores e equipamentos, tanto manual como automático, e em caso de falha do sistema em operação. Os Sistemas foram interligados podendo trocar os equipamentos e motor do Sistema de Ventilação Normal com o Sistema de Ventilação de Emergência durante a operação do reator quando houver falha de um dos equipamentos ou em caso de emergência. Na FIG. 8 é mostrado o comando do Sistema de Ventilação.

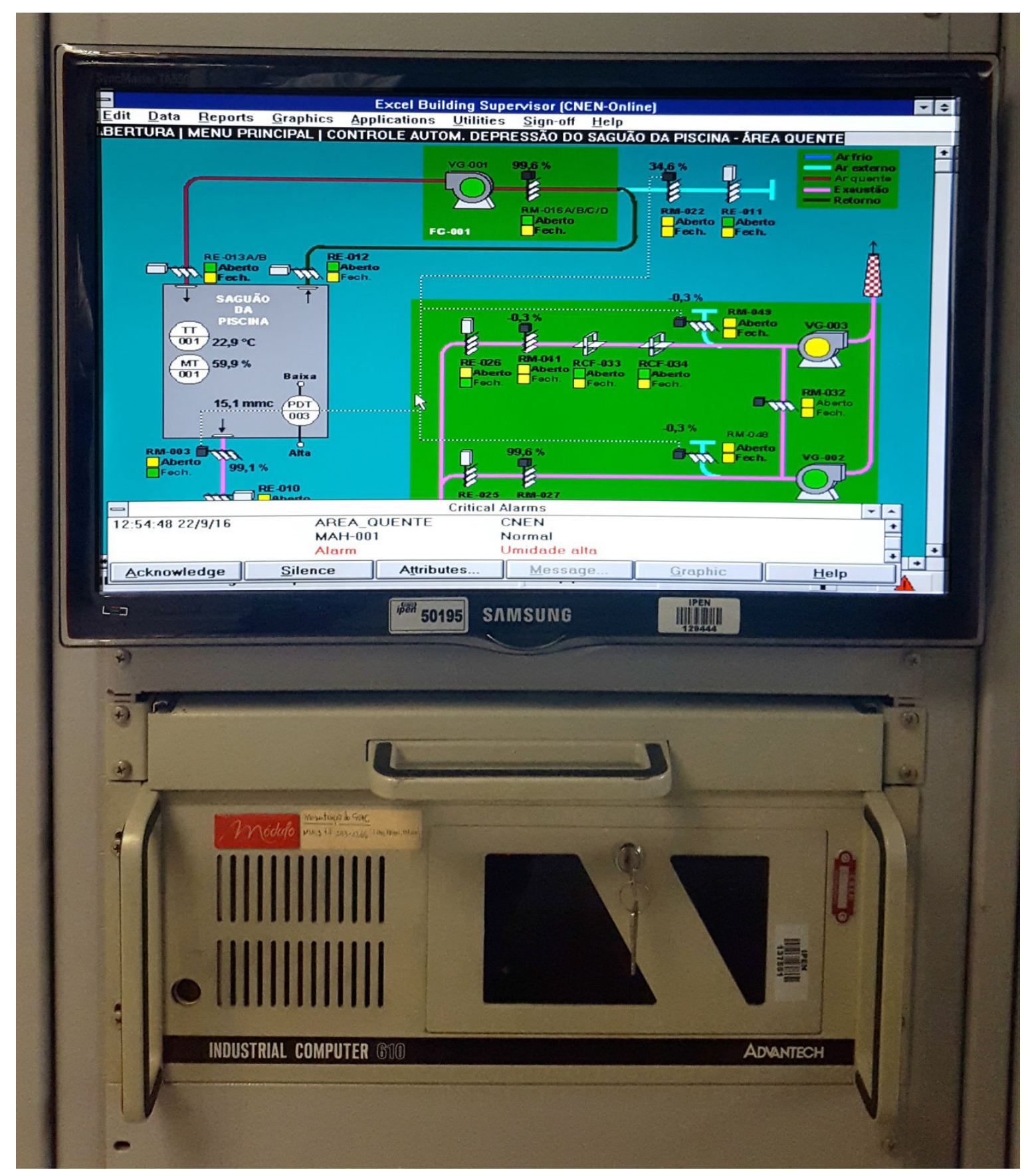

FIGURA 8 - Comando do Sistema de Ventilação (fonte própria) 


\subsubsection{Sistema de Refrigeração Primário}

O Circuito Primário, esquematizado no fluxograma da FIG. 9 - Sistema de Refrigeração do Reator IEA-R1, consiste da piscina com o núcleo do reator, válvula de convecção e difusor de alimentação, um tanque de decaimento e dois circuitos de troca de calor em paralelo (A e B). Cada circuito contém uma bomba de circulação, um trocador de calor, tubulações e válvulas, bem como a instrumentação necessária ao seu controle operacional. Sua função é prover o resfriamento adequado do núcleo durante qualquer condição normal de operação da planta.

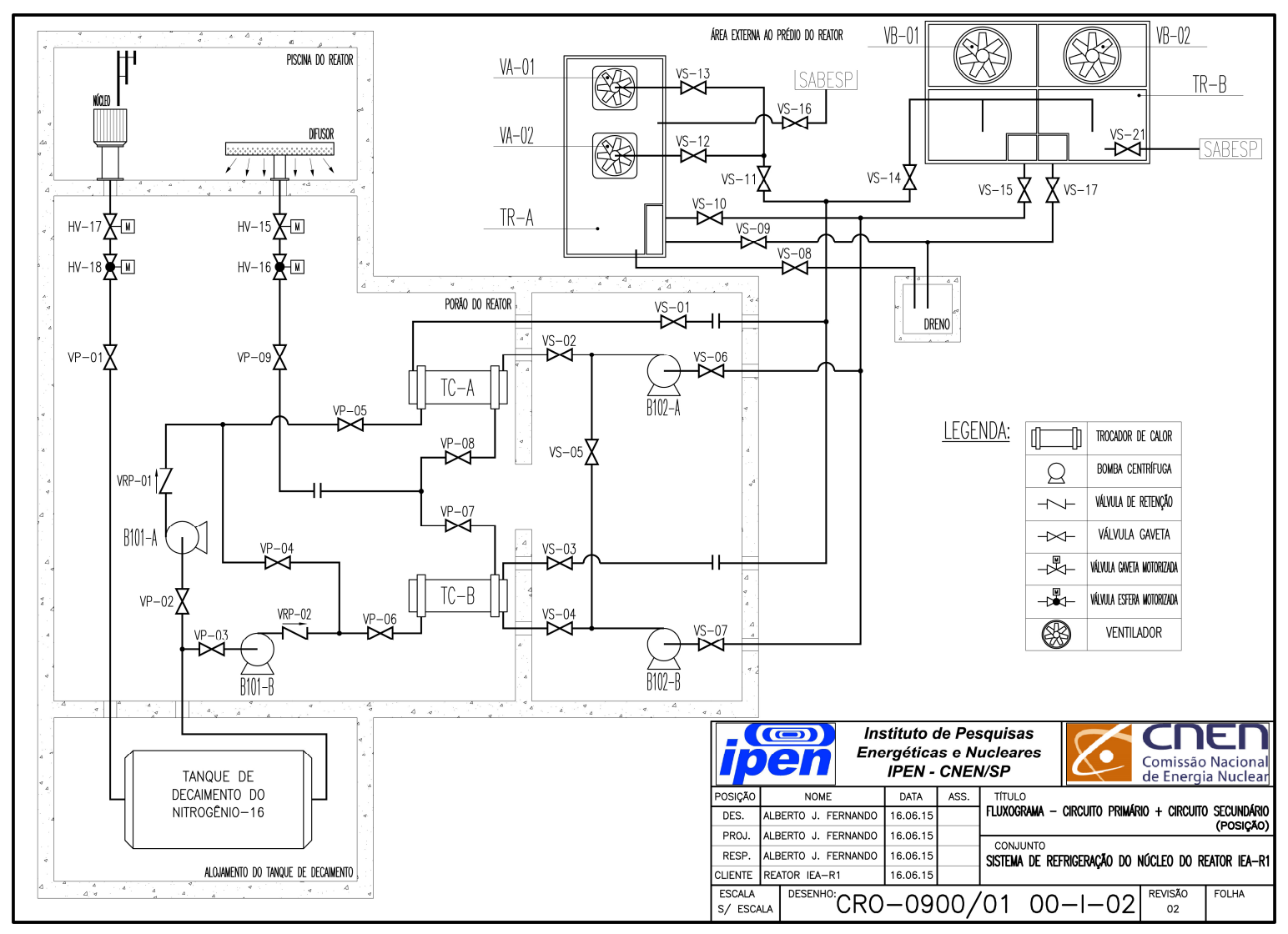

FIGURA 9 - Sistema de Refrigeração do Reator IEA-R1 [4]

A massa de água na piscina assegura a remoção de calor residual do núcleo quando da falta de energia elétrica, atuando como uma fonte de acúmulo e dissipação de calor. A água da piscina (refrigerante e moderador do núcleo do reator), também tem a função de blindagem contra a radiação direta emitida pelo núcleo. 
Para aumentar a segurança do reator foi acrescentado ao circuito primário o Sistema de Válvulas de Isolamento da Piscina e o Sistema de Resfriamento de Emergência (SRE).

\subsubsection{Sistema de Isolamento da Piscina}

A piscina do reator pode ser isolada do restante do circuito para o caso de manutenção normal ou para o caso de vazamento. Do projeto original, existem duas válvulas do tipo gaveta, providas de atuadores manuais, sendo uma delas instalada na tubulação de saída (perna quente) e outra instalada na tubulação de entrada (perna fria). Para garantir uma imediata e segura ação de isolamento da piscina, em eventos de grande perda de refrigerante, sem necessidade de acessar fisicamente o local de instalação, foram instaladas válvulas adicionais com atuação remota.

Na tubulação de saída, de 12 polegadas (perna quente), no trecho de linha compreendido entre o bocal do fundo da piscina e a válvula gaveta original, foram instaladas uma válvula gaveta e uma válvula esfera.

$\mathrm{Na}$ tubulação de entrada, de 10 polegadas (perna fria), no trecho de linha compreendido entre o bocal do fundo da piscina e a válvula gaveta original, foram instaladas uma válvula gaveta e uma válvula esfera.

Estas quatro válvulas adicionais são providas de atuadores motorizados que podem ser acionados manualmente tanto a partir da Sala de Controle como a partir da Sala de Emergência, estes comandos são individuais para cada válvula em ambos os painéis. Os atuadores também são acionados automaticamente no caso de ser detectado um nível baixo na piscina (nível de $400 \mathrm{~mm}$ abaixo do ladrão) através de um circuito lógico que utiliza os sinais de três instrumentos de nível instalados na piscina. É implementado um intertravamento com lógica de votação do tipo dois de três que comanda automaticamente o fechamento das válvulas se atingido o nível preestabelecido.

Os atuadores motorizados são alimentados em $440 \mathrm{~V}$ (trifásicos e $60 \mathrm{~Hz}$ ) através de alimentadores individuais localizados no quadro CCM-E/V-11 que, por sua vez, dispõem de dois barramentos eletricamente independentes pertencentes respectivamente ao Sistema de Distribuição Elétrica Essencial (SDEE) e ao Sistema de Distribuição Elétrica Vital (SDEV). Para evitar as consequências de uma falha simples, os atuadores elétricos são alimentados no 
modo "cruzado". Do barramento essencial partem as alimentações das válvulas 883-HV-15 (gaveta 10 polegadas perna-fria) e 883-HV-18 (esfera 12 polegadas perna-quente). Do barramento vital partem as alimentações das válvulas 883-HV-17 (gaveta 12 polegadas perna-quente) e 883-HV-16 (esfera 10 polegadas perna-fria). Em adição, são feitos encaminhamentos fisicamente separados para os cabos elétricos.

Na FIG. 10 são mostrados o Sistema de Resfriamento de Emergência e Sistema de Isolamento da Piscina.

\subsubsection{Sistema de Resfriamento de Emergência (SRE)}

Sua função é resfriar o núcleo do reator IEA-R1 no caso de ocorrência de um acidente de perda de refrigerante ou pela ocorrência de qualquer evento que leve ao esvaziamento da piscina do reator, como por exemplo: ruptura da fronteira do circuito primário; ruptura dos tubos dos "coelhos" pneumáticos; esvaziamento pelo dreno, através de ruptura na tubulação ou abertura indevida de válvulas.

O SRE tem atuação passiva por gravidade, através da abertura de válvulas que são acionadas automaticamente quando o nível da piscina atingir $4.500 \mathrm{~mm}$ abaixo do ladrão. Este sistema é alimentado por reservatórios localizados em posições elevadas com relação ao núcleo. São dois reservatórios de $75 \mathrm{~m}^{3}$ cada, que proporcionam ao sistema uma redundância de $100 \%$ na capacidade de resfriamento do núcleo. O dispositivo distribuidor é alimentado através de duas linhas (ramos A e B) de uma polegada e meia de diâmetro, independentes e fisicamente separadas. A alimentação desses reservatórios é feita com água da rede normal de abastecimento. O dispositivo foi dimensionado para resfriar o núcleo durante 14 horas, tempo suficiente para resfriamento do Reator, como é mostrado na FIG. 11 - Fluxo de Calor X Tempo Após Desligamento do Reator. 


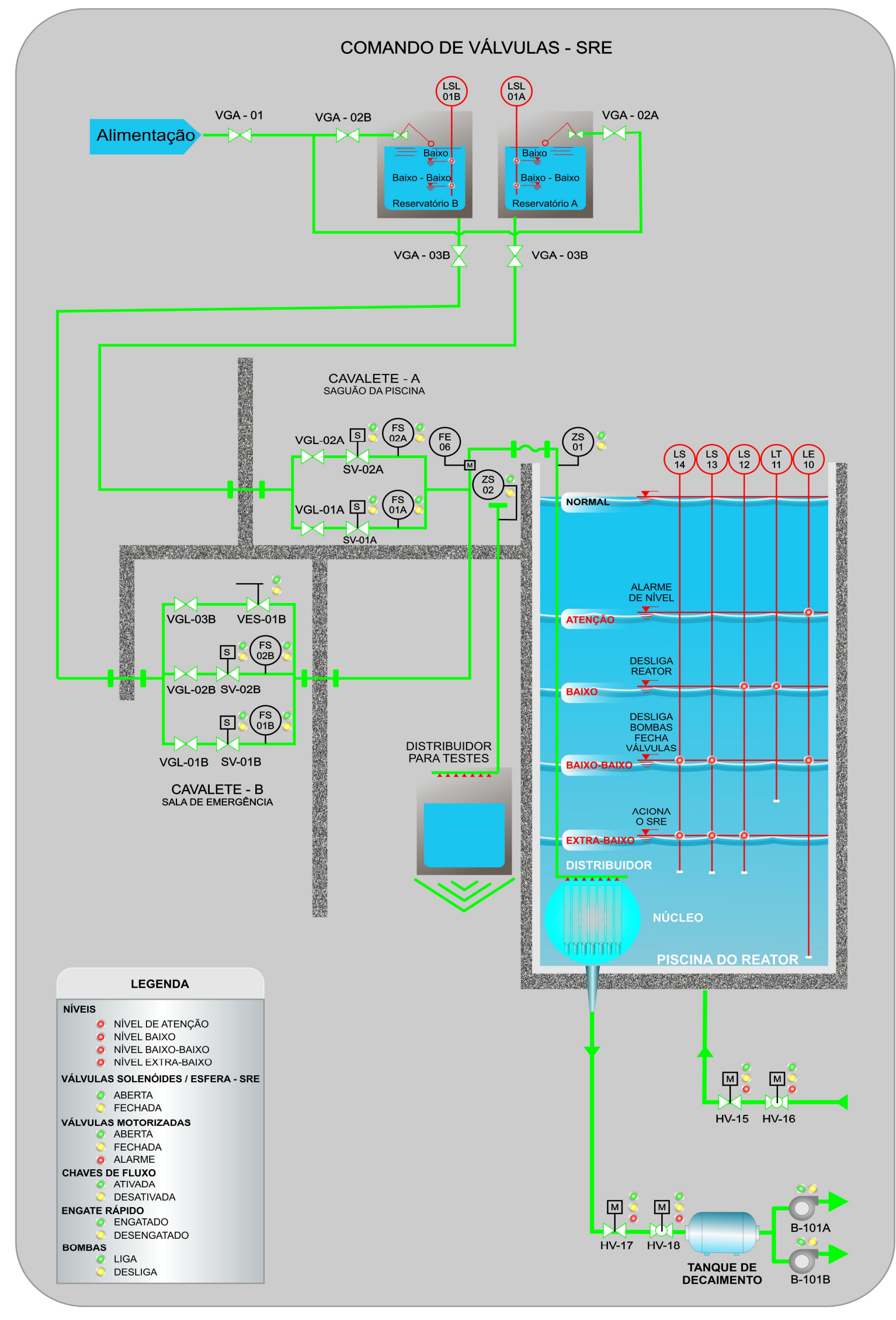

FIGURA 10 - Sistema de Resfriamento de Emergência e Sistema de Isolamento da Piscina (fonte própria) 


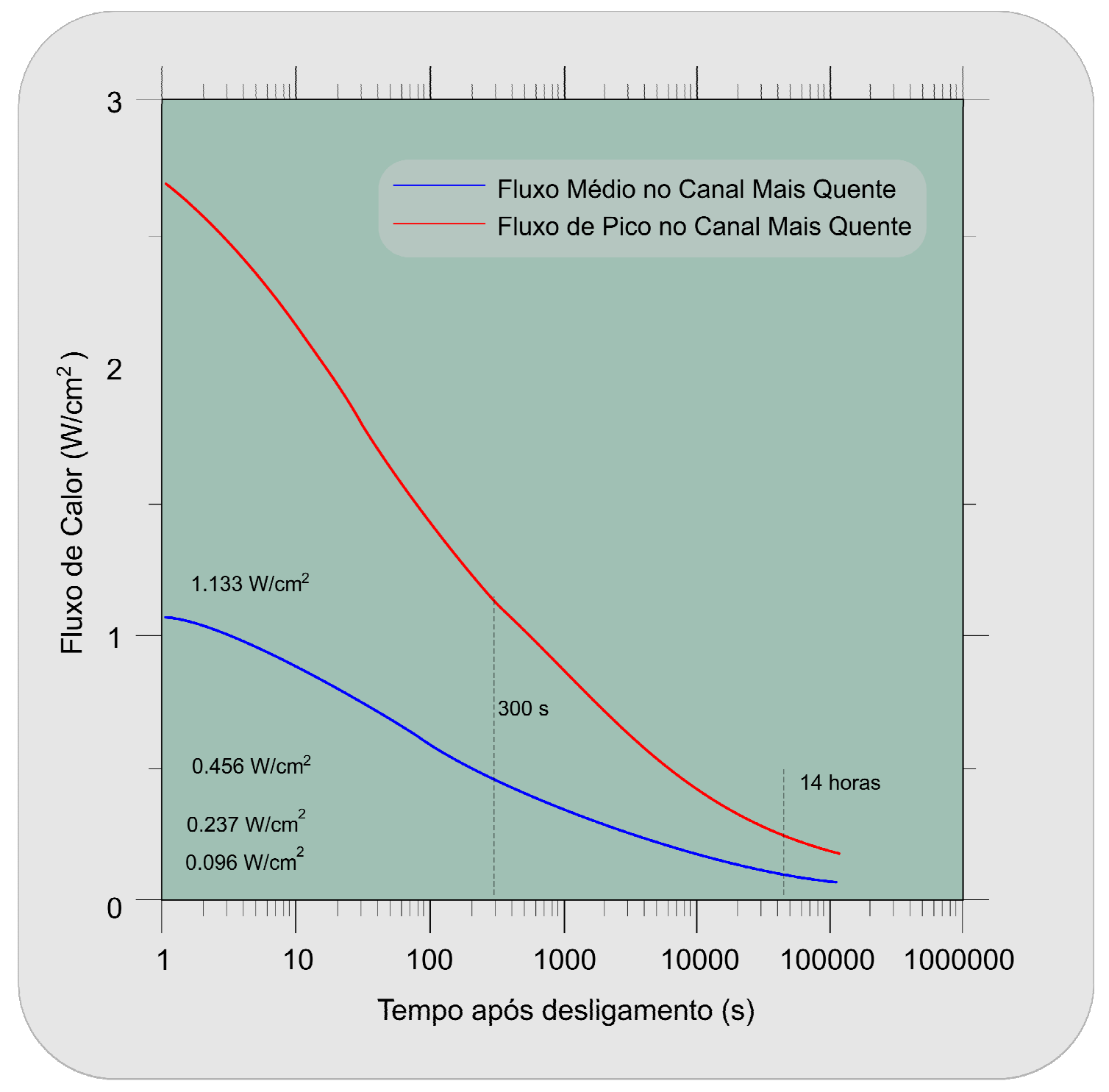

FIGURA 11 - Fluxo de Calor X Tempo Após Desligamento do Reator IEA-R1 [4]

\subsubsection{Sistema de Refrigeração Secundário}

O circuito secundário tem a função de prover o resfriamento adequado da água de refrigeração do circuito primário durante qualquer condição normal de operação da planta. $O$ circuito secundário, também esquematizado no fluxograma da FIG. 7, consiste de dois circuitos de troca de calor em paralelo. Cada circuito contém uma bomba de circulação, um trocador de calor, tubulações e válvulas, instrumentação necessária ao seu controle operacional e torre de refrigeração.

Para melhorar a capacidade de troca de calor para o aumento da potência do reator os motores das bombas que eram de 60HP foram substituídos por motores de 120HP, propiciando maior velocidade da água (2600 galões por minuto para 3200 galões por minuto) melhorando a capacidade de troca de calor. 
A substituição da chave de partida estrela-triângulo dos motores das bombas por chaves compensadoras foi outra mudança. Esta chave reduz a corrente de arranque, evitando sobrecarregar a linha de alimentação. Na chave compensadora a tensão é reduzida através de um autotransformador trifásico que possui geralmente "taps" de $50 \%, 65 \%$ e $80 \%$ da tensão nominal. Durante a partida alimenta-se com a tensão nominal o primário do autotransformador trifásico conectado em estrela e do seu secundário é retirada à alimentação para o circuito do estator do motor. A passagem para o regime permanente faz-se desligando o autotransformador do circuito e conectando diretamente à rede de alimentação o motor trifásico.

\subsubsection{Cabos, Fiações e Dispositivos de Proteção}

Primeiramente foi feita avaliação de toda a fiação, cabeamento, dispositivos de proteção e painéis do Sistema Elétrico. A partir dessa avaliação foram analisados os resultados e feitos cálculos de dimensionamento das cargas para a substituição dos fios, cabos e dispositivos de proteção que estavam em estado precário ou subdimensionado [36].

Posteriormente foram interligados eletricamente os sistemas e equipamentos de segurança com os grupos geradores de emergência, fazendo com que as cargas vitais sempre tenham uma alimentação redundante na falha da sua alimentação principal.

\subsubsection{Cabos Elétricos}

A distribuição de energia a partir dos quadros distribuidores (CBT, QDF e CCM) até os diversos pontos de utilização na planta é feita por cabos de cobre, contidos em canaletas, bandejas e/ou eletrodutos metálicos. No trecho entre o Prédio de Distribuição e Geração de Energia Elétrica e o Prédio do Reator os eletrodutos são de PVC (cloreto de polivinila). Neste trecho os eletrodutos estão enterrados no solo e envoltos por uma camada de concreto magro; o topo deste envelope está a uma profundidade mínima de 0,60 metros, em relação ao piso acabado. As caixas de passagem para derivação dos cabos são caixas de alvenaria, medindo aproximadamente $1,00 \mathrm{~m} \times 1,00 \mathrm{~m} \times 0,80 \mathrm{~m}$, com fundo de pedra britada e tampa de concreto pré-moldado rejuntada com asfalto. 


\subsubsection{Tipos de Cabos e Aplicação}

\section{a) Cabos de Força}

Os cabos de força são de cobre eletrolítico, têmpera mole, tensão de isolamento $0,6 / 1 \mathrm{KV}$, isolação em PVC-70C e capa externa em PVC, com características especiais quanto à não propagação e auto extinção do fogo.

Os cabos de força são tripolares até a bitola de $25 \mathrm{~mm}^{2}$ e singelos para bitolas maiores. A bitola $2,5 \mathrm{~mm}^{2}$ é a mínima seção adotada para esses cabos.

\section{b) Cabos de Comando e Controle}

Os cabos de comando e controle são de cobre eletrolítico, têmpera mole, multipolares, tensão de isolamento $0,6 / 1 \mathrm{kV}$, isolação em PVC-70C e capa externa em PVC, com características especiais quanto à não propagação e auto-extinção do fogo. A bitola $1,0 \mathrm{~mm}^{2}$ é a mínima seção adotada para esses cabos.

\subsubsection{Dimensionamento de Cabos Elétricos}

Os cabos elétricos foram dimensionados segundo as recomendações da norma ABNT-NBR 5410 [35]. As informações detalhadas de cálculo, assim como, diagramas elétricos e modificações estão disponíveis no Relatório Técnico: R743190003 - Avaliação das Instalações Elétricas do Reator IEA-R1 [36].

\subsubsection{Módulos de Potência Ininterrupta (MPI)}

Instalação dos Módulos de Potência Ininterrupta (MPI) para alimentação independente de sistemas de segurança.

Os MPI's (MPI-V-21, MPI-V-22 e MPI-V-31) fornecem através de quadros de distribuição exclusivos (QCA-V-21 e QCA-V-31) energia elétrica em tensão alternada regulada (estabilizada em amplitude e frequência) às seguintes cargas vitais de instrumentação:

- Instrumentação do Sistema de Resfriamento de Emergência.

- Instrumentação do Sistema de Proteção contra Incêndio ("dampers” corta fogo).

- Instrumentação do Sistema de Ventilação e Ar Condicionado.

- Instrumentação da Monitoração de Radiação. 
- Instrumentação e Controle das Válvulas de Isolamento da Piscina do Reator.

- Instrumentação da Medição de Nível da Piscina do Reator.

Os MPI-V-21 e MPI-V-22 são normalmente alimentados pelo CCM-E/V 11 (via transformador a seco TRF-E-21) e CCM-E-22, respectivamente; o MPI-V-31 é normalmente alimentado pelo CCM-V-31. O quadro QCA-V-21 é normalmente alimentado pelo MPI-V-22, pois o MPI-V-21 é reserva (utilizado apenas em caso de falha ou manutenção do MPI-V-22). O quadro QCA-V-31 é normalmente alimentado pelo MPI-V-31; entretanto em caso de falha ou manutenção deste MPI a alimentação do quadro será provida por uma alimentação alternativa derivada do QDF-V-11. Tendo em vista esta dupla possibilidade de alimentação para cada um desses quadros, a comutação de uma alimentação para a outra será feita sempre manualmente, quando necessária, pelo operador. Cada MPI consiste de um retificador estático, um inversor estático, um banco de baterias seladas e uma chave estática de transferência automática. $O$ retificador supre o inversor e mantém o banco de baterias em estado de flutuação; desta maneira ao faltar tensão para o retificador o inversor é alimentado pela bateria. A tensão de saída do inversor é sincronizada com a tensão de saída do transformador estabilizador situado na entrada do retificador. A chave estática transfere automaticamente, em casos de sobrecarga ou defeitos no retificador/inversor, a alimentação do quadro de distribuição alimentado para o transformador estabilizador, desde que a tensão na saída do transformador estabilizador esteja dentro dos parâmetros fixados.

As principais características de cada MPI são:

- Potência nominal: 3 kVA.

- Tensão de entrada: 220 VCA, 2 fases, + ou - $25 \%$.

- Tensão de saída: 220 VCA.

- Regulação dinâmica: \pm 5 \% para degrau de $100 \%$ na carga com retorno em dois ciclos.

- Autonomia a plena carga: 30 minutos.

- Distorção harmônica: < 6 \%.

- Ruído Acústico: $<55 \mathrm{db}$.

- MTBF: $>60000$ horas. 
Vê-se que a potência nominal de cada MPI é de $3 \mathrm{kVA}$, funcionando a plena carga por um período de 30 minutos. Como a potência demandada pelas cargas de instrumentação dedicadas a cada quadro (QCA-V-21 e QCA-V-31) é inferior a $50 \%$, a autonomia atual de cada MPI é equivalente a 1 (uma) hora aproximadamente.

\subsubsection{Atualização dos Diagramas e Esquemas Elétricos.}

Os diagramas e esquemas elétricos estão disponíveis no Relatório Técnico: R743190003 - Avaliação das Instalações Elétricas do Reator IEA-R1 [36].

\subsection{Ocorrências Devido a Perda de Alimentação Elétrica}

A perda de alimentação elétrica normal para o reator IEA-R1 é muito comum, pois existe uma única linha de alimentação da concessionária (ELETROPAULO), que alimenta uma única subestação para toda a Cidade Universitária. O IPEN é alimentado por uma linha independente a partir desta subestação. No caso de perda de alimentação elétrica externa no prédio do reator IEA-R1 podem ocorrer diferentes sequências de eventos, como descrito a seguir.

\subsubsection{Falha do Sistema de Distribuição Elétrica Normal}

Ao cair o fornecimento de energia elétrica externa no prédio do IEA-R1, entrará imediatamente em operação o Sistema de Distribuição Elétrica Vital, conforme descrito no Capítulo 4. Este sistema possui um gerador tipo "No- Break" que continuará suprindo energia por meio de baterias à mesa de controle do reator, e um gerador tipo "no-break", que possui um volante de inércia acoplado a um gerador elétrico, que deverá manter a alimentação elétrica da bomba de circulação do circuito primário durante os segundos iniciais da ocorrência deste evento. A bomba do primário é mantida em funcionamento a fim de que haja contínuo resfriamento do núcleo do IEA-R1. O grupo gerador "no-break" baterias, pertencente ao Sistema de Distribuição Elétrica Vital, deverá, por sua vez, suprir a energia elétrica para a mesa de controle do reator. Na sequência entra em operação o grupo de geradores a diesel do Sistema de Distribuição Elétrica Essencial, que deverá alimentar as demais cargas do prédio do reator IEA-R1. A descrição deste sistema é mostrada em detalhes no Capítulo 4. 
Após a sequência de atuação do Sistema Elétrico, descrito anteriormente, o reator continuará em funcionamento normal, com o suprimento de energia elétrica realizado pelos Sistemas de Distribuição Elétrica Vital e Essencial.

\subsubsection{Falha do Sistema de Distribuição Elétrica Essencial}

Pode ocorrer, quando da perda do fornecimento de energia elétrica externa que o Sistema de Distribuição Elétrica Essencial não entre em operação de acordo com o esperado. Neste caso, o Sistema de Distribuição Elétrica Vital continuará suprindo energia para a mesa de controle do reator e para as bombas de circulação do circuito primário. Neste caso não ocorrerá um desligamento imediato e automático do reator por atuação do Sistema de Proteção.

O desligamento do reator poderá ser realizado, neste caso, por duas formas. A primeira é o desligamento do reator, alguns minutos após a ocorrência do evento, pelo aumento da temperatura da água da piscina devido à perda da fonte fria, ou seja, perda do circuito secundário. A outra é uma decisão que poderá ser tomada pelo supervisor responsável da operação, que estará acompanhando por meio da mesa de controle o comportamento dos parâmetros nucleares e térmico-hidráulicos.

\subsubsection{Falha do Sistema de Distribuição Elétrica Vital}

No caso de perda do fornecimento de energia elétrica externa e consequente falha de um dos geradores "no-break" do Sistema de Distribuição Elétrica Vital, tem-se como consequência o desligamento automático do reator.

No caso de falha do grupo gerador "no-break" - $440 \mathrm{~V}$ que alimenta a bomba de circulação do circuito primário, sem que ocorra falha no grupo gerador "no-break"- $220 \mathrm{~V}$, que fornece energia elétrica para a mesa de controle, o reator será desligado por falha do fornecimento de energia elétrica para a bomba do primário.

Foi verificado experimentalmente, que a bomba de circulação do circuito primário continua em funcionamento, com rotação decrescente, por cerca de 80 segundos, após o início da perda de alimentação, devido à atuação do volante de inércia acoplado ao eixo da mesma. 
No entanto, embora o volante de inércia atue por 80 segundos, verificou-se, também experimentalmente, que ocorre o desacoplamento da válvula de convecção aos 24 segundos do início do incidente, provocando neste instante uma inversão da vazão de circulação forçada, em sentido descendente, para circulação natural em sentido ascendente.

Observa-se que este experimento foi realizado com uma vazão inicial de $2.600 \mathrm{gpm}$. Com uma vazão de $3.200 \mathrm{gpm}$ os tempos envolvidos serão um pouco maiores.

Quando ocorre a perda de fornecimento elétrico para a bomba do primário é dado o sinal de desligamento do reator. O tempo máximo de queda das barras de controle é cerca de 1 segundo, a partir do sinal de desligamento até o início do trecho de amortecimento da barra na base do núcleo.

Se após a perda do fornecimento de energia elétrica, ocorrer uma falha no grupo gerador "no-break"- $220 \mathrm{~V}$, que fornece energia elétrica para a mesa de controle, o reator será automaticamente desligado, porém continuará sendo resfriado pela circulação forçada de fluido promovida pela bomba do primário.

\subsubsection{Falha do Sistema de Isolamento da Piscina do Reator}

Considera-se que $\mathrm{o}$ isolamento da piscina falha quando as duas válvulas automáticas das pernas (fria ou quente) do circuito primário não fecham quando necessário (nível baixo da piscina). As válvulas não fecham se elas falham ao fechar, ou seus acionadores não recebem energia elétrica ou não recebem sinal de nível baixo da piscina para fechamento (sinal automático e comando manual dos operadores na sala de controle e sala de emergência).

\subsubsection{Falha do Sistema de Resfriamento de Emergência (SRE)}

O SRE falha se não é aspergida água sobre o núcleo quando este estiver descoberto. Isto pode ocorrer se houver falha (ruptura ou entupimento) nos dois ramos de alimentação ( $\mathrm{A}$ e $B$ ) ou a falha na abertura das quatro válvulas solenoides e da válvula manual ou a falha ou posicionamento errado da válvula de desvio ou entupimento dos aspersores. 


\subsubsection{Falha na Alimentação Elétrica para os Quadros de Segurança e Emergência}

A falha do Sistema Elétrico pode levar à falha do Sistema de Isolamento da Piscina e Sistema de Resfriamento de Emergência (SRE).

Os atuadores motorizados das válvulas de isolamento são alimentados em $440 \mathrm{~V}$ (trifásicos) a partir do centro de controle de motores (CCM-E/V-11) que, por sua vez, dispõe de dois barramentos eletricamente independentes pertencentes ao SDEE e ao SDEV. Para evitar uma falha simples, os atuadores das válvulas são alimentados no modo "cruzado". Do barramento essencial partem as alimentações das válvulas $883-\mathrm{HV}$ - 15 (gaveta 10 polegadas perna-fria) e 883-HV-18 (esfera 12 polegadas perna-quente). Do barramento vital partem as alimentações das válvulas $883-\mathrm{HV}-17$ (gaveta 12 polegadas perna-quente) e 883-HV-16 (esfera 10 polegadas perna-fria); a alimentação da instrumentação do SRE e do isolamento da piscina é efetuada em $220 \mathrm{~V}$ corrente alternada a partir dos quadros QCA-V-21 e QCA-V-31 pertencentes ao SDEV.

No SRE as válvulas solenoides são alimentadas no modo "cruzado", cada quadro alimentando uma válvula de cada ramo. No isolamento da piscina ocorre o mesmo tipo de alimentação "cruzada" para o controle das válvulas de isolamento.

\subsubsection{Estudo de Confiabilidade [37]}

Para a obtenção da probabilidade de falha do sistema de isolamento da piscina e do SRE foi utilizado o modelo de Arvore de Falha (AF). Portanto foi necessária também a obtenção da probabilidade de falha do fornecimento de energia elétrica nos seguintes quadros elétricos:

- CCM-E/V-11 em $440 \mathrm{~V}$ - barramento vital.

- CCM-E/V-11 em $440 \mathrm{~V}$ - barramento essencial.

- Quadro em Corrente Alternada em 220 V, QCA-V-21.

- Quadro em Corrente Alternada em 220 V, QCA-V-31.

Os quadros citados ficarão sem energia elétrica se houver uma falha intrínseca do próprio quadro ou ele não recebe energia (falha em cabos, disjuntores, chaves) ou o quadro que deve alimentá-lo não o fizer. Esta lógica é desenvolvida partindo-se do CCM-E/V-11 até se chegar ao ponto de entrada da ELETROPAULO. Já os quadros QCA-V-21 e QCA-V-31 ficarão sem energia se 
houver uma falha intrínseca do próprio quadro ou se ele não receber energia (falha em cabos, disjuntores, chaves) ou se aos MPI's falharem. O diagrama unifilar contendo os quadros QCA-V-21, QCA-V-31 e CCM-E/V-31 é mostrado na FIG. 12.

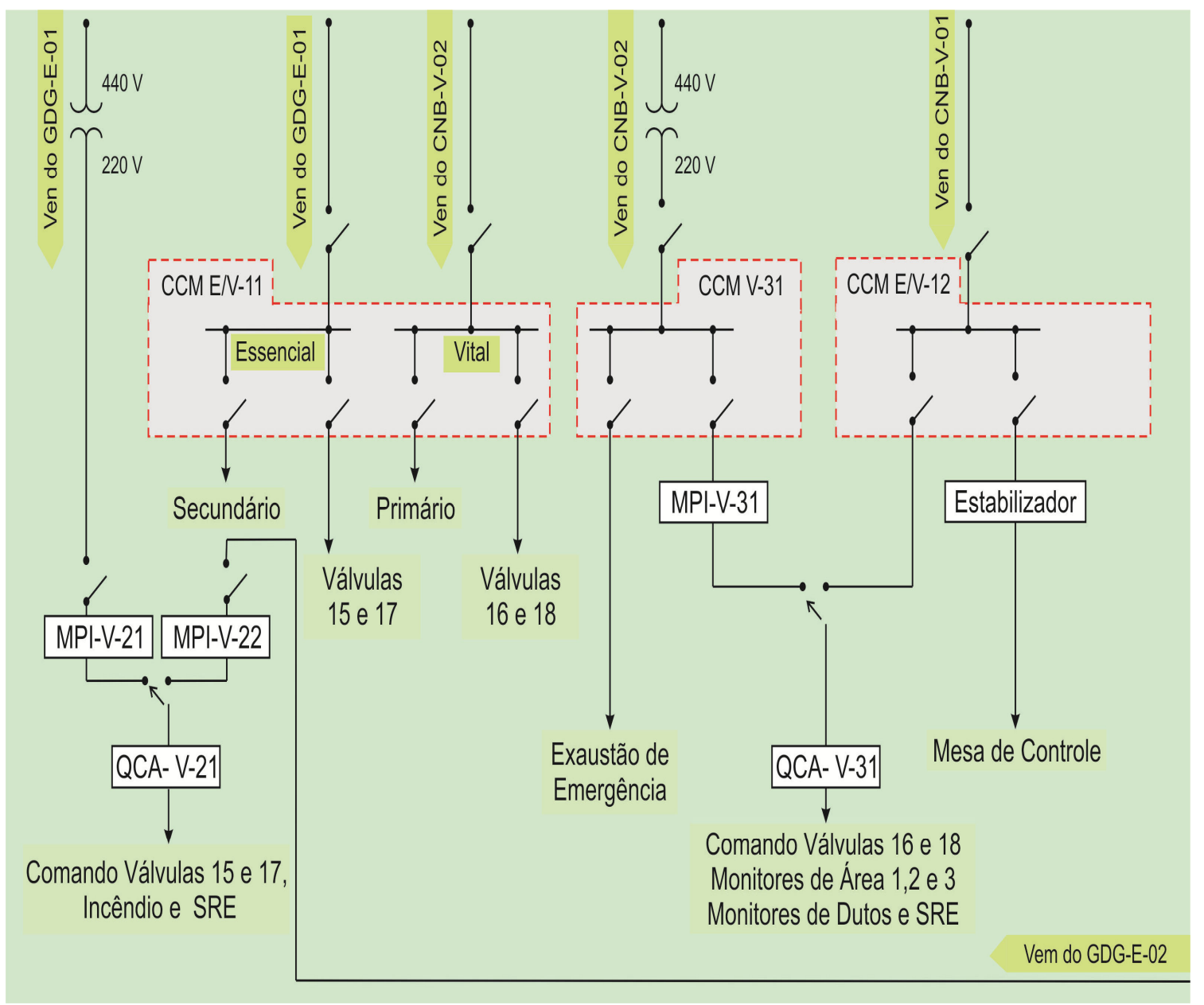

FIGURA 12 - Diagrama Unifilar: QCA-V-21, QCA-V-31 e CCM-E/V-11 (fonte . própria)

Com as AFs, utilizando-se o programa SAPHIRE [38] e os dados dos ANEXOS A e B foram obtidos os seguintes valores [37]:

- Probabilidade de perda de energia elétrica no centro de controle de motores (CCM-E/V-11) em $440 \mathrm{~V}$ - barramento vital igual a $1,062 \times 10^{-2}$

- Probabilidade de perda de energia elétrica no centro de controle de motores (CCM-E/V-11) em $440 \mathrm{~V}$ - barramento essencial igual a $4,305 \times 10^{-3}$; 
- Probabilidade de perda de energia elétrica no quadro em corrente

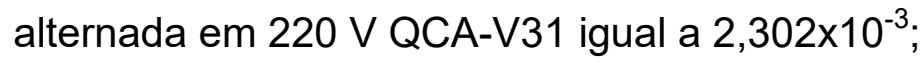

- Probabilidade de perda de energia elétrica no quadro em corrente

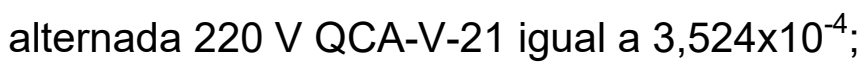

- Probabilidade de falha do isolamento da piscina igual a $1,047 \times 10^{-4}$;

- Probabilidade de falha do SRE igual a $1,022 \times 10^{-4}$.

Quanto ao Sistema Elétrico, os barramentos em $440 \mathrm{~V}$ do CCM apresentaram probabilidade relativamente alta de ficarem sem energia elétrica. Observando-se o evento topo "CCM-E/V-11 Barramento Vital Sem Energia" verifica-se que a falha simples de diversos componentes leva à perda da energia elétrica neste barramento. $O$ mesmo pode ser verificado para o barramento essencial deste CCM. Como as válvulas redundantes da mesma perna do circuito primário são alimentadas no modo "cruzado", para que o isolamento da piscina falhe devido à interrupção de fornecimento de energia elétrica aos acionadores das válvulas de isolamento é preciso que os dois barramentos do CCM fiquem sem energia simultaneamente. A análise para o barramento vital do CCM foi realizada levando-se em consideração a possibilidade do acionamento do moto gerador pelo motor diesel através da embreagem magnética. Entretanto, esta possibilidade não está sendo utilizada no momento, sendo a ELETROPAULO a única fonte de energia para o moto gerador, fazendo com que a probabilidade de interrupção de energia no barramento seja ainda maior. Isto diminui a confiabilidade do isolamento da piscina, mas não de modo significativo. $O$ que diminui bastante é a disponibilidade do reator, pois na configuração atual qualquer interrupção do fornecimento de energia pela ELETROPAULO leva ao desligamento do reator. 


\section{CONCLUSÃO}

As análises das reformas do Sistema Elétrico comprovam que a falta de alimentação elétrica no reator IEA-R1 não é um evento iniciador de acidentes, pois, a falha na alimentação elétrica externa e a falha de funcionamento dos geradores diesel acarretarão o desligamento do reator.

A partir dos resultados obtidos no estudo de confiabilidade, conclui-se que os principais quadros de alimentação elétrica para os sistemas de segurança e de emergência do Reator IEA-R1 apresentam um desempenho seguro e comparável com outros reatores de pesquisa. $\mathrm{O}$ estudo de confiabilidade destes quadros é importante, pois, estes alimentam o Sistema de Refrigeração (Primário e Secundário) e os Sistemas de Segurança e Emergência do Reator.

É interessante ressaltar que o uso de quatro geradores diesel de emergência compensou a falta de uma segunda linha de alimentação externa, levando o nível de confiabilidade do suprimento de energia elétrica em corrente alternada a níveis aceitáveis.

As modificações estão de acordo com a base normativa da CNEN e as normas técnicas da ABNT.

As modificações feitas no sistema elétrico aumentaram os níveis de segurança e colaboraram com o aumento da potência em regime continuo de operação do reator. Assim, os objetivos específicos esperados com o desenvolvimento deste trabalho foram alcançados. 


\section{TRABALHOS FUTUROS}

São previstos para o futuro, os seguintes trabalhos:

a) Troca dos Conjuntos "no-break" de 440 Volts (CNB-V-02) e Grupo Diesel Gerador de 440 Volts (GDG-E-01) e Grupo Diesel Gerador de 220 Volts (GDG-E-02).

A alimentação elétrica via rede aérea da concessionária e ligada fisicamente a um transformador sem "tap's" na ETD (Estação Transformadora de Distribuição), esta sujeita a todo tipo de ocorrências que possa existir ao longo da linha de distribuição, tais como, acidentes de trânsito, queda de árvores, depredações, maus contatos, etc., sem contar que em horários de pico, devido à demanda crescente temos afundamento de tensão e faltas de energia de curta duração (1s).

Uma situação que eventualmente ocorre no Reator e que deve ser levada em conta é um desligamento durante a operação. Após o desligamento há formação de elementos absorvedores de nêutrons produzidos pelo decaimento dos fragmentos de fissão. A população destes absorvedores irá aumentando após o desligamento e depois de certo tempo será impossível ligar novamente o Reator. Este intervalo de tempo não pode ser maior que 90 minutos, dependendo do tempo de operação e da queima dos combustíveis. Uma nova partida só será possível após o decaimento significativo destes elementos absorvedores o que só vai acontecer, aproximadamente, 36 horas após o desligamento do Reator.

Tomando, como exemplo, a TAB. 1 - Ano X Número de Falhas no Fornecimento de Energia, aconteceram muitos desligamentos, durante as operações, causados por queda de energia elétrica ou flutuação de tensão. Se somarmos o tempo para ligar o Reator que é de aproximadamente, 30 minutos com o tempo sem alimentação elétrica após o desligamento, temos um tempo considerável de parada do Reator. Não podemos esquecer que algumas vezes o Reator só pode ser ligado 36 horas após o desligamento. 


\begin{tabular}{cc}
\hline ANO & $\begin{array}{c}\text { Desligamentos do Reator por Falhas } \\
\text { no Fornecimento de Energia pela } \\
\text { Concessionária }\end{array}$ \\
\hline 2009 & 30 \\
2010 & 33 \\
2011 & 58 \\
2012 & 28 \\
2013 & 47 \\
2014 & 48 \\
2015 & 49 \\
\hline
\end{tabular}

TABELA 1 - Ano X Número de Falhas no Fornecimento de Energia (fonte própria)

Os grupos geradores são muito antigos (1973), e como o regime de funcionamento desses equipamentos deve ser contínuo, apresenta muitos problemas, tanto com as manutenções mecânicas, quanto com as manutenções elétricas e ainda existem as dificuldades para obtenção de peças sobressalentes, devido à descontinuidade de fabricação de peças de reposição, geralmente, as peças são tiradas de outros geradores no mercado ou é necessária à fabricação exclusiva de alguma peça que, por consequência, são caríssimas. A troca destes grupos geradores está sendo proposta, assim como a mudança no conceito de operação do sistema de alimentação em 440 Volts.

O conceito de operação do reator previa o funcionamento dos grupos geradores, em operações especiais e continuas, sem interrupção. Este conceito, no entanto, nunca se efetivou. Com a modernização do reator e a crescente demanda de produção de radioisótopos e devido à idade dos geradores (envelhecimento) que compõe o sistema elétrico uma mudança neste conceito é necessária. O conceito de operação proposto, com a aquisição de novos grupos geradores, é a de que na falta de energia elétrica no IPEN eles serão ligados para manter a operação até o final sem depender da energia externa, garantindo a produção até que se normalize o abastecimento de energia. O problema do abastecimento de energia elétrica externa do IPEN vem causando inúmeros problemas para a operação e aos seus equipamentos. Com este novo conceito de 
operação na ocorrência destes problemas o reator será religado e manterá a sua operação através destes geradores até o final do ciclo.

Devido ao fato do reator IEA-R1 não operar de forma ininterrupta, não será necessário a operação dos grupos geradores de forma contínua, para isso foi pensada a substituição do grupo gerador convencional 440V / 250kVA e o grupo gerador "no-break" 440V /205kVA por um só gerador convencional de 440V / 500kVA. Este gerador terá a finalidade de alimentar todas as cargas em 440V na falta de energia. Em operação, o reator estará alimentado pela rede normal, assim que houver uma falta de energia o grupo gerador, em um intervalo de tempo de até 10 segundos, irá suprir a falta. Nesse momento o gerador será colocado em modo "manual" e o reator poderá operar de forma contínua até o término de sua jornada pré-programada. Dessa forma, o reator terá apenas um desligamento e com isso diminuirão os inúmeros desligamentos por faltas de energia.

b) Adequação Civil e Elétrica para os Novos Grupos Geradores

Um projeto elétrico para adequação dos novos painéis de transferência e a interligação de todas as cargas conforme as normas técnicas de instalações elétricas deverá ser elaborado. Também será ponto de estudo de viabilidade econômica a substituição das chaves de partida dos motores do circuito primário por inversores de frequência, os quais eliminam correntes de partida elevada.

c) Estudo de Confiabilidade dos Grupos Geradores.

d) Troca da Mesa de Controle.

e) Estudo de Compatibilidade Eletromagnética da Mesa de Controle e Equipamentos de Segurança. 
ANEXO A - Dados de Falha Utilizados na Análise [37]

\begin{tabular}{|c|c|c|c|}
\hline COMPONENTE & DESCRIÇÃO & $\begin{array}{c}\text { TAXA DE } \\
\text { FALHA/HORA }\end{array}$ & $\begin{array}{l}\text { PROBABILIDADE DE } \\
\text { FALHA/DEMANDA }\end{array}$ \\
\hline ALARME & FALHA DE ALARME & $7,50 \times 10^{-5}$ & \\
\hline ASPERSORES & $\begin{array}{l}\text { FALHA DOS } \\
\text { ASPERSORES } \\
\text { (entupimento) }\end{array}$ & $1,40 \times 10^{-8}$ & \\
\hline $\begin{array}{c}\text { BARRAMENTO } \\
\text { MONOFÁSICO } \\
\text { 120-220V }\end{array}$ & $\begin{array}{c}\text { FALHA NO } \\
\text { BARRAMENTO }\end{array}$ & $7,20 \times 10^{-5}$ & \\
\hline $\begin{array}{l}\text { BARRAMENTO } \\
\text { TRIFÁSICO } \\
220-440 \mathrm{~V}\end{array}$ & $\begin{array}{c}\text { FALHA NO } \\
\text { BARRAMENTO }\end{array}$ & $3,10 \times 10^{-6}$ & \\
\hline $\begin{array}{c}\text { BARRAMENTO DE } \\
\text { DISTRIBUIÇÃO DE } \\
\text { POTÊNCIA } 13.2\end{array}$ & $\begin{array}{c}\text { FALHA NO } \\
\text { BARRAMENTO }\end{array}$ & $2,30 \times 10^{-6}$ & \\
\hline BATERIAS & FALHA NA BATERIA & $4,60 \times 10^{-6}$ & \\
\hline $\begin{array}{c}\text { CABOS E } \\
\text { CONEXÕES }\end{array}$ & $\begin{array}{c}\text { FALHA EM CABOS E } \\
\text { CONEXÕES }\end{array}$ & $\begin{array}{c}9,00 \times 10^{-7} \\
6 \text { ou } 4 \times 9 \times 10^{-7}\end{array}$ & \\
\hline $\begin{array}{c}\text { CHAVE } \\
\text { SECCIONADORA }\end{array}$ & SPURIOUS & $1,0 \times 10^{-6}$ & \\
\hline CONTATOR & $\begin{array}{c}\text { FALHA TODOS OS } \\
\text { MODOS }\end{array}$ & $6,0 \times 10^{-5}$ & \\
\hline $\begin{array}{l}\text { DIESEL } \\
\text { GERADOR }\end{array}$ & FALHA NA PARTIDA & & $4,23 \times 10^{-2}$ \\
\hline $\begin{array}{l}\text { DIESEL } \\
\text { GERADOR }\end{array}$ & FALHA EM OPERAÇÃO & $2,82 \times 10^{-2}$ & \\
\hline DISJUNTOR & FALHA NO DISJUNTOR & $2,0 \times 10^{-6}$ & \\
\hline
\end{tabular}




\begin{tabular}{|c|c|c|c|}
\hline COMPONENTE & DESCRIÇÃO & $\begin{array}{c}\text { TAXA DE } \\
\text { FALHA/HORA }\end{array}$ & $\begin{array}{l}\text { PROBABILIDADE DE } \\
\text { FALHA/DEMANDA }\end{array}$ \\
\hline ELETROPAULO & $\begin{array}{c}\text { INTERRUPÇÃO DE } \\
\text { ENERGIA ELÉTRICA } \\
\text { PELA } \\
\text { CONCESSIONÁRIA }\end{array}$ & $3,8 \times 10^{-3}$ & \\
\hline EMBREAGEM & FAIL TO ENGAGE & $3,0 \times 10^{-4}$ & \\
\hline OPERADOR & FALHA DO OPERADOR & & $1,00 \times 10^{-2}$ \\
\hline \multirow[t]{4}{*}{ INTERRUPTOR } & FALHA NO & $8,3 \times 10^{-6}$ & \\
\hline & DISPOSITIVO DE & & \\
\hline & INTERRUPÇÃO DE & & \\
\hline & ENERGIA & & \\
\hline FUSÍVEIS & FUSÍVEL FALHA & $5,00 \times 10^{-6}$ & \\
\hline INVERSOR & FALHA DO INVERSOR & $1,60 \times 10^{-5}$ & \\
\hline MÓDULO DE & FALHA NO & $3,75 \times 10^{-5}$ & \\
\hline CONTROLE & DISPOSITIVO LÓGICO & & \\
\hline GRUPO & FALHA NO GRUPO & $7,70 \times 10^{-6}$ & \\
\hline GERADOR (220V) & GERADOR & & \\
\hline GRUPO & FALHA NO GRUPO & $7,70 \times 10^{-6}$ & \\
\hline GERADOR (440V) & GERADOR & & \\
\hline
\end{tabular}


ANEXO B - Probabilidade de Falha dos Sistemas Analisados Obtidos nas Árvores de Falhas [37]

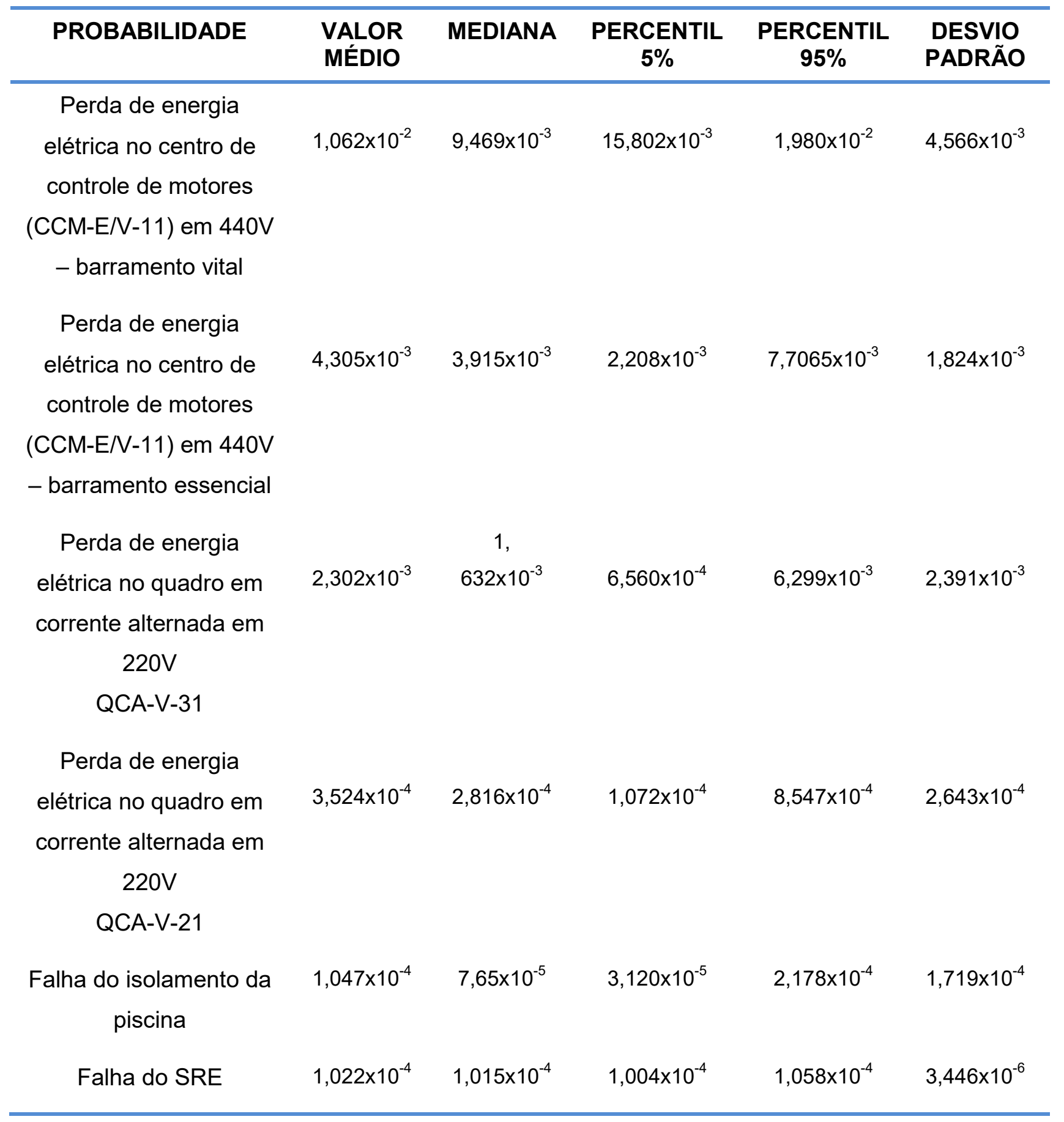




\section{REFERÊNCIAS BIBLIOGRÁFICAS}

[1] UNITED STATES NUCLEAR REGULATORY. Reactor Safety Study - An Assessment Of Accident Risks In U.S. Commercial Nuclear Power Plants. October, 1975 (WASH - 1400/ NUREG - 75/014).

[2] SAFETY SERIES 50-SG-D7 - Emergency Power Systems at Nuclear Power Plants -1988 .

[3] SAFETY SERIES 75 - INSAG 3 - Basic Safety Principles for Nuclear Power Plants -1988.

[4] INSTITUTO DE PESQUISAS ENERGÉTICAS E NUCLEARES, Relatório de Análise de Segurança do Reator IEA-R1. São Paulo.

[5] INSTITUTO DE PESQUISAS ENERGÉTICAS E NUCLEARES, Relatório de Análise de Segurança do Reator IEA-R1- Cap.9. São Paulo.

[6] ASSOCIAÇÃO BRASILEIRA DE NORMAS TÉCNICAS - ABNT-NBR6146/1980. Invólucros de Equipamentos Elétricos Proteção.

[7] ASSOCIAÇÃO BRASILEIRA DE NORMAS TÉCNICAS - ABNT-NBR-6808/ 1993. Conjunto de Manobra e Controle de Baixa Tensão.

[8] UNITED STATES NUCLEAR REGULATORY COMMISSION. Severe Accident Risks - An Assesment for Five United States Nuclear Power PlantsSummary Report. December 1990, (NUREG 1150).

[9] UNITED STATES NUCLEAR REGULATORY COMMISSION. Evaluation of Station Black Out Accidents at Nuclear Power Plants. June, 1988 (NUREG 1032).

[10] UNITED STATES NUCLEAR REGULATORY COMMISSION. Reliability of Emergency AC Power Systems at Nuclear Power Plants. July, 1983 (NUREG/CR-2989).

[11] UNITED STATES NUCLEAR REGULATORY COMMISSION. Proposed Staff Actions to Improve and Maintain Diesel Generator Reliability. July, 1984 (Generic Letter 84-15).

[12] UNITED STATES NUCLEAR REGULATORY COMMISSION. Emergency Diesel Generator Experience, 1981 -1964. October, 1985 (NUREG/CR-4347).

[13] NUCLEAR ENERGY AGENCY - Committee on The Safety of Nuclear Installations. Loss of Safety System Functions - Pilot Examination os Generic Safety Functions. November,1986 (CSNI Report n.127 - Volume I). 
[14] INSTITUTO DE PESQUISAS ENERGÉTICAS E NUCLEARES, Relatório de Análise de Segurança do Reator IEA-R1- Cap.16. São Paulo.

[15] INTERNATIONAL ATOMIC ENERGY AGENCY. Safety Assessment of Research Reactors and Preparation of the Safety Analysis Report. Safety Series no. 35-G1, Vienna, 1994.

[16] INTERNATIONAL ATOMIC ENERGY AGENCY. Code on the Safety of Nuclear Research Reactors: Design Safety Series no. 35-S1, Vienna, 1992.

[17] ANOUSSIS, J.; CHRYSOCHOIDES, N.G.; PAPASTERGIOU, C.N.. Basic Considerations for the Safety Analysis Report of the Greek Research Reactor-1 (GRR1). Greek Atomic Energy Commission, Nuclear Research Center "Democritus", September, 1980.

[18] UNITED STATE NUCLEAR REGULATORY COMMISSION. Safety Evaluation Report Related to the Renewal of the Operating License for the Union Carbide Subsidiary B, Inc. Research Reactor. NUREG-1059. June, 1984.

[19] BINFORD, F.T. The Oak Ridge Research Reactor - Safety Analysis, ORNL 4169 (Vol.II), March 1968. /6/ 1969 Status Report on the Omega West Reactor, with Safety Analysis. Los Alamos Scientific Laboratory of the University of California, LA-4192; TID-4500, May 1969.

[20] 1969 Status Report on the Omega West Reactor, with Safety Analysis. Los Alamos Scientific Laboratory of the University of California, LA-4192; TID4500, May 1969.

[21] Safety Analysis Report for the MIT Research Reactor (MITR-II). MITNE115. October, 1970.

[22] MATOS, J.E.; PENNINGTON, E.M.; FREESE, K.E.; WOODRUFF, W.L.; Safety-Related Benchmark Calculations for MTR-Type Reactors with EU, MEU and LEU Fuels - Research reactor core conversion guidebook, Volume 3: Analytical Verification, (IAEA-TECDOC-643), 1992.

[23] OBENCHAIN, C.F.; PARET - A Program for the Analysis of Reactor Transients, IDO17282, 1969.

[24] MOLNARY, L. Proposição e Desenvolvimento do Sistema de Análise de Consequências Ambientais e Radiológicas durante Acidentes - SACARA Etapa I, Projeto PED.RAS.IPEN.002 - RELT.001.R00. Instituto de Pesquisas Energéticas e Nucleares, IPEN-CNEN/SP. Agosto, 1997.

[25] U. S. NUCLEAR REGULATORY COMMISSSION, Assumptions Used for Evaluating the Potential Radiological Consequences of a Loss of Coolant Accident for Pressurized Water Reactors, Regulatory Guide 1.4 - rev. 2. June 1974. 
[26] U. S. NUCLEAR REGULATORY COMMISSSION, Atmospheric Dispersion Models for Potential Accident Consequence Assessment at Nuclear Power Plants, Regulatory Guide 1.145 - rev. 1. February 1983.

[27] U. S. NUCLEAR REGULATORY COMMISSION, Radiological Assessment Textbook on Environmental Dose Analysis, NUREG/CR-3332. September 1983.

[28] COMISSÃO NACIONAL DE ENERGIA NUCLEAR. Normas para Escolha de Locais para Instalação de Reatores de Potência. Resolução CNEN-09/69 D.O.U. 31/07/1969.

[29] UNITED STATES NUCLEAR REGULATORY COMMISSION. Standard Review Plan for the Review of Safety Analysis Reports for Nuclear Power Plants - LWR Edition. July, 1981 ( NUREG - 0800 ).

[30] ASSOCIAÇÃO BRASILEIRA DE NORMAS TÉCNICAS. Requisitos Gerais de Suprimento de Energia Elétrica para os Sistemas de Segurança Usinas Nucleolétricas. Novembro, 1984 (NBR-8671).

[31] Comissão Nacional d e Energia Nuclear. Licenciamento de Instalações Nucleares. Dezembro, 1984 (CNEN-NE-1.04).

[32] COMISSÃO NACIONAL DE ENERGIA NUCLEAR. CNEN-NN-1.16. Garantia da Qualidade para a Segurança de Usinas Nucleolétricas e outras Instalações. Setembro, 1999 (CNEN-NN-1.16).

[33] COMISSÃO NACIONAL DE ENERGIA NUCLEAR. Licenciamento de Instalações Nucleares. Dezembro, 1984 (CNEN-NE-1.04).

[34] ASSOCIAÇÃO BRASILEIRA DE NORMAS TÉCNICAS - ABNT-NBR-ISSO 9001:2008. Sistema de Gestão da Qualidade.

[35] ASSOCIAÇÃO BRASILEIRA DE NORMAS TÉCNICAS - ABNT-NBR-5410/ 1990. Instalações Elétricas de Baixa Tensão.

[36] COORDENADORIA PARA PROJETOS ESPECIAIS (COPESP). Avaliação das Instalações Elétricas do Reator IEA-R1. Relatório Técnico: R 743190003. São Paulo, 1989.

[37] HIRATA, D. M. Estimativa da Frequência de Danos ao Núcleo Devido a Perda de Refrigerante Primário e Bloqueio de Canal de Refrigerante do Reator IEA-R1 do IPEN-CNEN/SP - APS Nível 1. 2009. Dissertação (Mestrado), Instituto de Pesquisas Energéticas e Nucleares, São Paulo.

[38] INEL Idaho National Engineering Laboratory. Systems Analysis Programs for Hands-on Integrated Reliability Evaluations (SAPHIRE), version 6.41 USA, 1995. 